\title{
ZUR DONAUBULGARISCHEN GÜRTELMODE DES 10. JAHRHUNDERTS
}

\author{
EIN AUFSATZ VON 1997/1998 MIT EINARBEITUNGEN BIS 2005
}

\section{STANISLAV STANILOV-UWE FIEDLER}

\author{
fiedler.berlin@t-online.de \\ bat_slavko@abv.bg
}

\begin{abstract}
The pagan Bulgars on the Lower Danube have left only a few belt mounts. After Christianisation (864/865) the situation was changing, a lot of them have been found on the ground of old settlements and fortifications, especially during the last decades with the help of metal detectors. During the 1930s and 1940s the Hungarian archaeologist Géza Fehér was the first who noticed the similarity with the findings of the Conquest Period in Hungary. In the article, prepared nearly 20 years ago, the specimens of a type selection have been collected, which may have formed complete sets. It is proposed that the Bulgarian belt garnitures, being dated between ca. 900 and ca. $1000 \mathrm{AD}$, are the result of the military conflicts with the Hungarians on the Lower Danube at the end of the $9^{\text {th }}$ century and of cultural adoption by the Bulgarians (or vice versa).
\end{abstract}

Keywords: belt mounts of the so called Post-Sassanian type, Bulgaria, $10^{\text {th }}$ century, Bulgarian-Hungarian connections

\section{A. FORSCHUNGSÜBERBLICK}

\section{Einleitung}

Ein bedeutender Teil der Riemenbeschläge aus der entwickelten Phase der altbulgarischen Kultur erweist sich in formenkundlicher und stilistischer Hinsicht als Parallelerscheinung zum Fundniederschlag der ungarischen Landnahmezeit. Wie unten noch ausgeführt wird, ist dies in der bulgarischen archäologischen Literatur schon seit längerem bekannt. Die kunstgeschichtliche Umschreibung dieser nicht auf den Donauraum beschränkten Fundgruppe als ,postsasanidischer Stil“ ist seit Beginn dieses Jahrhunderts verbreitet. ${ }^{2}$ Obwohl sie keineswegs treffend deren Genese umschreibt, wird sie mangels griffiger Alternative auch hier als terminus technicus verwendet. Die stilistische Verwandtschaft der Riemenbesatzstücke ist bisher weder hinreichend beschrieben worden, noch ist geklärt worden, ob sie an der unteren Donau in gleicher Weise verwendet wurden wie die an der mittleren Donau. Letzterer Frage soll hier in Bezug auf die Gürtelbeschläge nachgegangen werden. Zierten also diese Beschläge bei den Bulgaren den Gürtelriemen in der gleichen Weise wie bei den Ungarn? Bevor dies aber anhand einiger ausgewählter Beschlaggruppen demonstriert werden soll, muss die Vorgeschichte der Gürteltracht bei den Donaubulgaren kurz erläutert werden.

${ }^{1}$ Der größte Teil des Textes, der Katalogteil und sämtliche Abbildungen stammen von St. Stanilov. Die Übersetzung, die Parallelen aus dem Karpatenbecken sowie einige Ergänzungen (insbesondere die Abschnitte A.7 und B.6), Änderungen und Umstellungen im
Text sowie den Nachtrag steuerte - mit Zuarbeiten von St. Stanilov - U. Fiedler bei.

${ }^{2}$ Vgl. BARTHA 1972, 119-121; JANSSON 1986, 80; BÁLINT 1989, 225 f.; Pletn’ov-PaVlova 1992, 194. 


\section{Die frühesten Gürtel mit reichem Metallbesatz bei den (Proto-)Bulgaren}

Die älteste Schriftquelle, die für die Gürteltracht bei den (Proto-)Bulgaren in Anspruch genommen wird, stellt ein von Gy. Moravcsik kommentiertes Papyrusfragment aus der Zeit um 600 dar. ${ }^{3}$ Auf ihm wurde der Empfang

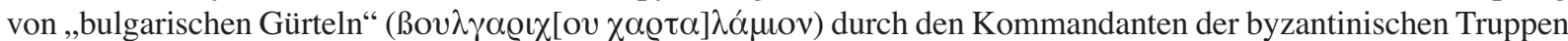
in Ägypten bestätigt. Dies gilt als Beleg, dass es zu dieser Zeit in Byzanz ethnisch determinierte (Waffen-)Gürtel gab. Von Gy. Moravcsik und N. Mavrodinov wurde zur Untermauerung auch eine Textpassage bei Pseudo-Maurikios angeführt, wonach Infanteristen „schmale Gürtel, aber keine bulgarische“ zu tragen hätten. ${ }^{4}$ Allerdings dürfte „bulgarisch“ dort auf das folgende Wort „Mäntel“ zu beziehen sein, sofern man nicht einer von R. Vári schon 1917 vorgeschlagenen Änderung der Interpunktion des Textes folgt. ${ }^{5}$

Seit der in den 1930er Jahren von N. Mavrodinov verfassten großen Studie über die protobulgarische Kunstindustrie, in der er Zeugnisse unterschiedlichen Charakters aus dem eurasischen Kulturraum als (proto)bulgarisch identifizierte, werden in Übersichtsdarstellungen der Archäologie und Geschichte der (Proto-)Bulgaren immer wieder auch die Gürtelbesatzstücke des wohl 626 im Zuge der Belagerung Konstantinopels verborgenen Schatzfundes von Ak-alan/Akalan bei Konstantinopel angeführt. ${ }^{6}$ Nach neueren Studien gehören diese jedoch in den Kreis der byzantinischen Garnituren der ersten Hälfte des 7. Jahrhunderts. ${ }^{7}$ Ähnliche Gürtelbeschläge treten zwar auch im (proto)bulgarischen Kontext in der Ukraine auf (Voznesenka), ${ }^{8}$ doch ist die Wahrscheinlichkeit recht gering, dass der Besitzer des Gürtels von Akalan ein Bulgare im Heer des awarischen Khagans Bajan war.

Der so genannte zweite Goldschmuck von Madara (obšt. Kaspičan, obl. Varna, Bulgarien), der ebenfalls bei N. Mavrodinov wie auch in fast allen Abhandlungen zur altbulgarischen Kultur zu finden ist, ${ }^{9}$ stammt nicht von dem Denkmalkomplex am Felsen von Madara, sondern gehörte zu einer relativ weit davon entfernten Nachbestattung in einem frühbronzezeitlichen Grabhügel. Diese granulationsverzierte Gürtelgarnitur mit Nebenriemenzungen ist singulär in Bulgarien, während Parallelen dazu weit gestreut aus dem eurasischen Steppenraum - von Sibirien bis nach Ungarn - bekannt sind. Nachdem das Grab von Madara bis vor wenigen Jahren meist schon in das 8. Jahrhundert datiert wurde, hat man es kürzlich einem landnehmenden (Proto-)Bulgaren zugewiesen, dessen Gürtel noch in der Mitte des 7. Jahrhunderts an der nördlichen Schwarzmeerküste gefertigt worden wäre. ${ }^{10}$ Aber auch diese Datierung ist noch zu früh. Der Gürtel muss schon aus dem ausgehenden 6. Jahrhundert oder dem ersten Drittel des 7. Jahrhunderts stammen. Sein Träger war wohl ein Ogure, der an einem Raubzug in die byzantinischen Donauprovinzen teilgenommen hat und dort verstarb. ${ }^{11}$

Beim jetzigen Forschungsstand lässt sich also noch keine spezifisch (proto)bulgarische Gürteltracht vor der Einwanderung dieses Volkes in den unteren Donauraum (680/681) fassen. Die beiden genannten Schriftzeugnisse gehören in die gleiche Zeit (letztes Drittel des 6. Jahrhunderts und erste Hälfte des 7. Jahrhunderts), als sich beschlagverzierte Nomadengürtel - vornehmlich bei der kriegerischen Oberschicht - durch byzantinische Vermittlung weiter Verbreitung erfreuten. ${ }^{12}$ Dieser Mode sind auch die damals noch an der nördlichen Schwarzmeerregion ansässigen (Proto-)Bulgaren gefolgt. Sie unterschieden sich in dieser Hinsicht aber eben auch nicht von den Awaren, Langobarden, Bajuwaren oder Byzantinern.

${ }^{3}$ MoravCsiK 1935; Goossens 1935; MaVRodinov 1936, 157 f.; VaKLinov 1977, 142. - Cs. Bálint bezweifelt allerdings, dass die Vorfahren der Donaubulgaren Namengeber dieser Gürtel waren (BÁLINT 1992, 414 f.). - Nachtrag: Vgl. jetzt auch DiETHART-KISLINGER 2000.

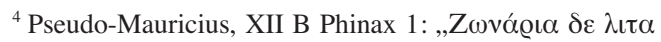

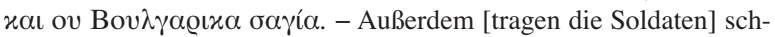
male Gürtel, aber keine bulgarischen Mäntel“ (S. 420 f.).

${ }^{5}$ Vgl. MoravcsiK 1935, $123 \mathrm{f}$.

${ }^{6}$ Mavrodinov 1936, 183-186; Mavrodinov 1959, 12, Abb. 1; VAKLINOV 1977, 143 und Abb. nach S. 96; Istorija na Bălgarija 2, 190, Abb. 1.

${ }^{7}$ Martin 1990, 72 f.; Fiedler 1995. - Zu den Münzen (mit weiterer Literatur): JuRUKOVA 1992; SOMOGYI 1997, 140-142, Anm. 19.

Acta Archaeologica Academiae Scientiarum Hungaricae 67, 2016
${ }^{8}$ VAKLINOV 1977, 37. - Es sei auch daran erinnert, dass ein Model zum doppelschildförmigen Beschlag von Akalan im Museum Kiew verwahrt wird (vgl. FIEDLER 1995, 44 f.).

${ }^{9}$ Mavrodinov 1936, 223-226; Mavrodinov 1959, $79 \mathrm{f}$ mit Abb. 71; VAKLINOV 1977, 144, Taf. vor S. 81; OvČAROV-ToTEVPopov 1980, 62, Abb. 72.

${ }^{10}$ FIEDLER 1992, 319-322; RAŠEV 1996.

${ }^{11}$ FIEDLER 1997; RAŠEV 2000, 72. - Nachtrag: In seiner im Druck befindlichen Monographie (STANILOv 2006) unterzieht der Koautor die Garnitur einer ausführlichen technischen Untersuchung und kommt zu einer abweichenden Einordnung.

${ }^{12}$ Glänzend herausgearbeitet in: WERNER 1974. - Vgl. auch MARTIN 1989 und BÁLINT 1992. 


\section{Die Gürteltracht der heidnischen (Proto-)Bulgaren an der unteren Donau}

Für die Zeit nach der Etablierung der (Proto-)Bulgaren im unteren Donauraum (680/681) ist die Quellenlage bezüglich der Gürteltracht sehr dürftig. In den zahlreichen heidnischen Gräberfeldern vom ausgehenden 7. Jahrhundert bis zum zweiten Drittel des 9. Jahrhunderts wurden keine kompletten Gürtelgarnituren gefunden. ${ }^{13} \mathrm{Zu}$ den Gürteln gehörten nur gewöhnliche Schnallen, einzelne Riemenzungen, Ringe, Ösenringe, Riemenschlaufen und dergleichen. Damit unterscheidet sich die Gürteltracht der (Proto-)Bulgaren auffallend von derjenigen der Awaren. Spätawarenzeitliche Gürtelbestandteile fanden sich nur vereinzelt in Gräberfeldern an der unteren Donau. ${ }^{14} \mathrm{Als}$ ab ca. 670/680 byzantinische Werkstätten prunkvolle Gürtelbesatzstücke des Kreises Vrap-Erseke herstellten, erreichten diese auch Bulgarien (Zlatari, Velino, Kamenovo, Umgebung von Preslav, Karamanite). ${ }^{15}$ Vielleicht befanden sich entsprechende Werkstätten sogar auf bulgarischem Boden. Doch entwickelten nur die Awaren auf dieser Basis einen eigenen Kunststil. Nur eines der angeführten bulgarischen Gürtelbesatzstücke stammt aus einem beobachteten Grabfund. Es handelt sich um die große Scharnierschnalle mit einer Tierkampfszene auf dem Beschlag aus einem heidnischen Grab des Friedhofs von Karamanite (obšt. Vălčidol, obl. Varna, Bulgarien). ${ }^{16}$ Sie lag aber zerbrochen, ohne Nieten auf den Beckenknochen des Toten. Es handelt sich also um eine symbolische Grabbeigabe eines Altstückes, das keine Trachtfunktion mehr erfüllte.

Gürtel wurden in der heidnischen Zeit durchaus von den (Proto-)Bulgaren getragen. Da ihnen aber in der Regel aufwendiger Metallbesatz fehlte, können sie kaum als Statussymbol oder Rangabzeichen gedient haben. Möglicherweise waren sie sogar von der Kleidung verdeckt.

\section{Die bulgarische Gürtelmode zur Zeit der Christianisierung (864/865)}

In die Zeit der Christianisierung gehört eine oft angeführte Schriftquelle zur Gürteltracht bei den Bulgaren. Es handelt sich um eine der Antworten des Papstes Nikolaus I. vom 13. November 866 auf die Fragen des bulgarischen Herrschers Boris. Die päpstliche Antwort Nr. 55 lautete: „Iam vero quod asseritis, Graecos vos prohibere communionem suscipere sine cingulis... " ${ }^{17}$ Einige der Forscher lesen dies zwar in dem Sinne, dass sich das Verbot der Byzantiner auf das Gürteltragen bezog, ${ }^{18}$ richtig ist aber die Übersetzung Lothar Hetzers: „Ferner erklärt ihr sogar, dass die Griechen euch verwehren, ohne Gürtel die Kommunion zu empfangen. "19 Hetzer kann dies durch die liturgische Bedeutung des Umgürtens bei den Byzantinern untermauern. Der Gürtel gehörte zu den Chitonen der Byzantiner, den Bulgaren bereitete die Vorschrift des Gürteltragens beim Abendmahl aber offensichtlich Probleme. ${ }^{20}$ Dies deutet darauf hin, dass das Tragen eines Gürtels bei den Bulgaren nicht den Regelfall darstellte.

In christlichen Gräbern sind Gürtelbestandteile nur vereinzelt anzutreffen. ${ }^{21}$ Hierzu gehört nach strittiger Datierung $^{22}$ auch das Massengrab 80 von Kjulevča bei Madara (obšt. Kaspičan, obl. Varna, Bulgarien). Den einfachen Gürtel des Skelettes 3 hat R. Rašev rekonstruiert. ${ }^{23}$ In dem christlichen Gräberfeld von Tabačka (obšt. Ivanovo, obl. Ruse, Bulgarien) wurden zwei rechteckige, durchbrochene Beschläge gefunden, an denen Lederreste hafteten. ${ }^{24}$ In der Publikation werden sie als Verschlüsse gedeutet, obgleich an einem der Beschläge ein Riemen mit Riemenzunge hängt. Weitere Befunde fallen nicht aus dem Rahmen - bis auf zwei bemerkenswerte Ausnahmen.

${ }^{13}$ Stanilov 1991b, 181 f., Abb. 1.5-6; Rašev 1992; FiedLER 1992, 197-205; FIEDLER 1996; PletN'ov-PAVLOVA 1994/1995, 100 f. bzw. 131; INKOVA 2005.

${ }^{14}$ FiedLer 1992, 202-205; Stanilov 2006. Darunter befinden sich auch Riemenzungen, die sich deutlich vom spätawarischen Stil absetzen und eher einem „Schwarzmeerkreis“ angehören; vgl. PletN'ov-PaVlova 1992, 196, Taf. 2.10, 14-15.

${ }^{15}$ FIEDLER 1996; DAIM 2000, 94-107 (mit einem späteren Datierungsansatz); INKOVA 2004; STANILOV 2006.

${ }^{16}$ RAŠEV 1990. - Die bei U. Fiedler (FIEDLER 1996, 257, Abb. 6.2 ; 259) wiedergegebene Umzeichnung mit einer Menschenfigur statt einer Lilie vor der Tierkampfszene ist falsch. Eine zutreffende Umzeichnung findet sich bei Stanilov 1991b, 184, Abb. 2.5 bzw. Stanilov 2006, 150, Abb. 26.
${ }^{17}$ DEČEV 1922, 62.

${ }^{18}$ RybaKov 1953, 54, Anm. 1; Mavrodinov 1959, 78; MiLČEV 1966, 348 (bulgarische Urfassung auf S. 33). - R. Rašev (RAŠEV 1984, 131 f.) glaubt sogar, dass nicht von einem Gürtel, sondern von einem Kreuzanhänger, der umgurtet wurde, die Rede gewesen sei, wozu ihn die Übersetzung von D. Dečev (DEČEv 1922, 63) verleitet hat.

${ }^{19}$ HeISER 1979, 451; vgl. ibidem 84 bzw. 92.

${ }^{20}$ Ibidem 145-149.

${ }^{21}$ Kuzev 1980, 261 f.; Pletn'ov-Pavlova 1992, 159 f.; 196, Taf. 2.15; 207 f., Nr. 15.

${ }^{22}$ FIEDLER 1992, 316-318.

${ }^{23}$ RAŠEV 1992.

${ }^{24}$ STANČEV 1984, 37-40, Abb. 4c.

Acta Archaeologica Academiae Scientiarum Hungaricae 67, 2016 
Es handelt sich um zwei goldene bzw. vergoldete Garnituren des letzten Drittels des 9. Jahrhunderts: einmal den so genannten ersten Schmuckfund von Madara ${ }^{25}$ und zum anderen die ähnlich gestaltete Garnitur aus dem Sarkophag 4 hinter der Großen Basilika von Pliska (obšt. Kaspičan, obl. Varna, Bulgarien). ${ }^{26}$ Beide Komplexe stammen aus christlichen Gräbern, die in die ersten zwei oder drei Jahrzehnte nach der Christianisierung zu datieren sind, irgendwann zwischen 865 und 893. Dazu passt, dass das Zwingenornament der Riemenzungen den altungarischen Taschenrandbeschlägen vom Typ Eperjeske gleicht, deren Laufzeit M. Schulze-Dörrlamm bis in die Zeit kurz nach 900 veranschlagt. ${ }^{27}$ Die beiden Gürtel weisen eine verhältnismäßig schlichte Konstruktion auf, bestehend aus Schnalle, Riemenzunge und zwei Ösenbeschlägen, in denen Dolch oder Säbel eingehängt werden konnten. In Pliska hat man in dem Sarkophag neben dem Goldgürtel noch einen zweiten Gürtel mit einfachen unverzierten Besatzstücken aus Silber gefunden.

\section{Das Aufkommen der Gürtel mit Metallbesatz bei den christlichen Bulgaren}

Erst einhundert Jahre nach der Christianisierung belegen zwei schriftliche Quellen eine auffällige Gürteltracht bei den Bulgaren. Ibrāhīm ibn Ja'qūb sah im Jahre 973 in Magdeburg eine bulgarische Gesandtschaft, die vom Kaiser Otto I. in Quedlinburg empfangen wurde. In der durch Bakrī überlieferten Mitteilung heißt es: „Sie tragen enge Kleidung und umgürten sich mit langen Gürteln, auf denen Gold- und Silberkugeln sitzen. “28 Fünf Jahre früher, also 965, war dem Bischof Liudprand von Cremona in Konstantinopel ein Gesandter des bulgarischen Zaren Peter begegnet, „der, nach ungarischer Weise geschoren, eine eherne Kette trug (aenea catena cinctum)“ ${ }^{29}$ Liudprand hielt ihn für einen Katechumenen. In Wirklichkeit dürfte dieser einen Gürtel mit Metallbesatz getragen haben, der nur deshalb auf abwertende Weise beschrieben wurde, weil dessen Träger gegenüber dem Erzähler vom byzantinischen Kaiser bevorzugt behandelt wurde. So ist dies ein indirekter Hinweis dafür, dass selbst die Gürtel bulgarischer Mönche Metallbesatz aufwiesen. ${ }^{30}$

Neben den beiden angeführten schriftlichen Zeugnissen ist noch eine Abbildung von altbulgarischen Gürteln in der Miniatur im Menologion des Kaisers Basileios II. (Bulgaroktonos) zu erwähnen, das in der Vatikanischen Bibliothek verwahrt wird. ${ }^{31}$ Dort tragen die Bulgaren dünne Gürtel mit runden Beschlägen. Nebenriemen sind nicht vorhanden. Das Menologion ist um 1000 entstanden, wenngleich die genannte Miniatur ein historisches Ereignis aus dem frühen 10. Jahrhundert illustriert.

Aus Grabfunden sind Beschläge im so genannten postsasanidischen Stil nur aus dem noch unpublizierten Friedhof von Varna-Troševo bekannt. ${ }^{32}$ Allerdings ist fraglich, ob die dort gefundenen wenigen Stücke im postsasanidischen Stil zum Gürtelbesatz gehörten. Ganz im Gegensatz zum Frauenschmuck wurden den Toten im 10. Jahrhundert offensichtlich keine Gürtel mit reichem Metallbesatz mehr beigegeben. Dagegen sind auf der Oberfläche von Siedlungen und Befestigungen des ersten bulgarischen Reiches bzw. in den Kulturschichten aus christlicher Zeit schätzungsweise annähernd zehntausend Gürtelbesatzstücke gefunden worden. Die Mehrzahl von ihnen befindet sich in Privatsammlungen. Beim heutigen Forschungsstand sind sie ab dem ausgehenden 9. Jahrhundert zu datieren. Es muss angemerkt werden, dass nur ein sehr kleiner Teil dieses Materials bei regulären Ausgrabungen zutage trat, was natürlich deren Einordnung erschwert.

${ }^{25}$ Mijatev 1926/1927; Mavrodinov 1959, 78 f. mit Abb. 70; VAKLinov 1977, 144 f., Taf. vor S. 81; VAKLinOv 1984, 170 f., Farbtaf. 3; Istorija na Bălgarija 2, 83, 103 (Farbfotos zweier Teile); STANILOV 2006, 190-228.

${ }^{26}$ Konservacija na nož i kolan ot sarkofag No 4. PliskaPreslav 1 (1979) 64-68; OvČARov-Totev-PoPov 1980, 422, Taf. 1, Abb. 1-4; Michajlov 1979, 51-58 mit Abb. 28-41; MichajlovSAVOV-MaLECKI-IVANOVA 1980, 61 f., Abb. 69-70 (schlechte Farbfotos); GeORGIEv 1993, 65-71 mit Abb. 49, bes. 71.
${ }^{27}$ FeHÉr 1940, 49, Abb. 17; Schulze-DörRlamm 1988, 405-407 (Grab 956 von Birka t.p.q. 893, im Wikingergrab von Rösta sogar 943).

$1927,15$.

${ }^{28}$ KUnIK-Rozen 1878, 37 f. Deutscher Text nach JACOB

${ }^{29}$ Liutprand von Cremona, Legatio 18 (ed. R. Pertz, 350 f.; ed. A. Bauer-R. Rau, 540 f., mit deutscher Übersetzung).

${ }^{30}$ GOŠEV 1932, 58.

${ }^{31}$ Cod. gr. 1613; StanČEv-Ivanov 1958, 21 f., Abb. 3-4; Istorija na Bălgarija 2, 126, 143 (Farbabbildungen).

${ }^{32}$ KuZev 1980; Pletn’ov-Pavlova 1992, 167. 


\section{Die Geschichte der bulgarischen (und rumänischen) Forschung zu den Gürtelbesatzstücken des 9./10. Jahrhunderts}

Die Frage, ob Gürtel, wie sie bei den Ungarn an der mittleren Donau üblich waren, auch im mittelalterlichen Bulgarien getragen wurden, wurde 1939 erstmals von G. Fehér gestellt. Aus der identischen Stilistik des damals noch zahlenmäßig begrenzten bulgarischen Materials und der zahlreichen ungarischen Funde leitete er die These einer gemeinsamen Entwicklung der Toreutik in beiden Kulturräumen ab. Dabei sprach er sich für eine bulgarische Priorität bei deren Genese aus. ${ }^{33}$ Die Forscher nach ihm schenkten den Funden von Gürtelbesatzstücken mit postsasanidischen Stilelementen nur wenig Beachtung, ${ }^{34}$ bis dann 1959 N. Mavrodinov in seiner posthum erschienenen Monographie zur altbulgarischen Kunst alles bis dahin bekannte Material zusammenstellte. ${ }^{35}$ N. Fettich folgend sprach er vom ,zweiten ungarischen Stil“, der von den Bulgaren und Chasaren geschaffen und von den Ungarn übernommen worden sei. Er bemühte sich, zehn Fundkomplexe als Garnituren anzusprechen, was allerdings nicht recht überzeugte, da er keine Rekonstruktion der Gürtel anbot. Mit dem ungarischen metallenen Kunstgewerbe verband N. Mavrodinov auch einen Gürtelanhänger, der ornamentale Parallelen auf ungarischen Taschendeckplatten aufwies.

Der erste, bei regulären Grabungen gefundene Komplex von Gürtelbeschlägen im postsasanidischen Stil trat in der Wallanlage („Gradišteto“) bei Jakimovo (obšt. Jakimovo, obl. Montana) in Nordwestbulgarien zutage. ${ }^{36}$ Er besteht aus sechs glatten, gerahmten und sechs reliefierten Beschlägen. Vier sind schlank und acht breit proportioniert. Man darf annehmen, dass ursprünglich Dreiergruppen von breiten und schlanken Beschlägen auf den Riemen montiert waren, ähnlich den weiter unten aufgezählten Lagebefunden in ungarischen Gräbern. In A. Milčevs Kommentierung des Materials aus Jakimovo ist einiges leider durcheinandergeraten. Er zitiert Arbeiten von V. Arendt, G. Fehér und N. Mavrodinov und führt als Analogien auch Stücke aus Devínská Nová Ves, Alattyán und Gnezdovo an. Er gelangt dann zu dem Schluss, dass die Gürtelbeschläge nach Jakimovo, einer nach seiner Interpretation rein slawischen Siedlung, vielleicht durch awarische Vermittlung gelangt seien. ${ }^{37}$ Auch S. Georgieva wies alle ähnlichen Funde aus Bulgarien der slawischen Kultur zu, wobei sie ihre Entstehung auf die „örtliche“ antike Kultur zurückführte. ${ }^{38}$

In den neueren Publikationen beziehen sich die bulgarischen Forscher gewöhnlich auf N. Mavrodinov und führen direkt oder indirekt Vergleichsstücke aus Ungarn an. ${ }^{39}$ In der rumänischen Literatur wird nur in einem Fall G. Fehér zitiert und dabei Vergleichsstücke in Ungarn und Bulgarien erwähnt, ${ }^{40}$ sonst wird solches Material mit phrasenhaften Kommentaren von östlicher Entstehung und byzantinischen Einflüssen versehen. Manchmal erinnert man auch an die Petschenegen, ohne allerdings die augenscheinlichen Parallelen aus Ungarn anzuführen. ${ }^{41}$

Ein Überblick über die altbulgarischen Gürtel wurde 1977 von St. Vaklinov publiziert, in dem die Theorie vom nomadischen Gürtel als Rangabzeichen in der Militärgesellschaft vertreten wird. Nach diesen allgemeinen Gedanken behandelt er die Garnituren aus Akalan, Sadovec, Madara (1. und 2. Fund) und Pliska (Sarkophag 4 hinter der Großen Basilika). ${ }^{42} \mathrm{Zu}$ den gewöhnlichen Gürteln mit kupfernen oder bronzenen Besatzstücken im postsasanidischen Stil äußert er sich nicht.

In den bulgarischen Publikationen der 1980er Jahre wurden mehrmals Gürtelbestandteile im postsasanidischen Stil abgebildet, ihre Erläuterungen sind aber widersprüchlich und unklar. Auf die ungarischen Analogien wird in den monographischen Publikationen der Grabungen in den altbulgarischen Festungen bei Stărmen (obšt. Bjala, obl. Ruse, Bulgarien) von polnischer ${ }^{43}$ und bei Krivina (obšt. Zenovo, obl. Ruse, Bulgarien) von deutscher Seite ${ }^{44}$ verwiesen. In der Publikation des bulgarischen Grabungsareals in Stărmen blieben diese Stücke jedoch entweder unkommentiert ${ }^{45}$ oder wurden ohne besondere Begründung mit verschiedenen frühmittelalterlichen Kulturen vom

${ }^{33}$ FEHÉR 1939, 27, 83-87; 92; 24, Abb. 49-50, 59, 62; FeHÉR 1940, 71 ff.; FeHÉr 1942, 25. Bildliche Gegenüberstellung auch bei FEHÉR-GÖLLNER 1942.

${ }^{34}$ ANGelov-STANČEv 1955, 440 f., Abb. 17.13; ČAnGOVA 1957, 239 f., Abb. 8.2-2a

${ }^{35}$ Mavrodinov 1959, 229-232.

${ }^{36}$ MiLČEv 1966, 349 ff., Abb. 11, Abb. 13 (bulgarische Urfassung: 33-35, Abb. 12, Abb. 15)

${ }^{37}$ Ibidem $350 \mathrm{f}$

${ }^{38}$ GeOrgieva 1963, 356, Abb. 19; 357; 359-361 mit Abb. 22, 23a-e, 24a; 364, Abb. 27.

${ }^{39}$ Z. B. Totev 1976, 49-51, Abb. 15.3-4, 6; Plet'NovPavlova 1994/1995, passim.
${ }^{40}$ Capidava 1, 233, 235, Abb. 118.5.

${ }^{41}$ BARNEA-MitREA 1959, 470 f. mit Abb. 10.12 (nur Verweis auf Garvăn/Dinogetia); Dinogetia 1, 293-297 mit Abb. 171-173, 181; Diaconu 1969, 501-506 mit Abb. 1; DiaconU-VîlCEANU 1972, 154 f. mit Abb. 62.1-5.

${ }^{42}$ VAKLINOV 1977, 142-145. Vgl. VAKLINOV 1994, 168-171.

${ }^{43}$ Hensel 1980, 124; 152, Abb. 53.182, 728, 1286, 1414; 191, Taf. 12.237; 195, Taf. 16.209; 197, Taf. 18.827; 206, Taf. 17.364; 208, Taf. 19.971

${ }^{44}$ Wendel 1986, 177-179, 216, 223, Taf. 64.648, Taf. 65.644-645; Taf. 73.10-11.

${ }^{45}$ Džingov 1982, 57-59 mit Abb. 60.13, 15-16, 18-19. 


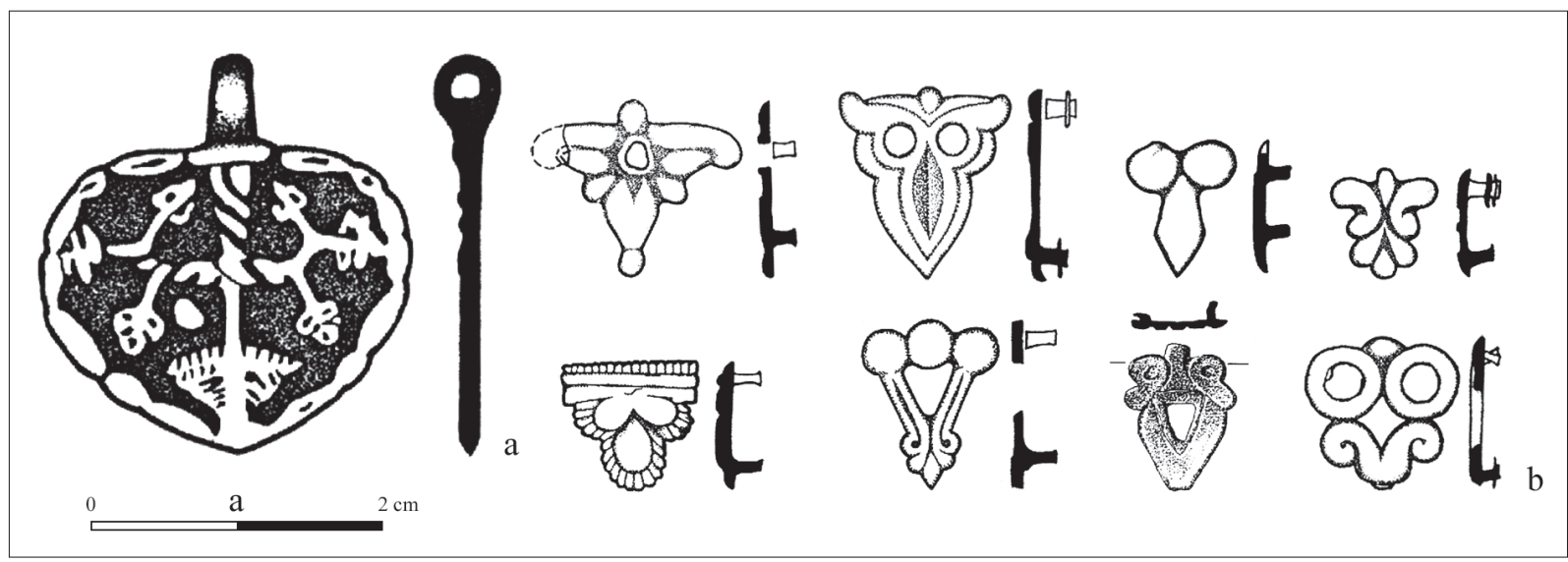

Abb. 1. a. Silberner Anhänger aus dem Magazin des Šumener Museums (M. 3:2);

b. Mutmaßliche Köcher-, Bogenfutteral- oder Taschenbeschläge aus Bulgarien (M. 1:1) (Zeichnung: Mariela Inkova)

östlichen Ende des eurasischen Steppengürtels bis zu den Awaren und Byzanz verbunden. ${ }^{46}$ Einen ähnlich verwirrenden Kommentar findet man in der aus dieser Zeit stammenden Publikation von Einzelfunden aus Veliki Preslav (obšt. Preslav, obl. Varna, Bulgarien) ${ }^{47}$ Nur kurz wurden auch die vier Beschläge aus der Erdfestung von Kladenci (obšt. Tervel, obl. Varna, Bulgarien) erläutert, ohne die Verbindungen mit dem Material aus Ungarn zu suchen. ${ }^{48}$ Diesen Hinweis gab es dann in deutlicher Form in der Publikation der Grabung in der Festung bei Chuma (obšt. Samuil, obl. Ruse, Bulgarien), wenngleich er nur zwei Beschläge betraf. ${ }^{49}$

Im Jahre 1984 publizierte R. Rašev einen Aufsatz über die Semantik eines der Ornamentmotive auf den altbulgarischen Gürtelbeschlägen des 9.-11. Jahrhunderts. ${ }^{50}$ Unter diesen wählte er diejenigen mit Gesichtsdarstellungen aus und führte diese auf einen apotropäischen Brauch zurück. Er glaubte, dass die schmalen Riemenzungen zu hängenden Nebenriemen von Gürteln mit dem Charakter eines Rangabzeichens gehörten und datierte sie in das 7. bis 11. Jahrhundert. Obgleich eine ausgezeichnete Ausarbeitung, wie man es von diesem Autor gewöhnt ist, werden darin die augenscheinlichen ungarischen Parallelen nicht erwähnt.

Nach ihm beschäftigte sich speziell G. Atanasov mit den Gürtelbeschlägen, veranlasst durch Funde in der altbulgarischen Festung von Središte (obšt. Kajnardža, obl. Ruse, Bulgarien). ${ }^{51}$ Sein Versuch, die dortigen Beschläge als vollständige Garnitur zu deuten, ist missglückt. Er basiert auf fehlerhafte Vergleiche aus dem Bereich der Saltovo-Majaki-Kultur nach dem Konzept von S. Pletneva. In diesem Sinne suchte er die Genese des bulgarischen Materials weiträumig innerhalb der eurasischen Steppenkulturen und sogar in Byzanz. Die Analogien in Ungarn erwähnte aber auch er nicht.

In der zweiten Hälfte der 1980er Jahre wurden zwei Publikationen mit Funden von den nur von bulgarischer Seite fortgesetzten Grabungen in Odărci (obšt. Dobrič, obl. Varna, Bulgarien) vorgelegt. Darin findet man nur eine Beschreibung der Ornamentik der Gürtelbeschläge mit den gängigen osteuropäischen Vergleichen und einer Datierung in die zweite Hälfte des 8. und in das 9. Jahrhundert. ${ }^{52}$ In dem 1986 (1989) erschienenen Aufsatz von V. Antonova über ,altbulgarischen Gürtelschmuck aus dem historischen Bezirksmuseum in Šumen“ herrscht - ähnlich wie in der Arbeit A. Milčevs gut zwei Jahrzehnte früher - ein wahres Durcheinander. ${ }^{53}$ Neben Funden des 6. Jahrhunderts (Maskenbeschläge und eine Schnalle vom Typ Sucidava) werden dort auch eine spätawarenzeitliche Riemenzunge und spätmittelalterlicher sowie neuzeitlicher Schmuck (bis in das 17. Jahrhundert) aufgeführt. Der Kommentar der Gürtelbeschläge des 9./10. Jahrhunderts enthält die üblichen östlichen Ableitungen. Um diese Zeit erschienen auch zwei Grabungspublikationen, worin abgebildete, ähnliche Funde unkommentiert blieben. ${ }^{54}$

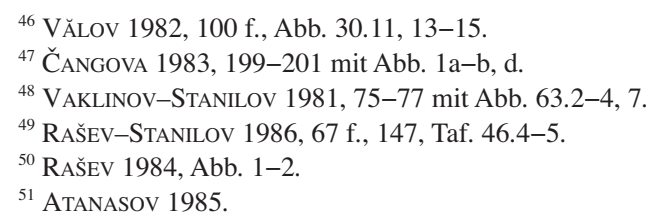

${ }^{52}$ DonČeva-Petkova 1986, 166 f. mit Abb. 4; DonČevaPetKova 1987, 76 f. mit Abb. 8. - Kritik hierzu: Stanilov 1990, 89 f ${ }_{53}^{5}$ AnTONOVA 1986. - Kritik hierzu: STANILOv 1990, 90-94.

${ }^{54}$ Antonova-VitLjanov 1985, 69 f.; Todorova 1989, 

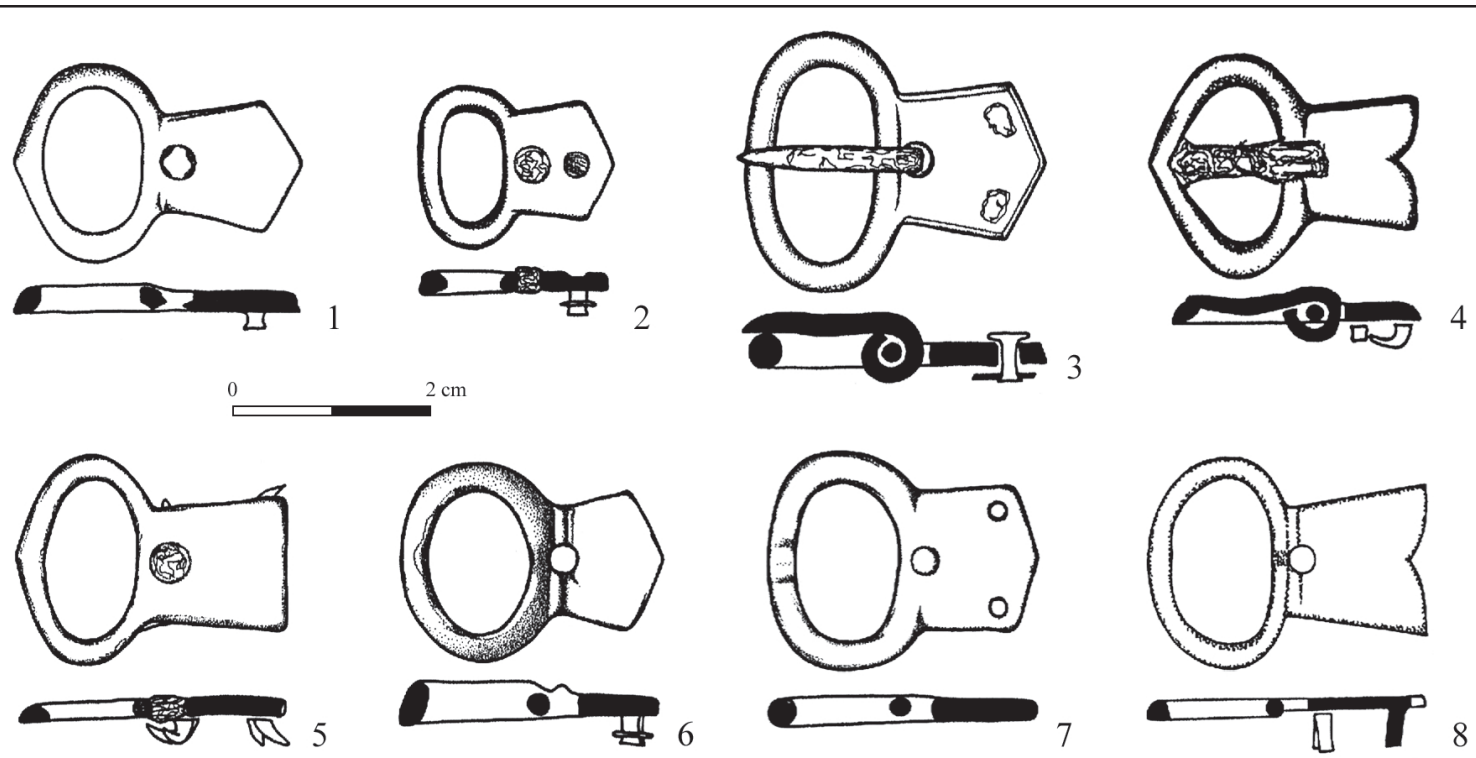
$2 \mathrm{~cm}$
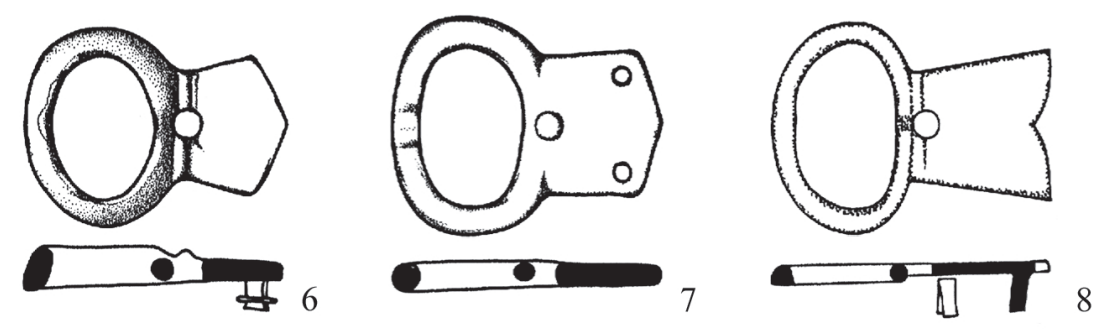

Abb. 2. Schnallen (Nr. 1-8) (M. 2:3) (Zeichnung: Stanislav Stanilov)
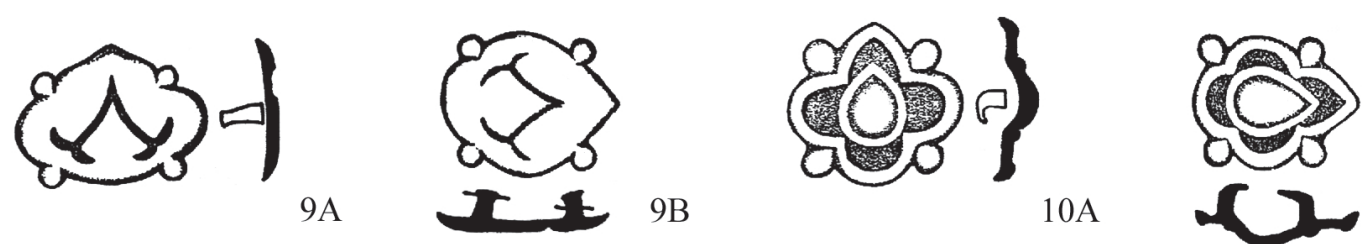

$9 \mathrm{~A} T \leq 2 \mathrm{~B}$
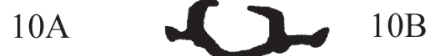

(5)
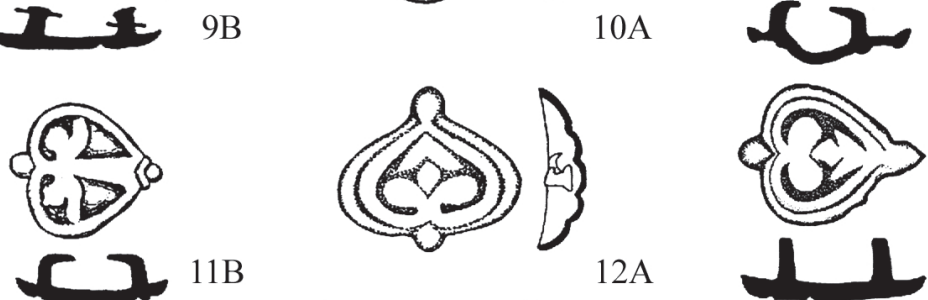

$12 \mathrm{~B}$

(2)

$13 \mathrm{~A}$
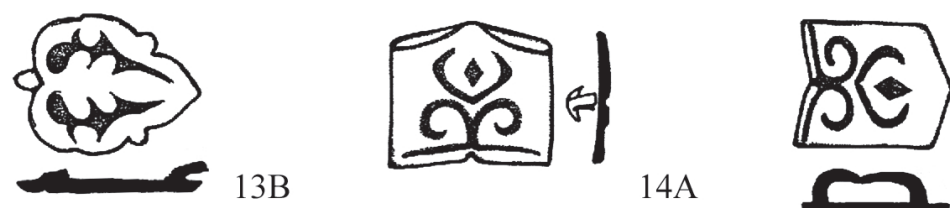

$14 \mathrm{~A}$

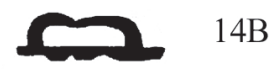

Abb. 3. Kleine Gürtelbeschläge (Nr. 9-14) (M. 1:1) (Zeichnung: Stanislav Stanilov) 
Beschläge von Gürtelgarnituren im postsasanidischen Stil gibt es auch im Preslaver Goldschatz, dessen Verbergung aufgrund der Münzen (t.p.q. 945) mit den historischen Ereignissen von 969 oder 971 verbunden werden kann. ${ }^{55}$ Von noch größerer Bedeutung ist, dass zusammen mit ihnen auch goldener und silberner Kleiderbesatz gefunden worden ist, der aus einigen Derivaten von bronzenen und kupfernen Gürtelbeschlägen mit Parallelen in Ungarn besteht. ${ }^{56} \mathrm{Zu}$ diesen existiert eine Spezialstudie aus der Feder von St. Stanilov mit Betrachtungen zur Genese des altbulgarischen metallenen Kunsthandwerks. ${ }^{57}$

Der bis zum Ende der 1980er Jahre zu verzeichnende Mangel an detaillierten Untersuchungen und katalogartigen Zusammenstellungen der altbulgarischen Riemenbesatzstücke erklärt sich aus der relativ kleinen Anzahl der Besatzstücke und dem hohen Anteil an Lese- und fundortlosen Funden. Es gab auch keine Rekonstruktionsversuche der Gürtel selbst. Dies ist auf deren völliges Fehlen in den altbulgarischen Gräbern, sowohl aus heidnischer wie auch aus christlicher Zeit, zurückzuführen. Eine Ausnahme machen die genannten Oberschichtgräber bei Madara (1. Schatzfund) und Pliska (Sarkophag 4 hinter der Großen Basilika) mit andersartigem Metallbesatz der Gürtelriemen. Die Mehrzahl der Autoren beschränkt sich auf die Nennung des publizierten Vergleichsmaterials. Sie suchen aber Vergleichsstücke auch dort, wo es sie nicht gibt, oder tun der Chronologie Gewalt an. ${ }^{58}$

Der erste Versuch einer Typengliederung und Einordnung wurde 1991 bei der katalogmäßigen Vorlage der Stücke aus dem Nationalen Historischen Museum in Sofia durch St. Stanilov vorgelegt. ${ }^{59}$ Kurz darauf erschien ein Katalog eines Teils der Riemenzungen aus den umfangreichen Magazinbeständen des Museums in Varna. ${ }^{60}$ Die ausführlichen Darlegungen von St. Stanilov wurden nur ungenügend rezipiert. Viele Autoren legten in den 1990er Jahren weitere Besatzstücke vom postsasanidischen Stil ohne oder fast ohne Erläuterung vor. ${ }^{61}$ Andere zogen zu deren Herleitung die unterschiedlichsten Garnituren vom Kaukasus bis Ungarn heran, ohne zu berücksichtigen, dass sie wahrscheinlich erst unmittelbar nach dem Ungarneinfall (896) an der unteren Donau aufkamen. ${ }^{62}$ Eine weitere, dritte Gruppe von Autoren erinnert ausschließlich an die Vergleichsstücke aus Ungarn. ${ }^{63}$ In einem Fall, einer Untersuchung zur Herstellungstechnik, wurden die altbulgarischen Gürtel des 9. bis 11. Jahrhunderts nach der Konzeption von G. Fehér und St. Vaklinov mit einer Funktion als militärisches Rangabzeichen gedeutet, ohne dass eine nähere Rekonstruktion erfolgte. ${ }^{64}$

Erst nachträglich in diesen Aufsatz eingearbeitet werden konnte die 1998 erschienene Monographie der Festung Skala bei Kladenci (obšt. Tervel, obl. Varna, Bulgarien), bei der eine Reihe von Gürtelbesatzstücken - auch solche Typen, die hier behandelt werden - zwar nicht stilistisch analysiert, aber kompetent kommentiert und mit ihrem Fundkontext adäquat vorgelegt werden. ${ }^{65}$ Gleiches gilt für die endgültige Vorlage des Bestandes der Siedlung Odărci (obšt. Dobrič, obl. Varna, Bulgarien), wobei auch eine Abgrenzung zu den ungarischen Stüicken versucht und mit einer bulgarischen Produktion gerechnet wird. ${ }^{66}$ Schließlich wurden in einem über zweihundert Seiten umfassenden Aufsatz im Jahr 2000 auch die 858 Nummern umfassenden Riemenapplikationen im Museum Varna katalogmäßig publiziert, worin eine detaillierte Klassifizierung erfolgt und auf Parallelen hingewiesen wird. ${ }^{67}$ Herstellungstechnik, Ornamentik und Gürtelrekonstruktionen werden ebenfalls kenntnisreich erörtert. Ähnlich wie I. Fodor sehen die Autoren die Genese des Zierstils in Donaubulgarien in der zweiten Hälfte des 9. Jahrhunderts, wobei die Werkstätten aus dem byzantinischen Ornamentschatz schöpfen konnten. Charakteristisch für die danubischen Besatzstücke seien die rundlichen Fortsätze, sie kämen im Osten nicht vor. Die Ungarn hätten den Stil übernommen und eine eigene Lokalvariante ausgeformt. Die Zahl der den Bulgaren und Ungarn gemeinsamen Formen sei so doch recht begrenzt. ${ }^{68}$

\footnotetext{
${ }^{55}$ Totev 1986, 102-105, Taf. 5.3, Taf. 6.1-2, Taf. 23.2-4. - Vgl. Totev 1983, 98 f., Abb. 41; Totev 1993, 73, Abb. 46.

${ }^{56}$ Totev 1986, 102-105, Taf. 20-21, Taf. 22.3-4; Totev

1983, 82-89, Abb. 32-35; Totev 1993, 69-74, Abb. 42-48.

${ }^{57}$ STANiLOV 1993a.

${ }^{58}$ Stanilov 1990.

${ }^{59}$ STANilov 1991a.

${ }^{60}$ Pletn'ov 1992.

${ }^{61}$ SlavČev 1991, 65, Abb. 9; Pletneva 1992, 42, Abb. 10; 61, Abb. 32; Bonev 1993, 72-74 mit Abb. 72a-f; PopkonstantinovATANASOv 1993 (zugehörige Abb. versehentlich bei STANILOv 1993b,
}

153, Abb. 2.6-15, 17-19); Ivanov 1996, 79 f. mit Abb. 8; Totev 1998, Abb. S. 98, Taf. 36.1-2.

${ }^{62}$ ČANGOVA 1992, 130, Abb. 123.22-24; $143 \mathrm{f}$.

${ }^{63}$ DonČEva-PetKova 1993, 138-142; AtANASOV-Jor-

Danov 1994, 20 f., Taf. 3; Pletn'ov-Pavlova 1994/1995, 194.

${ }^{64}$ DONČEVA-PETKOVA 1992.

${ }^{65}$ Jotov-Atanasov 1998, 109-111, 313, Taf. 114 (Fund-

kontexte vgl. Taf. 1.3, 5, 7 und 23)

${ }^{66}$ DonČeva-PetKova 1999, 105-107; Taf. 50-52.

${ }^{67}$ Pletn'ov-Pavlova 1994/1995.

${ }^{68}$ Ibidem 112-114 (bzw. 132). 
Die Frage der gemeinsamen Züge der Metallerzeugnisse des mittleren und unteren Donauraumes stellte sich schon in den frühen 1990er Jahren nach der Entdeckung eines vergoldeten Silbermedaillons mit Gesichtsdarstellung in Preslav und deren Publikation. ${ }^{69}$ Die gefiederten Blätter und deren Mittellinie mit Punkt am Ende verbindet der Autor, St. Vitljanov, mit den charakteristischen ungarischen Taschendeckblechen und blattförmigen Pferdegeschirranhängern aus Černigov und Tabaevka. Er folgt allerdings der Konzeption N. Mavrodinovs und St. Vaklinovs von der Einzigartigkeit der altbulgarischen Stilistik, bei der - ungeachtet der Analogien - die ungarische Verbindung vernachlässigt bleibt.

Einen konkreten Ausdruck findet diese Verbindung in einem Anhänger aus dem Magazin des Šumener Museums $(A b b .1 a)$. Er ist von einer Girlande aus schmalen Blattschlaufen gerahmt und zeigt einen Lebensbaum mit gewundenen Stamm und Ästen. Alles findet man in einer begrenzten Stilgruppe des frühmittelalterlichen eurasischen Metallhandwerks. Dies war Anlass und Argument, dass diese Stücke aus der gleichen Region herstammen wie die, welche im 9. Jahrhundert nach Ungarn gelangten. Wahrscheinlich haben die Ungarn diesen Anhänger bei ihrem Einfall 896 in das Land gebracht. In der altbulgarischen Kultur fand er keine Nachahmungen. ${ }^{70}$

Die große Anzahl von Gürtelbesatzstücken, die Anfang der 1990er Jahre in die Magazine verschiedener Museen und in viele Privatsammlungen gelangten, ermöglichten eine neue Typengliederung nach Formen und Verzierungen, einige ergänzende Ausführungen zu deren Entstehung sowie Rekonstruktionen von Garnituren. ${ }^{71}$ In jedem Fall gibt es in unterschiedlicher Anzahl Analogien im Karpatenbecken, ohne dass allerdings ersichtlich würde, dass Gürtel des ungarischen Typs mit vollem Metallbesatz und Zubehör getragen worden sind. Den Versuch eines Nachweises erbrachte die Publikation einer Garnitur, die bei den regulären Ausgrabungen in der altbulgarischen Siedlung auf den Ruinen der spätantiken Festung Debrene (obšt. Dobrič, obl. Varna, Bulgarien), gut 15 km nördlich von Varna, gefunden worden war. ${ }^{72}$ Die erstellte Rekonstruktion V. Jotovs ist allerdings nicht überzeugend, da sie teilweise vom Lagebefund der Besatzstücke abweicht und dort bedeutend mehr Besatzstücke abgebildet sind als gefunden wurden. Dazu gehört auch die im Fundkomplex fehlende Riemenzunge. Schließlich ist keine der Rekonstruktionszeichnung ähnliche Anordnung aus Ungarn bekannt. Unstrittig ist aber, dass die Besatzstücke zu einem Gürtel gehört haben, der den ungarischen Gürteln entsprach.

Während der Kampagne 1997 der deutsch-bulgarischen Ausgrabungen in Krivina wurde in einem Grubenhaus ein vollständiger Gürtelbesatz entdeckt, der neben Schnalle und Riemenzunge auch 40 Bronzeblechbeschläge enthielt. Leider blieb die Fundlage dieser Besatzstücke undokumentiert und anhaftende Leder- und Textilreste wurden bei der Restaurierung beseitigt. ${ }^{73}$ Da diese Garnitur noch unpubliziert ist und die Beschlagtypen nicht zu der unten vorgestellten Auswahl gehören, bleibt dieser Gürtel hier unberücksichtigt.

Die obigen Studien haben trotz ihrer Mängel wichtige Forschungsbeiträge geleistet, indem sie aufzeigten, in welchem Maße die Gürtelbesatzstücke des postsasanidischen Stils im ersten bulgarischen Reich verbreitet waren. Direkte ungarische Parallelen wurden mehrmals in den bulgarischen Publikationen angeführt. Es gab aber auch Forscher - und diese bildeten leider die Mehrzahl -, die ungeachtet der Stilgleichheit diese Parallelen unbeachtet ließen.

\section{Die Rolle der bulgarischen Gürtelbesatzstücken in der ungarischen Forschung}

In der ungarischen Forschung fanden die fraglichen Besatzstücke nach G. Fehér wenig Beachtung. In der 1978 verteidigten, aber erst 1991 gedruckten Dissertation von Cs. Bálint mit dem Titel „Südungarn im 10. Jahrhundert" ist der landnahmezeitliche Metallbesatz außerhalb der landnahmezeitlichen Siedlungsgebiete erstmals in einer Kartierung zusammengestellt worden. Darin sind auch fünf Fundorte von Beschlägen in Bulgarien aufgeführt. Im Kommentar hierzu stellt Cs. Bálint fest, dass in den Gebieten unter bulgarischer Herrschaft die Gürtelbeschläge ,in nicht kompletten Garnituren“ aufträten, während sonst Anhänger von Kleiderbesatz vorherrschen würden. In einer

\footnotetext{
${ }^{69}$ Vitluanov 1990; Vitluanov 1994.

${ }^{70}$ Stanilov 1992. - Zum Motiv vgl. auch Mesterházy

1994, 30, Nr. 16; 38, Abb. 7.7, 10; 40, Abb. 9.6; 42, Abb. 11.7, 9 .

${ }^{71}$ Stanilov 1993b; Stanilov 1994.

${ }^{72}$ Jotov 1993.
}

\begin{abstract}
${ }^{73}$ Die Garnitur bestand aus: Schnalle, Riemenzunge, 17 breit proportionierte Besatzstücke, davon eines mit herabhängender Ringöse und 21 schlanke Besatzstücke. Für die Informationen danken wir Frau G. Fuchs-Gomolka, Berlin (zur Publikation vgl. Nachtrag).
\end{abstract}


Anmerkung fügt er hinzu: „Die hier verbreiteten Gürtelbeschläge ungarischen Typs halte ich in Übereinstimmung mit I. Dienes für Handelswaren, und das nicht allein in Bezug auf den Balkan, sondern auf ganz Osteuropa." "74

Ansonsten blieben die bulgarischen Gürtelbeschläge von der ungarischen Forschung weitgehend unbeachtet. K. Mesterházy nennt als Parallele von Beschlägen aus Szolnok-Strázsahalom und Nagykörủ (Kom. Jász-Nagykun-Szolnok, Ungarn) u. a. einen Beschlag aus Jakimovo ${ }^{75}$ und A. M. Horváth verweist bei der Garnitur aus dem Grab 3 von Homokmégy-Halom (Kom. Bács-Kiskun, Ungarn) wegen zu wenigen Parallelen im Karpatenbecken auf nicht namentlich aufgeführte Vergleichsstücke im bulgarischen Fundstoff. ${ }^{76}$

\section{B. AUSGEWÄHLTE BESATZSTÜCKE UND DEREN VEREINIGUNG ZU HYPOTHETISCHEN GÜRTELN}

\section{Der Aufbau des ungarischen Gürtels und das bulgarische Fundgut}

Nunmehr soll zu der Frage zurückgekehrt werden, welche Gürtel mit diesen Besatzstücken verziert wurden. Wie gezeigt, waren bei den (Proto-)Bulgaren in der heidnischen Zeit (680/681-864/865) Gürtel mit reichem metallenem Besatz nicht üblich. Erst in der Zeit der Christianisierung kamen wertvolle Gürtelgarnituren des Typs Madara/Pliska auf. Sie wurden aber nur von der Oberschicht getragen. Die hier behandelten Gürtel mit Beschlägen im postsasanidischen Stil kamen etwas später, Ende des 9. Jahrhunderts, auf und waren aufgrund ihres relativ geringen Materialwertes für weite Kreise der Bevölkerung erschwinglich. Fraglich ist, ob die Anordnung der Besatzstücke der der ungarischen entsprach.

Die von der ungarischen Forschung, namentlich von I. Dienes, ${ }^{77}$ angefertigten Gürtelrekonstruktionen basieren einerseits auf Lagebefunden mit Beschlägen, die noch Lederreste aufweisen aus Nagykőrös (Kom. Pest, Ungarn), Grab 2, ${ }^{78}$ Pribeta (Perbete, okr. Komárno, Slowakei) ${ }^{79}$ und Sárbogárd (Kom. Fehér, Ungarn), Grab $33^{80}$, sowie auf Lagebefunden u. a. in dem reichen Grab von Zemplín (Zemplén, okr. Trebišov, Slowakei), ${ }^{81}$ in den Gräberfeldern von Tiszaeszlár-Bashalom (Kom. Szabolcs-Szatmár-Bereg, Ungarn), ${ }^{82}$ Szeged-Jánosszállás (Kom. Csongrád, Ungarn), ${ }^{83}$ Karos (Kom. Borsod-Abaúj-Zemplén, Ungarn) ${ }^{84}$ und Malé Kosihy (Ipolykiskeszi, okr. Nové Zámky, Slowakei) ${ }^{85}$ Eine analoge, überzeugende Rekonstruktion des Gürtels von Karancslapujtő (Kom. Nógrád, Ungarn), Grab 1 gelang I. Dienes unter Heranziehung einer mordwinischen Parallele (Krjukovo-Kužnovo) und anderer russischer Lagebefunde ${ }^{86}$ Die Basis ließe sich um weitere Grabfunde im heutigen Russland (namentlich Tankeevka bei Bolgary und Bol'šie Tigany im Oberwolgagebiet sowie Martan-Ču in Tschetschenien) ${ }^{87}$ und um solche auf der Insel Birka Björkö im Mälarsee (Ksp. Adelsö, Prov. Uppland, Schweden) erweitern. ${ }^{88}$ Als Ergebnis bieten sich drei Rekonstruktionsvarianten des ungarischen Gürtels an, die zugleich Ausstattungsgruppen widerspiegeln.

a) Die Schnalle spielte nur eine untergeordnete Rolle, weshalb auch der Hauptriemen sich vor dem Schnallenbeschlag verengen konnte. Noch schmaler war gewöhnlich der Riemen, der durch den Schnallenbügel geführt wurde. Er wies keine Riemenzunge auf. Sein anderes Ende war mit der Innenseite des Haupt- bzw. Leibriemens

${ }^{74}$ Bálint 1991, 105-108 mit Anm. 162 und Taf. 34. Wie Herr Cs. Bálint freundlicherweise mitteilte, ist die Fundliste leider der redaktionellen Kürzung zum Opfer gefallen. Das Original konnte er in seinen Unterlagen auch nicht mehr auffinden. Die bulgarischen Fundorte von Gürtelbeschlägen lassen sich aber weitgehend auflösen: 7 Jakimovo; 8 (?); 9 Ruse; 10 Stărmen; 11 V. Tărnovo; 12 Pliska; 13 Preslav.

${ }^{75}$ Mesterházy 1994, 34, Abb. 3.9, 14; 47, Nr. 21; vgl. MiLČEv 1966, 349, Abb. 11.

${ }^{76}$ Fodor 1996, 313. - Vgl. hierzu: Pletn'ov 1997, 88, Taf. 5.10, 16-17.

${ }^{77} \mathrm{Vgl}$. BónA 1997, bes. 330.

${ }^{78}$ Dienes 1960, Taf. 30; LÁszló 1988, 68, Abb. 46.

${ }^{79}$ Dienes 1959, bes. Taf. 27-28; Točík 1968, 37 f. (Nr. 6); 82, Taf. $16.22-26$

${ }^{80}$ ÉRY 1968, 105-107 mit Abb. 18.1; 128, Taf. 32.21, 24.

${ }^{81}$ BudINSKÝ-KRIČKA-FETTICH 1973, 17 f.; 55-57; 160 f., Abb. 4-5; 173-175, Abb. 17-19; 184, Abb. 28.
${ }^{82}$ Dienes 1959, 154 mit Abb. 9, Taf. 30; Fodor 1996, 185-190 mit Abb. 1 (Grab B von Friedhof I und Grab 7 von Friedhof II). In Grab 7 lag auch ein wahrscheinlich zwischen 832 und 839 geprägter Solidus (KovÁcs 1989, 70, Nr. 382; MESTERHÁZY 1994, 54).

${ }^{83}$ Dienes 1959, 151, Abb. 6; 153, Abb. 8; Dienes 1972, 98; Taf. 21.

${ }^{84}$ Révész 1996, 104, Abb. 52 (Grab II/14); 108, Abb. 57-56 (Gräber II/29 und II/35); 209 f., Abb. 126-127 (Grab II/29).

${ }^{85}$ Hanuliak 1994, 157, Taf. 18 (Grab 82); 192, Taf. 53 (Grab 261).

${ }^{86}$ Dienes 1964, bes. 30, Abb. 8; vgl. Mesterházy 1994 , 28, Nr. $1 ; 33$, Abb. 2

${ }^{87}$ Chalikova-Kazakov 1977, 42 f. mit Abb. 10; 68; 183, Taf. 9 (Grab 267); 186, Taf. 12 (Grab 351); 190, Taf. 16 (Grab 472); 192, Taf. 18 (Grab 642); 193, Taf. 19 (Grab 648); 196, Taf. 22 (Grab 709); JANSSON 1986, 90 f. mit Abb. 10; VinOGRADOv 1983, 216, Abb. $6.1-5 ; 218$, Abb. 8 .

${ }^{88}$ JANSSON 1986, bes. $98-103$ mit Abb. 15-16. 

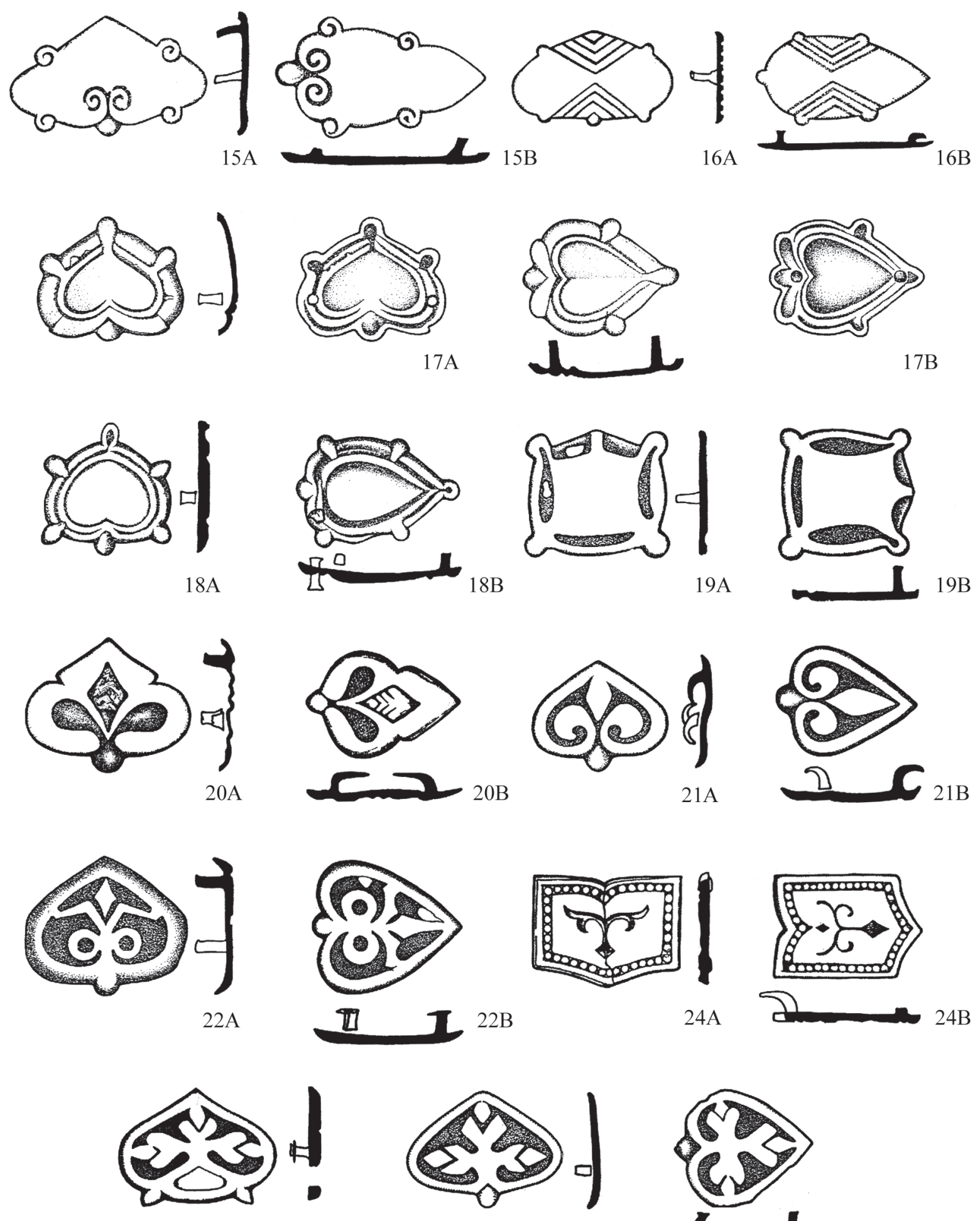

$23 \mathrm{~A}$

$23 \mathrm{~B}$
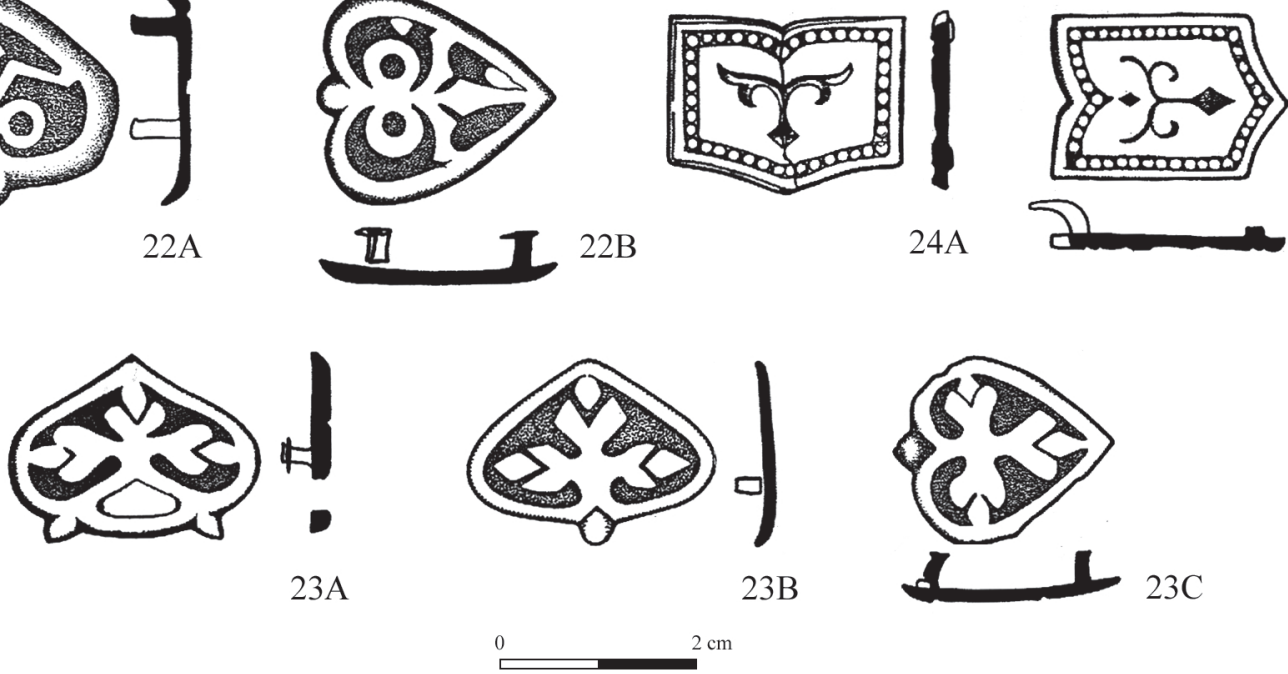

Abb. 4. Große Gürtelbeschläge (Nr. 15-24) (M. 1:1) (Zeichnung: Stanislav Stanilov) 
vernäht. Der Hauptriemen war so lang, dass er nicht nur die Schnalle vorne verdeckte, sondern auch jenseits der Schnalle nochmals unter den Gurt geschoben wurde. Sein immer noch langes Ende hing dann herunter, um seinen Abschluss mit einer Riemenzunge zu finden.

b) Anordnung wie oben, jedoch mit unterschiedlich proportionierten (breiten oder schlanken) Beschlägen auf den Riemen - die breiten (teilweise mit Ösen) auf dem Leibriemen bis in Höhe der Schnalle und die schlanken auf dem herabhängenden Gurt bis zu der Riemenzunge.

c) Zusätzlich zu den beiden Gürtelvarianten noch eine Tasche, die entweder auch Metallbesatzstücke aufwies oder von einer Metallplatte gänzlich bedeckt war.

An den ungarischen Gürteln waren neben den Taschen auch Säbel, Köcher und Bogenfutterale befestigt, die ebenfalls mit Metallbesatz versehen sein konnten. ${ }^{89} \mathrm{Im}$ bulgarischen Material lassen sich Besatzstücke aussondern, die zwar nur entfernte, aber gut dokumentierte Analogien in den ungarischen Komplexen von Taschen-, Köcher- und Bogenfutteralzier besitzen. Sie gleichen sich in den Grundzügen der Kontur, die den Rundungen des Ornaments folgt und haben eine Durchbrechung im Zentrum (Abb. 1b). Möglich ist, dass sie Waffenzubehör zierten, aber das ungarische „Schema“ bietet hier keine eindeutige Lösung an. Zwei unterschiedliche, in einer Privatsammlung befindliche Beschläge, die nach M. Schulze-Dörrlamm als Taschenrandbeschläge vom Typ Kiew angesprochen werden könnten, ${ }^{90}$ dienten wahrscheinlich zur Aufhängung von Bogenfutteralen, ${ }^{91}$ was zusammen mit den oben genannten Beschlägen das Vorhandensein von beschlagverzierten Bogenfutteralen bei den Bulgaren wahrscheinlich macht. Ein grob verzierter Säbelscheidenbeschlag aus der Festung Car Asen ähnelt nur noch in der Kontur den ungarischen Vorbildern. ${ }^{92}$ Unter dem ziemlich umfangreichen Material in den bulgarischen Museen und Privatsammlungen gibt es jedoch bisher keine rautenförmige Taschenbeschläge vom Typ Černigov (nach M. SchulzeDörrlamm) oder Taschendeckbleche. Einzig ein versilberter Bronzebeschlag mit rechteckiger Schlaufe aus der Festung bei Suvorovo (obšt. Suvorovo, obl. Varna, Bulgarien) dürfte einen Taschenbeschlag anderen Typs darstellen. ${ }^{93}$ Taschen des ungarischen Typs mit Metallbesatz scheinen jedenfalls nicht in nennenswerter Zahl an die untere Donau gelangt zu sein.

Oben wurden zwei Rekonstruktionsversuche von Gürteln (Središte und Debrene) vorgestellt und verworfen. Abgesehen von dem noch unpublizierten Neufund von Krivina sind dies die einzigen Fälle, bei denen in Umriss und Verzierung identische, jedoch in den Proportionen unterschiedliche Beschläge in einem Kontext gefunden worden sind. Um Gürtelrekonstruktionen nach dem ungarischen Modell vorzunehmen, wurde deshalb der Versuch unternommen, im reichen Fundbestand Beschlagtypen ähnlicher Form und Verzierung auszusondern und künstlich zu Garnituren zu vereinen. Hierzu wurde sämtliches publiziertes und ein Großteil des unpublizierten Materials aus Bulgarien erkundet (Sammlungen der Museen in Silistra, Dobrič, Veliko Tărnovo, Šumen, Veliki Preslav, Pliska und des Nationalen Archäologischen Museums in Sofia). Es wurden dabei 16 Beschlagtypen, 8 Varianten der für ungarische landnahmezeitliche Gürtel typischen Schnallenform sowie 8 Typen von Riemenzungen ausgewählt, die eine Kombination zu Gürtelgarnituren erlauben. Im Katalogteil sind überdies alle bekannten Vergleichsstücke des unteren Donauraumes angeführt, nicht nur die publizierten, sondern auch die unpublizierten aus Museumsbeständen und Privatsammlungen.

\section{Schnallen (Nr. 1-8)}

Die 8 im Katalog aufgeführten Bronzeschnallen besitzen die gleichen Charakteristika (Abb. 2). Sie weisen einen ovalen Bügel, teilweise mit spitz verbreiteter Dornauflage sowie einen festen, meist trapezförmigen Beschlag mit geradem, spitz zulaufendem oder eingesatteltem Ende auf. Bei zwei Schnallen ist der Übergang vom Rahmen zum Beschlag durch einen schwachen Wulst markiert (Nr. 6 und 8). Die Befestigung mittels Nieten oder Dorne ist unterschiedlich bewerkstelligt, deren Anzahl auf dem Beschlag von 1 bis 4 schwankt. Die Dornen sind auf der Rück-

\footnotetext{
${ }^{89}$ RÉVÉSz 1996, 134 f., Abb. 66-67, 70-71; 163, Abb. 94-96; 164, Abb. 97-98; 240, Taf. 18; 278, Taf. 56; 304, Taf. 81; 326, Taf. 103; 348, Taf. 125; 372, Taf. 149; 377, Taf. 154; 379, Taf. 156.

${ }^{90}$ Privatsammlung von B. T. Ivanov (Varna), die von B. Domanov (Sofia) bearbeitet wird (freundliche Mitteilung von St. Angelova). Vgl. SchUlze-DöRRLAMm 1988, 392 ff. mit Abb. 17-18; 409, Abb. 32.
}

\footnotetext{
${ }^{91}$ FODOR 1996, 74, Abb. 7; 76, Abb. 9.

${ }^{92}$ Stanilov 1999, 35, Abb. 1.2.

${ }^{93}$ Pletn'ov-Pavlova 1994/1995, 32 bzw. 120 (Typ A V); 135 f., Nr. 38; 193, Taf. 2.38 (er wird zu Unrecht dem Typ Černigov nach M. Schulze-Dörrlamm zugwiesen). - Vgl. SCHULZE-DöRRLAMM
} 1988, 397, Abb. 21, 423 f. 
seite mitgegossen oder angelötet, ${ }^{94}$ die Nieten durchbrechen die Beschlagplatte und sind auch auf der Vorderseite noch sichtbar. Der Schnallendorn fehlt heute meist, doch zeigen die erhaltenen Stücke, dass er gewöhnlich aus Eisen war.

Die Varianten dieser Bronzeschnallen mit festem Beschlag sind zahlenmäßig wie folgt verteilt: 1 Exemplar von Nr. 4; 2 Exemplare von Nr. 8; 5 Exemplare von Nr. 5; 9 Exemplare von Nr. 1; 7 Exemplare der heterogenen Gruppe, die von den Nummern 2-3 und 6-7 gebildet wird.

Schnallen mit festem Beschlag sind aus unterschiedlichen Fundorten in Nordbulgarien bekannt (einer auf der rumänischen Donauinsel Păcuiul lui Soare). Von den insgesamt 24 Exemplaren sind 15 bei regulären Ausgrabungen gefunden worden, 5 sind Lese- bzw. Raubgrabungsfunde aus altbulgarischen Festungen und bei 4 ist der Fundort unbekannt. Von allen sind 16 publiziert.

Aus dem Karpatenbecken sind zahlreiche Parallelen aller Schnallenvarianten bekannt. ${ }^{95}$

\section{Gürtelbeschläge (Nr.9-24)}

Die Beschläge im Katalog sind in zwei Gruppen eingeteilt, in kleine ( $A b b$. 3) und große ( $A b b$. 4.) Exemplare. Man darf annehmen, dass sie von unterschiedlich breiten Gürteln stammen. Für deren Breite lassen sich demnach Mindestmaße von 1,5 bis 2,3 cm angeben. Die Beschläge sind nochmals in breite, aufrecht applizierte (Spitze nach oben) und schlanke, liegende (Spitze zur Seite) Exemplare unterteilt. Die unterschiedliche Ausrichtung auf dem Riemen wird durch die geringfügige Abweichung von Höhe bzw. Breite der Beschläge untermauert. Sie liegt nur bei $0,2-0,3 \mathrm{~cm}$.

Die Beschläge beider Größengruppen sind nach der Zier vom einfachen zu komplizierten Mustern unterteilt. Auffällige Formen (Nr. 14, 19 und 24) sind ungeachtet der Zier an das Ende gesetzt.

Kleine Beschläge (Nr. 9-14): Die erste Gruppe besteht aus 6 Garnituren (Abb. 3), wovon 5 die für diese Beschläge typische herz- oder blattförmige Kontur aufweisen, die von dem darin oft enthaltenen Palmettenmotiv herrührt. Die Lesefunde stammen - soweit nicht anders angegeben - von altbulgarischen Festungen.

Nr. 9 (42 Exemplare, davon 23 Lesefunde und 19 fundortlos): Die Stücke, die ausschließlich aus Nordostbulgarien stammen, sind blattförmig mit 4 symmetrisch angeordneten Kügelchen am Rand. Die Verzierung auf der glatten, leicht gewölbten Oberfläche besteht aus einem einfachen pflanzlichen Motiv: zwei von einem Punkt ausgehende, geschwungene Gravurlinien, deren Enden sich nochmals in je zwei geschwungenen Fortsätzen verzweigen.

$\mathrm{Zu}$ den breiten Beschlägen existiert ein Satz (mit etwas breiteren Proportionen) im Inventar des Grabes von Ladánybene-Benepuszta (Kom. Bács-Kiskun, Ungarn), der dort allerdings mit anderen schlanken, blattförmigen Beschlägen vergesellschaftet ist. ${ }^{96}$ Das Grab enthielt 10 Denare Berengars I. (888-915/915-924). ${ }^{97} 6$ damit übereinstimmende, breite Beschläge aus Budapest-Farkasrét sind dort mit 5 vergleichbaren Ösenbeschlägen und 8 andersartigen schlanken Beschlägen vergesellschaftet. ${ }^{98}$ Die Ösenbeschläge besitzen wiederum Parallelen im Grab 16 des ersten Friedhofs von Kenézlő (Kom. Borsod-Abaúj-Zemplén, Ungarn). ${ }^{99}$

Nr. 10 (60 Exemplaren, davon 6 Ausgrabungsfunde, 20 Lesefunde und 34 fundortlos): Die in Nordostbulgarien und Südostrumänien gefundenen Beschläge weisen vier Blätter in kreuzförmiger Anordnung auf, wobei eines spitz, die anderen aber rund enden. Auch hier sind vier Kügelchen am Rand in den Blattzwickeln zu verzeichnen. Eine breite Randleiste umgibt ein tropfenförmiges, buckelförmiges Ornament mit flacher Rahmung im Zentrum. Oft sind seitlich des Medaillons nochmals halbkreisförmige Fortsätze zu beobachten, die den Rundungen der seitlichen Felder folgen. Einer der im Katalog aufgeführten Beschläge besteht aus Zinn oder Silber.

Nr. 11 (29 Exemplare, davon 2 Ausgrabungsfunde, 13 Lesefunde und 14 fundortlos): Die Beschläge sind herzförmig mit einem kleinen Kügelchen an der Einbuchtung und einem noch kleineren mit Manschette an der

${ }^{94}$ Vgl. SZEGEDY 1960, 317 f. mit Abb. 58b, e; 322.

${ }^{95}$ Z. B. Dobrá (Kisdobra, okr. Trebišov, SK), drittes Reitergrab: HAMPEL 1905, 643, Taf. 424.22. - Kenézlő I (Kom. BorsodAbaúj-Zemplén, Ungarn), Gräber 10 und 11: JósA 1914, 311, Abb. 18; 316, Abb. 25. - Kenézlő II, Grab 31: FetTich 1931, 85, Abb. 61. Malé Kosihy (Ipolykiskeszi, okr. Nové Zámky, SK), Grab 261: HANULIAK 1994, 56, Abb. 52.64b; 59; 192, Taf. 53.7. - Tarcal (Kom. Borsod-Abaúj-Zemplén, Ungarn), Reitergrab von 1894: FEтTICH 1937, 223 (h), Taf. 43.32; FODOR 1996, 123 mit Abb. 7.
${ }^{96}$ FetTich 1937, 216, Nr. 4; Taf. 35.15-29; FOdOR 1996 339 mit Abb. 5-6. - Vgl. FeHÉr 1940, 52, Abb. 21.

${ }^{97}$ Schulze-DöRrlamm 1988, 448, Nr. 20; KovÁcs 1989 , 42 f., Nr. 202-211.

${ }^{98}$ Dienes 1973, 190 f. mit Abb. 6.1-18, bes. 9-14; Mesterházy 1994, 32, Nr. 2; 34, Abb. 3.1-2.

${ }^{99}$ Mesterházy 1994, 32, Nr. 2; 35, Abb. 4.1-2. 


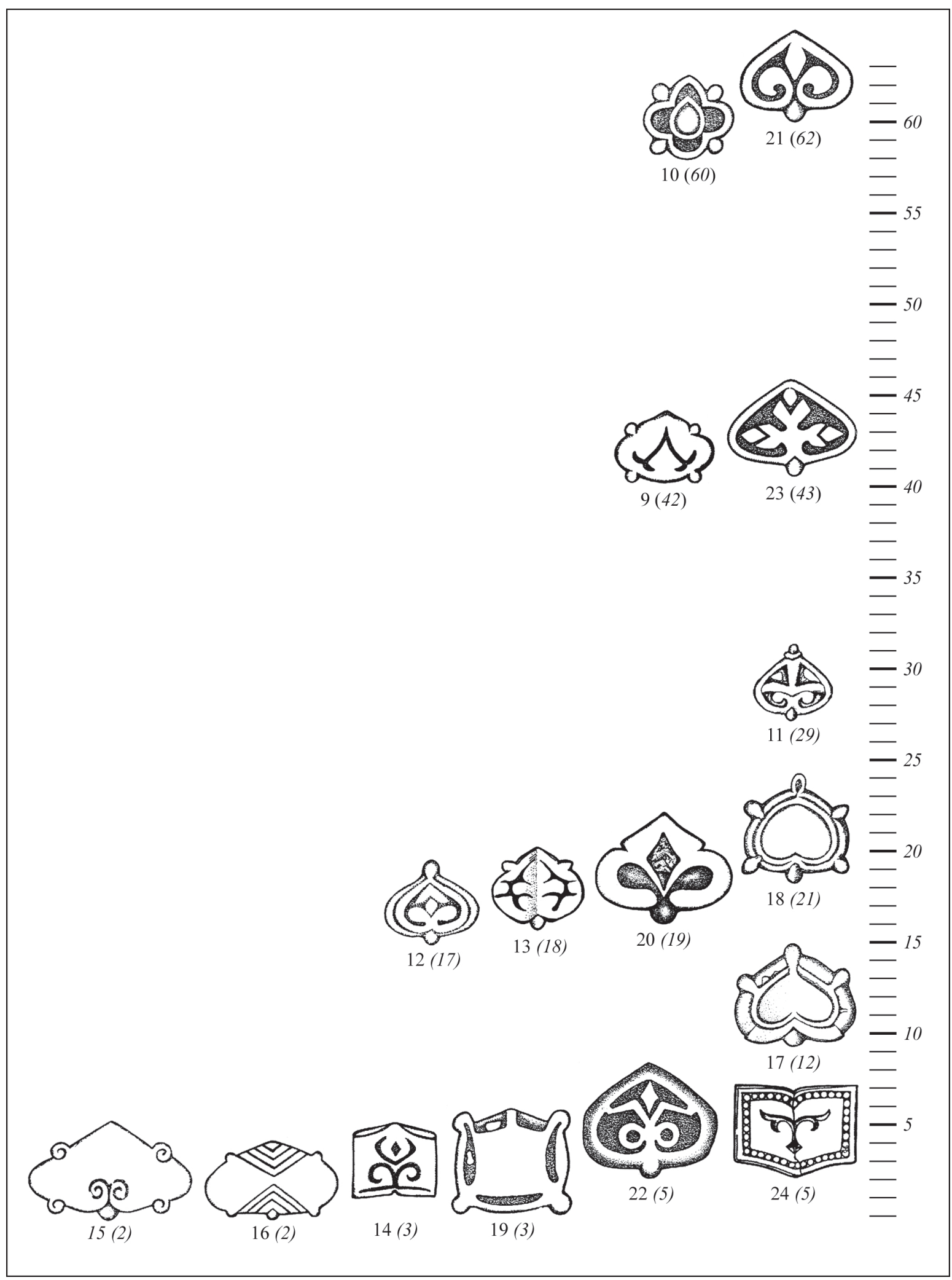

Abb. 5. Häufigkeitsverteilung der Beschläge in Bulgarien.

Unter den Beschlägen Angabe der Typenbezeichnung und Anzahl der Vertreter in Klammern (Graphik: Stanislav Stanilov/Uwe Fiedler) Acta Archaeologica Academiae Scientiarum Hungaricae 67, 2016 
Spitze. Abgesehen von der relativ breiten Randleiste wird fast die ganze Innenfläche von einem Palmettenmotiv eingenommen, dessen mittleres Blatt mit der Randleiste verschmilzt. Die Unterschiede zwischen den Beschlägen liegen im Detail. Einmal fehlt das Kügelchen an der Spitze, ein anderes Mal sind die unteren zwei Blätter der Palmette von den oberen drei getrennt und ein drittes Mal ist das mittlere Palmettenblatt isoliert. Diese Unterschiedlichkeit könnte ein Hinweis auf größere Produktionsmengen sein.

Nr. 12 (17 Exemplare, davon 2 Ausgrabungsfunde, 7 Lesefunde und 8 fundortlos): Wie die Vertreter der vorherigen Garnitur, sind die Beschläge herzförmig mit Kügelchen an Basis und Spitze. Die breite Randleiste ist zweigeteilt. Das Palmettenmotiv unterscheidet sich von dem der vorherigen Garnitur. An der Basis des Innenfeldes gehen zwei breite Blätter mit rundlichem Ende ab. Zwischen ihnen und der Beschlagspitze ist ein zweigeteiltes Blatt eingepasst. Dessen Unterteil ist spitzoval, der Oberteil schwebt als großer, nach unten offener Winkel darüber. Unter den verschiedenen Vertretern gibt es Unterschiede bei der Form der Blätter. Selten ist das Mittelblatt nur ungenügend abgegrenzt. Einer der Beschläge besteht aus Zinn oder Silber.

Nr. 13 (18 Exemplare, davon 3 Ausgrabungsfunde, 8 Lesefunde und 7 fundortlos): Die herzförmigen Beschläge weisen ein Kügelchen an der Basis und zwei weitere beiderseits der Spitze auf. Als Randleiste fungieren zwei stark stilisierte dreiblättrige Halbpalmetten. Im Zentrum ist wiederum eine Palmette eingeschrieben, diesmal mit fünf Blättern und weniger ausladenden unteren Blattpaaren. Die Blatteinschnitte sind meist in gleicher Höhe wie die der randlichen Halbpalmetten angebracht. Zwei Exemplare weisen Besonderheiten in der Oberflächengestalt auf. Eines (A) weist in der Mitte einen Grat auf, ein anderes war vergoldet. Die übrigen Vertreter weisen vor allem Unterschiede bei der Ausgestaltung der Palmettenblätter auf.

Eine vollständige, 54-teilige Garnitur dieses Typs ist aus Szarvas (Kom. Békés, Ungarn), Tessedik Sámuel utca, Grab 8 bekannt. In der Publikation sind neben Schnalle und Riemenzunge 18 breite Beschläge, 6 breite Beschläge mit Öse und 23 schlanke Beschläge zu erkennen. ${ }^{100}$

Eine Variante des breiten Beschlags mit einer nur dreiblättrigen Palmette im Zentrum und aufgelösten Halbpalmetten am Rand stammt vom Donauufer in Belgrad-Zemun (Serbien). ${ }^{101}$

Nr. 14 (3 Exemplare, alle Lesefunde von der Festung Središte): In der Gruppe der kleinformatigen Beschläge sticht nur diese Garnitur durch die winkelförmige Gestalt heraus. Ihre eingravierte Verzierung verbindet sie mit der Garnitur Nr. 9, doch sind hier nicht Zweige, sondern stark stilisierte, in drei Teile geteilte fünfblättrige Palmetten zu finden. Die drei fundortgleichen Stücke, die alle zwei Befestigungsdorne auf der Rückseite aufweisen, stammen aufgrund ihres identischen Ornaments zumindest aus der gleichen Werkstatt, wenn nicht gar vom gleichen Gürtel.

Große Beschläge (Nr. 15-24): Diese Gruppe besteht aus 10 Garnituren (Abb. 4), wobei nur zwei (Nr. 19 und 24) von der üblichen herz- bis blattförmigen Kontur abweichen.

Nr. 15 (2 fundortlose Exemplare): Die beiden im Magazin des Šumener Museums befindlichen Beschläge sind breit-herzförmig und blattförmig. An der Basis bzw. der Einkerbung befindet sich je ein Kügelchen, von denen zwei gegenständige kleine Spiralen als Ritzlinien abgehen. An beiden Seiten befinden sich jeweils zwei rundliche Fortsätze, die innen eine kurze Spiralfurche aufweisen. Sonst ist die Oberfläche der Beschläge glatt. Rückseitig sind zwei Nietstifte vorhanden. Beide werkstattgleiche Stücke dürften vom gleichen Gürtel stammen.

Wenn auch direkte Parallelen aus dem Karpatenbecken nicht bekannt sind, so sei doch der Hinweis erlaubt, dass randliche, aus Spiralen gebildete Fortsätze auch dort auftreten, wie auf Zaumzeugbeschlägen des Grabes von Izsák-Balázspuszta (Kom. Bács-Kiskun, Ungarn) oder den Gürtelbeschlägen des Grabes 1 von Karos I (Kom. Borsod-Abaúj-Zemplén, Ungarn). ${ }^{102}$

Nr. 16 (2 Exemplare, davon 1 Lesefund einer Siedlung und 1 fundortlos): Die beiden Stücke ähneln der Nr. 15. Es ist jedoch keine Einkerbung der Kontur mehr zu beobachten. Nur ein kleiner rundlicher Fortsatz ist an dieser Stelle weiter vorhanden, zu dem sich an beiden Seiten je zwei weitere Fortsätze gesellen. Von Letzteren gehen zwei Dreierbündel von gravierten Winkellinien aus, die im Zentrum der Beschläge mit ihren Spitzen fast aneinanderstoßen. Bemerkenswert ist, dass diese Winkellinien einmal Basis und Spitze und beim anderen Beschlag die beiden Längsseiten einnehmen. Bei der Anbringung auf dem Gürtelriemen waren diese Winkellinien aber beide vertikal ausgerichtet. Die übrige Oberfläche der Beschläge ist glatt. An der Zugehörigkeit der beiden Exemplare zu einer Garnitur dürfte kein Zweifel bestehen.

${ }^{100}$ MRT 8 (Békés megye régészeti topográfiája. A szarvasi járás IV/2. Budapest 1989), 447-449, Nr. 8/117 - A 8, Taf. 70; JuHÁsZ 1996, 159, 172, Abb. 6.
${ }^{101}$ Bajalović-HadžI-PešIĆ 1984, 114, Nr. 495, Taf. 13.9; BÁLINT 1991, 106, Taf. 33a.8.

${ }^{102}$ FodOR 1996, 319-322 mit Abb. 5; 84 mit Abb. 3-4.

Acta Archaeologica Academiae Scientiarum Hungaricae 67, 2016 


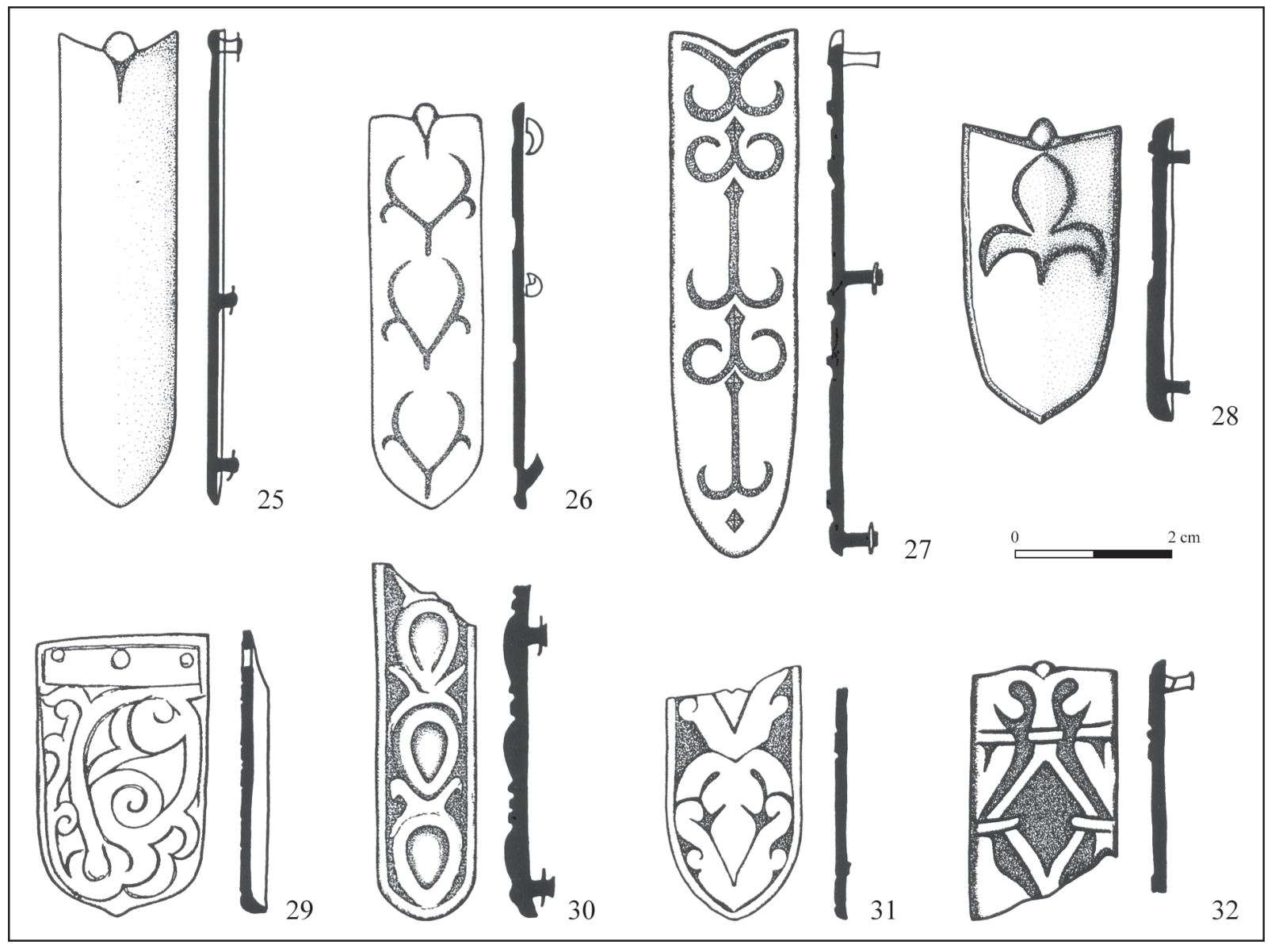

Abb. 6. Riemenzungen (Nr. 25-32) (M. 1:1) (Zeichnung: Stanislav Stanilov)

Nr. 17 (12 Exemplare, davon 9 Lesefunde von der Festung Debrene und 3 fundortlos): Die herzförmigen Beschläge weisen jeweils vier kugelige Fortsätze auf, je einen an Basis und Spitze und zwei beiderseits der Spitze. Zwei Leisten, außen breit und innen schmal, umrahmen das herzförmige, unverzierte Mittelfeld, das nur bei einem schmalen Beschlag (B) einen Mittelgrat aufweist, sonst aber flach ausgestaltet ist. Abweichungen gibt es bei der Ausgestaltung der Basis der Beschläge. Dort ist zwischen Kügelchen und Randleiste ein Streifen eingeschoben, dessen Enden teilweise glatt (A), teilweise blattförmig-gerundet (B) oder schwalbenschanzförmig ausgestaltet sind. Alle Beschläge weisen die gleiche Verzierung, Befestigungs- und Herstellungsweise auf. Sie sind aus sehr dünnem Blech gefertigt, so dass sich das Negativ des Ornaments auch auf der Rückseite deutlich abzeichnet. Die Befestigung erfolgt mittels zweier Nietstifte von nahezu gleicher Dicke. 4 der breiten und 5 der länglichen Besatzsstücke sind wahrscheinlich mittels desselben Models geformt worden. Wahrscheinlich stammen alle 12 Exemplare aus einer Werkstatt, die sich wohl in der Festung Debrene in der südlichen Dobrudscha befand.

Eine Variante der schlanken Beschläge mit nur vier Fortsätzen ist von zwei Fundorten der Slowakei bekannt. ${ }^{103}$ Nur entfernt verwandt ist auch die Garnitur des Grabes 45 von Kenézlő II, die mit einer zwischen 907/908 und 911/912 geprägten arabischen Münze vergesellschaftet war. ${ }^{104}$

Nr. 18 (21 Exemplare, davon sind 4 Grabungsfunde, 7 Lesefunde und 10 fundortlos): Die herzförmigen Beschläge, von denen nur 2 Exemplare breit proportioniert sind, besitzen randlich 6 kugelförmige Fortsätze (je

${ }^{103}$ ToČík 1992, 151 f. (Nr. 6) mit Abb. 95.16 (GalantaMatúškovo/Galanta-Takšoň, Galánta-Taksonyfalva, okr. Galanta, Slowakei); 158 (Grab 1); 160, Abb. 102.3 (Sládkovičovo/Magyardiószeg, okr. Galanta, Slowakei).
${ }^{104}$ FeTTICH 1931, 94-97 mit Abb. 77 und 80; FodOR 1996, 156 mit Abb. 13; Fodor et al. 1998, 111, Abb. 78; 172, Nr. 266-268. - Zur Münze: SchUlze-DöRRLAMm 1988, 447, Nr. 17; KovÁcs 1989, 37 f., Nr. 147; MesterháZy 1994, 47; 49, Abb. 16; 53. 
einen an Basis und Spitze und je zwei an den Seiten). Eine Doppellinie - die Äußere berührt die Ansätze der kugelförmigen Fortsätze - umrahmt das glatte, herz- bis tropfenförmige Medaillon. Unterschiede liegen im Detail, besonders in der Ausgestaltung des Fortsatzes an der Spitze, der meist flach ist. Dies ist eine Sonderheit, die auf eine gemeinsame Werkstattherkunft hindeutet.

Nr. 19 (3 Exemplare, alle fundortlos): Die Beschläge sind von rechteckigem, fast quadratischem Umriss mit konvexen Seiten und kreisförmigen Fortsätzen an den Ecken. Während das Mittelfeld der Beschläge glatt ist, verlaufen an den Seiten unregelmäßig ausgeformte, längliche Vertiefungen. An einer Seite sind diese nur randlich und in der Mitte von einem Steg unterbrochen. Beide Beschläge dürften zu einer Garnitur gehört haben.

Nr. 20 (19 Exemplare, davon 3 Ausgrabungsfunde, 10 Lesefunde und 6 fundortlos): Diese herz- bis blattförmigen Beschläge besitzen ein Kügelchen an der Basis und zwei Kerben beiderseits der Spitze. Das dreiblättrige Palmettenmotiv zeichnet sich also auch deutlich in der Kontur ab. Die drei Blätter - zwei tropfenförmige, geschweifte Blätter und ein rautenförmiges Mittelblatt - sind als Vertiefungen im Mittelteil der Beschläge kenntlich gemacht. Im Mittelblatt ist ein Tannenzweigmuster eingeritzt. Unterschiede bei den einzelnen Exemplaren sind bei dem Ornament (in einem Fall ist das Mittelblatt anders ausgeformt) sowie bei der Herstellungsweise feststellbar. Es gibt Beschläge, die aus dickem und solche, die aus dünnem Blech gefertigt worden sind. Zugehörigkeiten zu einzelnen Garnituren lassen sich schwer nachweisen. Die Beschläge dieser Form waren offensichtlich weit verbreitet.

$\mathrm{Zu}$ den abgebildeten beiden Stücken gibt es eine nahezu identische Garnitur aus dem bekannten, 1894 geborgenen Reitergrab von Tarcal-Veréb-árok (Kom. Borsod-Abaúj-Zemplén, Ungarn), das auch eine Taschendeckplatte (Typ Vécs nach M. Schulze-Dörrlamm) und einen Säbel enthielt. Die silberne Gürtelgarnitur weist in den Vertiefungen eine Vergoldung auf und bestand aus mindestens 6 breiten und 8 schlanken Beschlägen. ${ }^{105}$

Nr. 21 (62 Exemplare, davon 7 Ausgrabungsfunde, 30 Lesefunde und 25 fundortlos): Die Beschläge aus dem mittleren Nordbulgarien und Nordostbulgarien sind herzförmig mit einem kugeligen Fortsatz am basalen Einschnitt. Die breite Randleiste geht in zwei gegenständige, sich nicht berührende Kreislappenblätter über, in deren Mitte ein lanzettförmiges Mittelblatt eingeschoben ist. Es gibt wohl Abweichungen bei den einzelnen Vertretern dieses Typs. Die beiden abgebildeten Stücke mit Befestigungsdornen und schwach konturierter Verzierung mögen aber zu einer Garnitur gehört haben.

Eine aus 8 breiten und 13 schlanken Bronzebeschlägen bestehende Garnitur dieses Typs wurde im Grab 31 des ungarischen Gräberfeldes Kenézlő II vorgefunden. ${ }^{106}$ Ein schlanker Beschlag dieses Typs ist sogar aus dem schwedischen Handelsplatz Birka bekannt. ${ }^{107}$

Nr. 22 (5 Exemplare, davon sind 4 Lesefunde und 1 ist fundortlos): Die Stücke gleichen sich annähernd in Proportionen und Verzierung, nur in Details gibt es Abweichungen. Sie sind herzförmig mit einem Kügelchen am basalen Einschnitt. Eine relativ breite Randleiste umgibt ein stark stilisiertes, fünfblättriges Palmettenmotiv. Die unteren Blätter sind zu Kreisen, die mittleren zu Winkeln umgeformt. Nur das rhombische Mittelblatt ist gut zu erkennen. Bei deren Ausgestaltung gibt es jedoch Abweichungen bei den einzelnen Vertretern. Trotz der einheitlichen Erscheinung sind die Beschläge weit verbreitet. Dennoch ist anzunehmen, dass sie von einer Hand gefertigt worden sind.

Nr. 23 (43 Exemplare - 15, 10 und 18 Exemplare der abgebildeten Formen -, davon 2 Ausgrabungsfunde, 15 Lesefunde und 26 fundortlos): Die Beschläge sind herz- bis blattförmig mit einem Kügelchen an der Basis. Bei den 9 Ösenbeschlägen finden sich beiderseits der Öse kugelförmige Fortsätze. Eine relativ dünne Randleiste umrahmt eine aus drei dreiblättrigen Palmetten in kreuzförmiger Anordnung bestehende Verzierung. Das Ornament stellt eine Vereinfachung des Lebensbaummotivs dar (vgl. Abb. la). Es gibt hierbei aber erhebliche Unterschiede zwischen den einzelnen Exemplaren. Einmal sind die Blätter der Palmetten nur schwach konturiert und ein anderes Mal sind die Blätter so deformiert, dass der Eindruck einer neunblättrigen Palmette entsteht. Es lässt sich nicht mit Sicherheit sagen, ob sich unter den Beschlägen zusammengehörige Garnituren verbergen. Dazu ist ihre Anzahl immer noch zu klein.

Dieser Beschlagtyp ist nicht nur in Bulgarien häufig belegt, sondern hat auch die zahlreichsten Parallelen im Karpatenbecken.

${ }^{105}$ Hampel 1905, Bd. 1, 772 mit Abb. 2157-2158; FetTich 1937, 221 ff., bes. 223 (e), Taf. 43.1-15; Fodor 1996, 122 mit Abb. 3-4; FoDOR et al. 1998, 108 f., Abb. 72-73; 170, Nr. 217-218.

\footnotetext{
${ }^{106}$ FetTich 1931, 85, Abb. 61.1-21; $87 \mathrm{f}$.

${ }^{107}$ ARNe 1914, 138 mit Abb. 198.
} 
Eine vollständige Garnitur dieses Typs, bestehend aus mindestens 8 schlanken und 4 Ösenbeschlägen (und weiteren 5 Fragmenten), hat man im Grab 46 des zweiten Friedhofs von Kenézlő gefunden. ${ }^{108}$ Eine Garnitur, u. a. mit einem Ösenbeschlag und drei herzförmigen Beschlägen, stammt aus dem dritten Reitergrab im slowakischen Dobrá (Kisdobra, okr. Trebišov, Slowakei). ${ }^{109}$ Auch aus dem gestörten Gab 2 des dritten Gräberfeldes von KarosEperjesszög (Kom. Borsod-Abaúj-Zemplén, Ungarn) stammen drei Ösen- und zwei schlanke Beschläge sowie eine Riemenzunge. ${ }^{110}$

Ein schlanker vergoldeter Silberbeschlag mit anders ausgestalteten Seitenarmen des Ornaments ist aus Almásneszmély (Kom. Komárom, Ungarn) bekannt. ${ }^{111}$

Drei einzelne Ösenbeschläge dieses Typs sind bereits seit Langem bekannt: Deta (Detta, jud. Timişoara, Rumänien) ${ }^{112}$ und Kiskunhalas (Kom. Bács-Kiskun, Ungarn) ${ }^{113}$ - weiter eine Variante eines solchen mit abweichender Kontur und Muster aus der ,Schwarzen Erde“ von Birka. ${ }^{114}$

Eine Vorstellung der Anordnung der drei Beschlagtypen, einschließlich von Ösenbeschlägen, vermittelt die Gürtelgarnitur des Grabes 2 von Rétközberencs-Paromdomb (Kom. Szabolcs-Szatmár-Bereg, Ungarn). ${ }^{115}$

Nr. 24 (5 Exemplare, davon 3 Ausgrabungsfunde aus Preslav und 2 fundortlos, wahrscheinlich aber ebenfalls aus Preslav): Die Beschläge haben die gleiche winkelförmige Gestalt wie die kleinen Beschläge Nr. 14. Eine vom Rand leicht abgesetzte Randleiste ahmt ein Perlband nach. Auf der Mittelachse befinden sich ein bzw. zwei Rhomben. Von dem größeren Rhombus an der Spitze geht ein geritzter Stamm ab, der sich in zwei zweiblättrige Halbpalmetten verzweigt. Dieses Verzierungsmotiv ist verschieden ausgeführt. Einmal ähnelt es mehr Ranken und ein anderes Mal mehr Palmetten. Bei einem Exemplar ist der Rhombus am Fußpunkt des Pflanzenmotivs in eine tropfenförmige Vertiefung umgeformt. Unter den bekannten Exemplaren lassen sich keine zusammengehörigen Garnituren zusammenstellen. Diese Beschläge scheinen aber typisch für die Hauptstadt zu sein und sind dort wohl auch hergestellt worden.

Den Umriss der schlanken Garnitur mit der Perlbandimitation findet man in fünf vergoldeten, silbernen Pressblechbeschlägen des Reitergrabes 11 von Červeník (Vörösvár, okr. Trnava, Slowakei) wieder. ${ }^{116}$

\section{Riemenzungen (Nr. 25-32) und deren Zuweisung zu Beschlagtypen}

Merklich seltener als Beschläge sind Riemenzungen gefunden worden. ${ }^{117}$ Aufgrund ihrer begrenzten Anzahl ist eine Gruppierung nach stilistischen Gesichtspunkten schwer möglich. Deshalb werden die auf $A b b .5$ wiedergegebenen und im Katalog aufgeführten Stücke primär nach ihren Proportionen und erst senkundär nach ihren Verzierungen den obigen Beschlagtypen zugeordnet (Abb.6). Ähnlich wie bei den in Ungarn geborgenen vollständigen Gürtelgarnituren könnte auch hier manchmal die Verzierung der Riemenzungen von der der übrigen Besatzstücke abgewichen haben. Bemerkenswert ist bei der Mehrzahl der Riemenzungen der Umstand, dass sie nur eine Schauseite aufweisen. An ihrer Rückseite verlief das Ende des Gürtelriemens, mit dem sie mittels Nietstifte verbunden waren. Nur die Nr. 29 weist eine andere Befestigungsart auf.

Nr. 25 (5 Exemplare, davon 4 Lesefunde und 1 fundortlos; 2 Exemplare bereits publiziert): Die Vertreter dieses Typs weichen in Größe und Proportionen erheblich voneinander ab. Sie sind unverziert und weisen einen Mittelgrat sowie einen schwalbenschwanzförmigen oberen Abschluss auf, in dessen Spalt ein Kügelchen eingeschoben ist. Dies ist eine deutliche Reminiszenz an die herzförmigen Beschläge. Am besten lassen sich diese Riemenzungen noch mit den Beschlägen Nr. 16 kombinieren. Deren Parameter, einschließlich der daraus erschlossenen Riemenbreite, passen gut zu den Riemenzungen dieses Typs. Natürlich harmonieren die Riemenzungen besser mit Garnituren unverzierter Beschläge, doch fehlen diese bisher im altbulgarischen Fundmaterial. Mittige Grate, wie

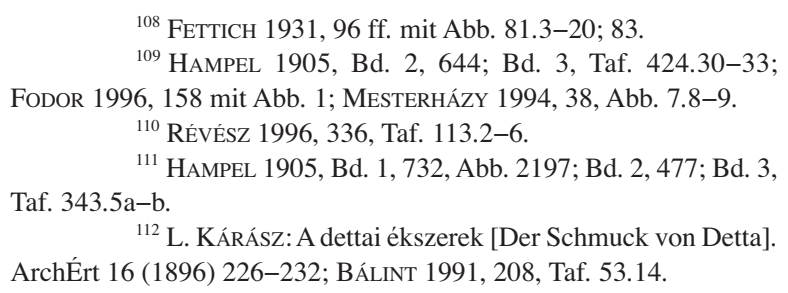

${ }^{113}$ Hampel 1905, Bd. 1, 726 f. mit Abb. 2177; Bd. 2, 642; Bd. 3, Taf. 426 (von der Flur Balotapuszta).

${ }^{114}$ ARNe 1914, 136 mit Abb. 184

${ }^{115}$ FODOR 1996, 166-168 mit Abb. 1-4

116 Тос̌ík 1968, 19, Abb. 7.6; 20 (Grab 11, Nr. 1); 78, Taf. 12.21-25; 124, Taf. 48.44 .

${ }^{117}$ Ihre Anzahl ist jüngst durch die Publikation der Festung Skala um sieben Exemplare bereichert worden (JoTOV-ATANASOV 1998, 315, Taf. 116, Nr. 473-479). 


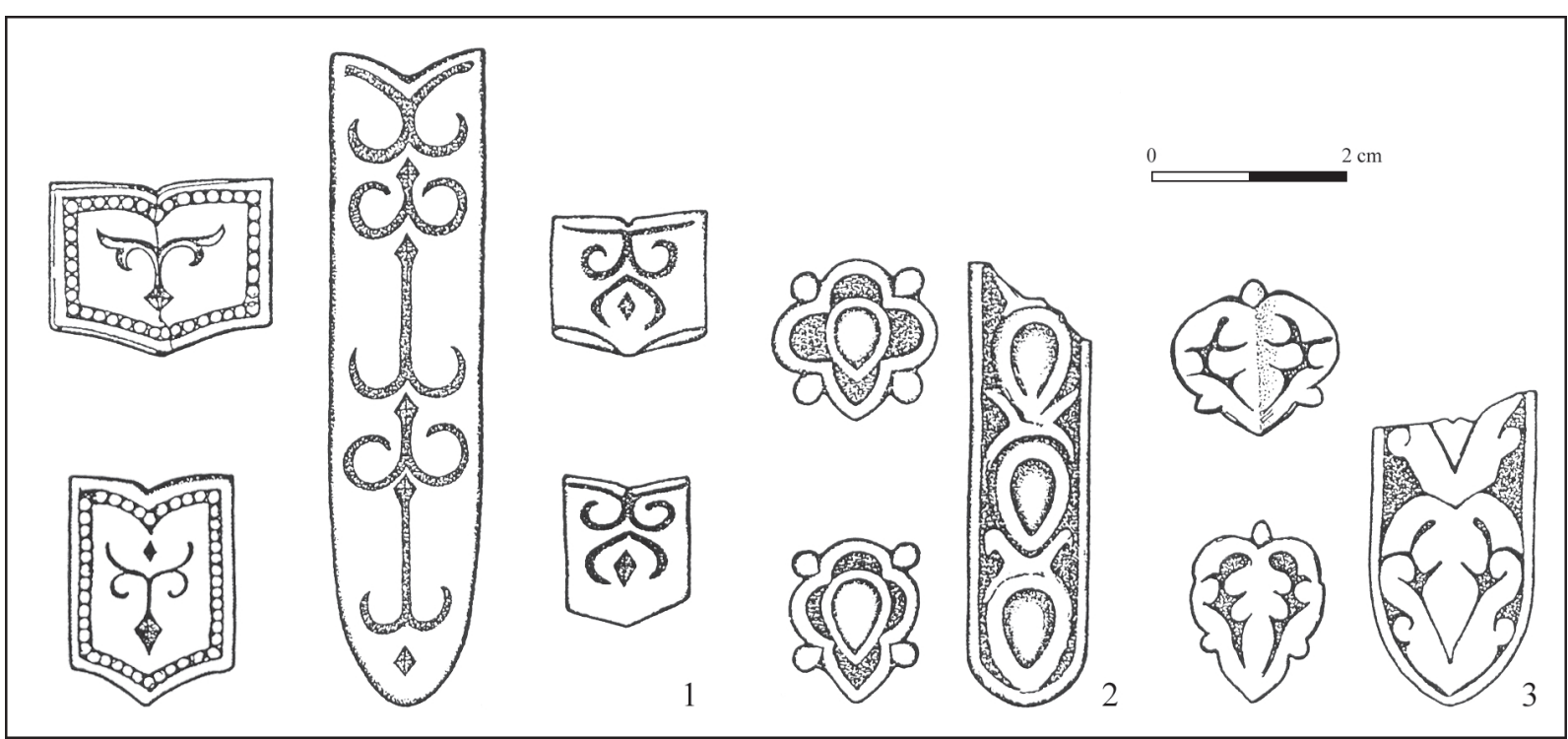

Abb. 7. Hypothetische Kombinationen von Beschlägen und Riemenzungen aufgrund der Verzierung (M. 1:1)

(Zeichnung: Stanislav Stanilov)

bei diesen Riemenzungen, treten auch bei den Beschlägen Nr. 13A und 17B auf, so dass diese durchaus auch eine Kombinationsmöglichkeit böten. Eine Gürtelschnalle lässt sich nur bedingt zuordnen, da Kriterien dafür fehlen. Selbst die Weite des Bügels muss nicht notwendigerweise der Breite des Hauptriemens genügen, wie die vorgestellte Rekonstruktion in Anlehnung an I. Dienes zeigt (Abb. 7.1).

Nr. 26 (3 Exemplare, davon 1 Ausgrabungsfund, 1 Lesefund von einer Siedlung (?) und 1 fundortlos; 2 Exemplare bereits publiziert): Am oberen Abschluss findet man hier einen Einschnitt mit einem kugelförmigen Fortsatz. Die Verzierung ist eingraviert. Von einem Stamm gehen jeweils zwei Äste ab, die sich nochmals verzweigen und damit Halbpalmetten bilden. Die drei Exemplare unterscheiden sich nicht in ihren Umrissen und ihrer Verzierung, sondern nur in ihren Proportionen. Die Breite der Riemenzungen und ihre Verzierung stimmen mit den Beschlägen Nr. 9 völlig überein. Wie oben, kann man ihnen bei der Rekonstruktion eine beliebige Schnalle zugesellen (Abb. 7.2).

Die weiteren aufgeführten Riemenzungen (Nr. 27-32) sind alle Einzelstücke.

$N r$. 27: Diese fundortlose Riemenzunge mit schwalbenschwanzförmigem oberen Ende weist längs einer Mittelachse eine ziselierte Verzierung auf, die aus mehreren hängenden Voluten besteht. Den Ausgangspunkt des Volutenstammes bilden jeweils kleine Rhomben. Ein weiterer Rhombus bildet isoliert den Schlusspunkt dieser Achse. Das Pflanzenornament ist ähnlich stilisiert wie bei der Riemenzunge Nr. 26. Vergleichbar komplizierte Muster begegnen auch auf anderen Riemenzungen, ${ }^{118}$ besitzen dort aber keine wirklichen Analogien. Sie lässt sich gut mit den Beschlägen Nr. 14 verbinden. Weniger gut passen die Beschläge Nr. 24 zu der Riemenzunge, da diese eine Randleiste aus imitiertem Perldraht aufweisen (Abb. 6.1). Dafür harmonieren diese Beschläge wegen ihrer Größe besser mit der Riemenzunge, obwohl auch sie nicht die Breite des Riemens der Riemenzunge erreichen (Abb. 7.4). Doch dürfte der Unterschied von 0,5 bis $1 \mathrm{~mm}$ für die Praxis ohne Bedeutung gewesen sein.

Nr. 28: Der obere Abschluss dieses Lesefundes aus der Außenstadt von Veliki Preslav ist nur wenig eingesattelt und mittig mit einem kugeligen Fortsatz versehen. Die Ränder sind abgesetzt. Wie die Nr. 25 weist auch diese Riemenzunge einen Mittelgrat auf. Zusätzlich ist in der oberen Hälfte eine durch eine Gravur konturierte, dreiblättrige Palmette eingeschrieben. Zur Verzierung fehlen Parallelen unter den Riemenzungen und Beschlägen. Als zentrales Motiv erscheinen solche Palmetten - „heraldische Lilien“ nach J. Hampel ${ }^{119}$ - aber auf Riemenzungen aus den Gräbern 46 und 50 von Kenézlő II und aus dem Grab 1 von Piliny-Leshegy (Kom. Nógrád, Ungarn) ${ }^{120}$ sowie auf verschiedenen Schnallenbeschlägen des Karpatenbeckens. ${ }^{121}$

${ }^{118}$ MaVrodinov 1959, 228, Abb. 267 (Pliska); Pletn'ov 1997, 88, Taf. 5.1-2.

${ }^{119}$ HAMPEL 1905, Bd. 1, 721.
${ }^{120}$ Ibidem Bd. 1, 727 f. mit Abb. 2180; MesterháZy 1994, 45, Nr. 9; 34 f., Abb. 3.18-19; Abb. 4.11.

${ }^{121}$ Mesterházy 1994, 45, Nr. 10; 35, Abb. 4.9, 12, 14-15. 


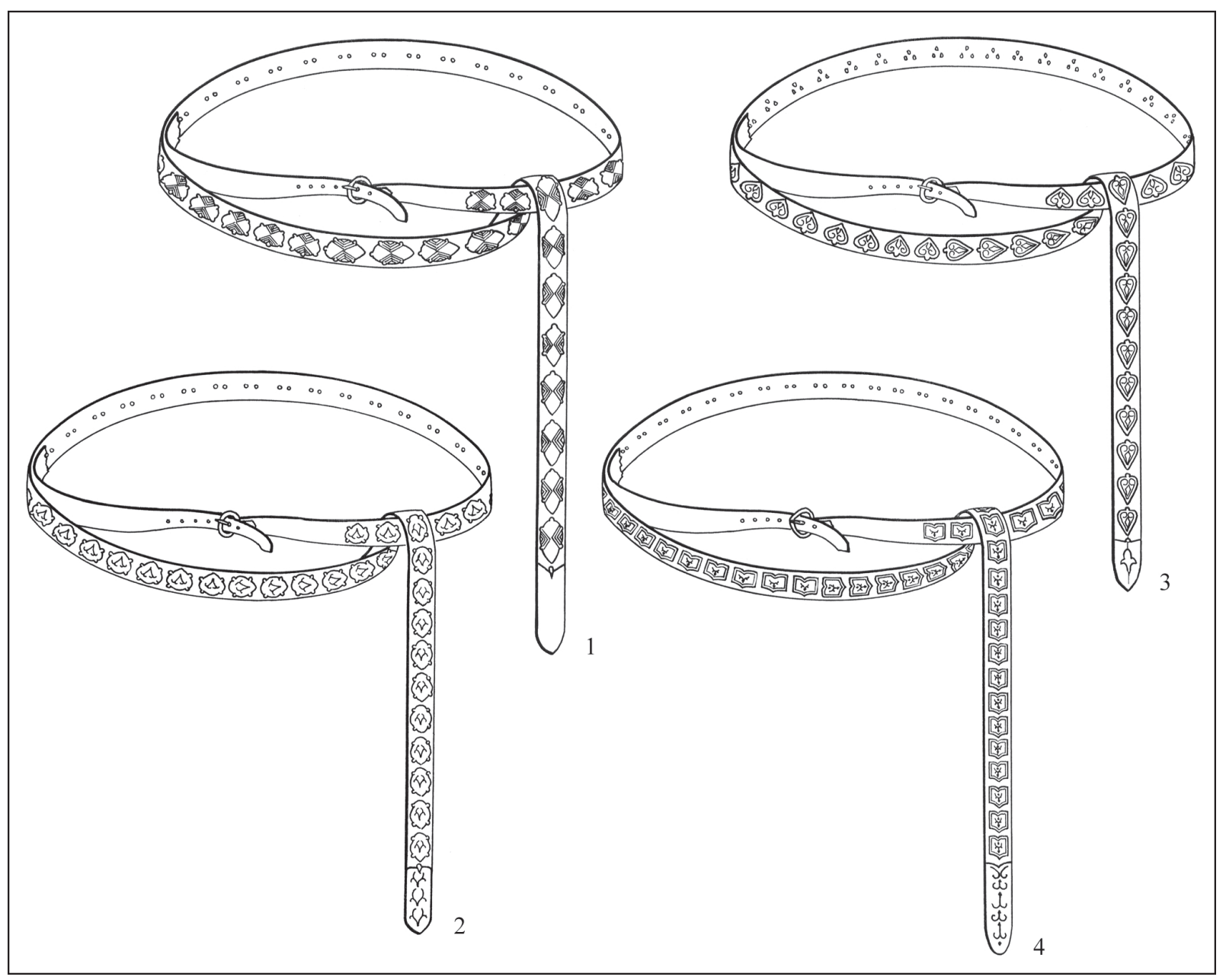

Abb. 8. Rekonstruktionsversuche von hypothetischen Gürteln mit Beschlägen.

1. Beschläge Nr. 16 und Riemenzunge 25; 2. Beschläge Nr. 9 und Riemenzunge 26; 3. Beschläge Nr. 21 und Riemenzunge 28;

4. Beschläge Nr. 24 und Riemenzunge 27 (Entwurf und Zeichnung: Mariela Inkova)

Als Kriterium bei der Zusammenstellung einer hypothetischen Garnitur bleibt die Riemenbreite. Hier eignen sich besonders die Beschläge Nr. 21, deren reliefiertes Palmettenmotiv entfernt an die Kerbverzierung der Riemenzunge erinnert ( $A b b$. 7.3). Die erwähnte, reicher verzierte Riemenzunge des Grabes 46 von Kenézlő II ist mit Beschlägen ähnlich Nr. 23 vergesellschaftet. ${ }^{122}$ Im Grab 50 desselben Friedhofs mit identischer Riemenzunge sind die Beschläge noch komplizierter verziert, ${ }^{123}$ was sehr schön verdeutlicht, welche Variationsbreite bei der Zusammenstellung von Gürtelgarnituren möglich war.

Nr. 29: Unter den ca. 500 bekannten Riemenzungen an der unteren Donau sind solche nur sehr schwach vertreten, die die für die großen Beschläge erforderliche Breite aufweisen. Die am Preslaver Südtor gefundene Riemenzunge Nr. 29 zählt hierzu. Von der Riemenbreite her mag die Riemenzunge zu den Beschlägen Nr. 17 oder 23, besser noch zu Nr. 19, passen. Das eingravierte, asymmetrische Rankenmotiv, das die ganze Oberfläche einnimmt, hat nur einige allgemeine Bezüge zum postsasanidischen Stil der altbulgarischen Gürtelbesatzstücke. Eher entspricht es dem skandinavischen Stilempfinden, ohne dass hier Parallelen auszumachen wären. Dies lenkt die Aufmerksamkeit darauf, dass sich die Konstruktion dieser Riemenzunge von der der vorherrschenden Zahl der altbulgarischen Riemenzungen des 9.-11. Jahrhunderts unterscheidet. Sie war mittels am oberen Ende angebrachter Nieten am Gürtelriemen befestigt, der wahrscheinlich nicht bis zur Spitze der Rückseite lief. In der Befestigungsart

$$
{ }^{122} \text { FetTich 1931, 97, Abb. 81.1-20. }
$$

${ }^{123}$ Ibidem 88, Abb. 88.1-19; vgl. MESTERHÁZy 1994, 356, Abb. 5.13-16. 
zeigt sie eine entfernte Verwandtschaft zu den spätawarischen Riemenzungen des späten 7. bis frühen 9. Jahrhunderts, steht aber den Riemenzungen des großmährischen Horizonts des 9. Jahrhunderts näher.

Nr. 30-31: Oben wurde schon die Ähnlichkeit der Beschläge Nr. 14/24 mit der Riemenzunge Nr. 27 erwähnt (Abb. 6.1). Auch die Ornamentik der fragmentierten Riemenzungen Nr. 30 und 31 aus Preslav erlaubt eine relativ verlässliche Zuordnung zu Beschlaggruppen. Die gerahmten Medaillons der Riemenzunge Nr. 30 ähneln denen der Beschläge Nr. 10 (Abb. 6.2) und das Palmettenmotiv der Riemenzunge Nr. 31 findet man auf den Beschlägen Nr. 13 wieder (Abb. 6.3). Die Breiten der beiden letztgenannten Riemenzungen harmonieren allerdings nicht mit den Parametern der Beschläge, so dass sie nicht auf einen Riemen vereinigt werden können. Dies schließt nicht aus, dass in der Zukunft noch adäquate Exemplare gefunden werden können, um weitere „ideale“ Gürtelrekonstruktionen zu erstellen. Eine solche vollständige Riemenzunge mit - soweit es dem unscharfen Publikationsfoto zu entnehmen ist - identischer Zier wie bei Nr. 31 liegt aus dem oben unter Nr. 13 angeführten Grab 8 von Szarvas ${ }^{124}$ vor, was die Richtigkeit unserer Garniturzusammenstellungen bekräftigt.

$N r$. 32: Schließlich gibt es unter den Riemenzungen noch Stücke mit komplizierter Ornamentik. Ein kompliziertes Pflanzenmotiv weist die fragmentierte Riemenzunge Nr. 32 aus Rujno (obšt. Dulovo, obl. Ruse, Bulgarien) auf. Ein entfernt vergleichbares Stück mit einem imitierten Perldraht als Randleiste aus Samotino (obl. Varna, Bulgarien) ist kürzlich vorgelegt worden. ${ }^{125}$ Diese Exemplare sind aber selten und können bislang noch nicht einer Reihe von Gürtelbeschlägen zugeordnet werden. Die Riemenzunge Nr. 32 kann wegen ihrer Breite nur den Beschlägen Nr. 22 zugeordnet werden. Diese Kombination ist allerdings sehr hypothetisch.

\section{Die quantitative Bedeutung der bulgarischen Gürtelgarnituren im postsasanidischen Stil}

Die Zahl der ursprünglich hier vorgelegten Gürtelbeschläge betrug 215, doch können die 14 Riemenzungen, deren Zugehörigkeit zu Gürtelgarnituren allerdings ungewiss ist, und die 23 Schnallen hinzugerechnet werden, so dass sich die Gesamtzahl auf 252 belief. Durch die im Jahre 2000 veröffentlichten Bestände aus Varna hat sich die Zahl der Gürtelbeschläge um 130 auf 345 erhöht, so dass sich die Gesamtzahl der berücksichtigten Beschläge nunmehr 383 beträgt. Die Häufigkeit der hier vorgestellten Beschlagtypen wird in einem Diagramm verdeutlicht (Abb. 8). Die kleineren (Nr. 9-14) und größeren (Nr. 15-24) Beschlagtypen bilden keine Häufigkeitsgruppen. Spitzenreiter ist der große Typ Nr. 21 mit 62 Vertretern - worunter allerdings auch einige kleinere Ausformungen gezählt wurden -, gefolgt von dem kleinen Typ Nr. 10 mit 60 Stücken. Zusammen mit den Beschlagtypen Nr. 23 und Nr. 9 mit 43 bzw. 42 Exemplaren ergibt dies 207 Beschläge und damit genau $60 \%$ der berücksichtigten 345 Beschläge, obwohl so nur ein Viertel der hier behandelten 16 Typen erfasst sind. Nimmt man noch die fünf Beschlagtypen hinzu, die in der Rangfolge anschließen (Nr. 11 mit 29, Nr. 18 mit 21, Nr. 20 mit 19, Nr. 13 mit 18 und Nr. 12 mit 17 Vertretern), so kommt man auf 309 Exemplare und $90 \%$ aller berücksichtigten Beschläge, obwohl darin nur neun von 16 Typen eingeschlossen sind.

Die Reihe der Beschlagtypen mit dem geringsten Auftreten wird von den winkelförmigen (Nr. 14 und Nr. 24), quadratischen (Nr. 19) und extrem breiten (Nr. 15-16) Formen gebildet. Nur die Nr. 22 besitzt die herzförmige Normalform der Beschläge. Unter den häufiger belegten Formen fallen nur die Nr. 9 und Nr. 10 mit ihrer Blatt- und Vierpassform heraus. Schwerlich sind bei den Verzierungsmotiven Häufigkeiten auszumachen. Glatte Mittelflächen (Nr. 17-19) sind eher selten, wenn man die zentralen Medaillons der Nr. 10 nicht hierzu zählt. Aus Gravurlinien bestehende Ornamente sind vornehmlich in der unteren Hälfte des Diagramms zu finden (Nr. 14-16 und 24). Eine Ausnahme macht jedoch die Nr. 9 mit 42 Fundstücken. Tendenziell häufiger ist die sowieso größte Gruppe der sieben Beschlagtypen mit reliefierter Palmettenzier (Nr. 11-13 und Nr. 20-23), wozu aber auch die stark stilisierten Palmetten des Typs Nr. 22 gehören, der nur fünf Vertreter aufweist.

Die Häufigkeitsverteilung darf als repräsentativ gelten. Sie beruht auf einer Sammlung von ca. 3000 Beschlägen. (Wie oben erwähnt, dürften bislang fast 10000 Besatzstücke in die bulgarischen Sammlungen gelangt sein.) Die aufgeführten Gürtelbeschlagtypen stehen damit für mehr als ein Zehntel des bekannten Fundbestandes. Der Brauch, breit proportionierte und schlanke Beschläge auf Gürtelriemen zu befestigen, stellte demnach in der Spätzeit des ersten bulgarischen Reiches zwar nicht den Regelfall dar, erfreute sich aber weiter Verbreitung.

$$
{ }^{124} \text { Vgl. Anm. } 100 .
$$

${ }^{125}$ Pletn'ov-Pavlova 1992, 184 f.; 205, Taf. 11.85; 218, Nr. 85 . 


\section{Ein Vergleich des bulgarischen mit dem ungarischen Gürtelbesatz}

Gewiss sind die vorgestellten Rekonstruktionen von Gürtelgarnituren ( $A b b .4)$ mit einem gehörigen Maß an Unsicherheiten behaftet. Sie stammen eben nicht aus geschlossenen Komplexen, sondern sind künstlich aus den zahlreichen Streufunden zusammengestellt worden. Zu dieser Vorgehensweise sind wir durch die ungünstige Quellenlage gezwungen. Sie wird aber durch die zahlreichen Parallelen aus dem Karpatenbecken und den Neufund aus Krivina abgesichert. In Form und Zier stimmen die vorgestellten Schnallen, Riemenzungen und Beschläge mit den Charakteristika des reichen mitteldanubischen Fundmaterials überein. Speziell für die Beschläge Nr. 13 (samt Riemenzunge Nr. 31) und Nr. 20-21 sowie Nr. 23 konnten nahezu identische Gegenstücke aus dem ungarischen Siedlungsbereich angeführt werden. Die Beschläge Nr. 9, 18 und 24 sowie die Riemenzunge Nr. 28 besitzen dort zumindest verwandte Analogien. Auffällig ist auch, dass der Beschlagtyp Nr. 23, der zahlenmäßig an dritter Stelle in Bulgarien steht, auch im Karpatenbecken recht häufig auftritt. Damit stellt sich die Frage, ob hier überhaupt zwei verwandte Werkstattkreise von Metallbesatz vorliegen oder besser von nur einem Kunstkreis gesprochen werden sollte.

Es sollte aber nicht vergessen werden, dass von den hier ausgewählten 16 Beschlagtypen über die Hälfte (56\%), nämlich neun, ohne direkte Parallelen im Karpatenbecken sind. ${ }^{126}$ Dazu gehört auch der zweithäufigste Typ Nr. 10 mit seiner charakteristischen vierblättrigen Form.

Sucht man nach Unterschieden, so mag man die mit Gravuren angedeutete vegetabile Zier wie bei den $\mathrm{Nr}$. 9, 14, 24 und 26-27 als spezifisch bulgarische Eigenart anführen. (Diese darf man gewiss nicht direkt von den Beschlägen des Martinovka-Kreises des 6. Jahrhunderts ableiten, wie dies jüngst V. Pletn'ov getan hat. ${ }^{127}$ ) Bei solchen Stücken aus dem Karpatenbecken wurde so auch auf die bulgarischen Parallelen verwiesen. Doch tritt die Gravur ebenfalls im ungarischen Siedlungsgebiet in nicht unbeträchtlicher Zahl auf, teilweise auf qualitativ hochstehenden Stücken. ${ }^{128}$ Die recht spärliche Zier der Beschläge Nr. 15-19 mag zu der Annahme verleiten, dass in Bulgarien schlichte Formen ein größeres Gewicht besaßen als bei den Ungarn. Allerdings kommen diese zusammen gerade auf 40 Vertreter $(A b b$. 8) und bilden damit einen Anteil von knapp $12 \%$ der hier berücksichtigten Beschlagtypen. In diesem Zusammenhang sei aber auf eine Zusammenstellung von 23 reich verzierten, herzförmigen Beschlägen mit Perldrahtimitation verwiesen, ${ }^{129}$ die alle aus Bulgarien stammen und deutlich an die bekannten Beschläge von Zemplín - und den gussgleichen Beschlag von Več/Bodrogvécs, okr. Trebišov, Slowakei ${ }^{130}-$ erin- $^{3}$ nern. Zudem gibt es auch in Ungarn einfache Garnituren (einschließlich Zaumzeugbeschläge). ${ }^{131}$

Die hier vorgestellten 16 Typen von Gürtelbeschlägen stellen nur einen Ausschnitt aus dem bulgarischen Fundbestand dar. Oben wurden bereits die lunulaförmigen Riemenbeschläge vom Typ Tiszaeszlár ${ }^{132}$ aus Debrene kurz erwähnt. Während M. Schulze-Dörrlamm 1988 noch kein bulgarischer Vertreter dieses Gürtelbeschlagtyps bekannt war, können jetzt 44 Exemplare von acht bulgarischen Fundorten genannt werden. ${ }^{133}$ (Von 6 Exemplaren ist der Fundort unbekannt.) In der Arbeit von M. Schulze-Dörrlamm findet man noch weitere Belege für die Zuge-

\footnotetext{
${ }^{126}$ Auf diesen Umstand machen aufmerksam auch PletN'ov-PaVlova 1994/1995, 114 bzw. 132. kovo); 43, Abb. 12.10-11. - Weiterer Nachtrag außerhalb Bulgariens: Hansca (raion Ialoveni, Moldau), Grubenhütte HL 72 (PostiC̆ 1994, Abb. 53.8).

${ }^{133} 21$ Exemplare aus Debrene (obšt. Dobrič, obl. Varna, Bulgarien): Jotov 1993, 123, Nr. 1; 126 f., Taf. 2.7, Taf. 3.7. Die von V. Jotov erwähnten weiteren zwei Exemplare im Museum Dobrič und sieben Exemplare im Museum Varna vom gleichen Ort sind nunmehr publiziert: Erstere bei STANILOV 1993b, 152, Abb. 2.5; 162, Nr. 11; Letztere - in Wirklichkeit acht Exemplare - bei PLETN'OV-PAVLOVA

1994/1995, 190; 238, Taf. 47.838; 239, Taf. 48.842-848. - Je ein Exemplar aus Kalimanci (obšt. Suvorovo, obl. Varna, Bulgarien) und Izvornik (obšt. Vălčidol, obl. Varna, Bulgarien): PlETN'ov-PAVLovA 1994/1995, 190; 238, Taf. 47.840; 239, Taf. 48.850. - Je ein Exemplar aus Malăk Preslavec (obšt. Glavinica, obl. Ruse, Bulgarien), Mogila (obšt. Kaspičan, obl. Varna, Bulgarien), Okorš (obšt. Dulovo, obl. Ruse, Bulgarien) und aus dem Museum Šumen: Stanilov 1993b, 152, Abb. 2.1-4; 162, Nr. 7-10. - Ein Exemplar aus Staro selo „Golemijat graxd“ (obšt. Mezdra, obl. Montana, Bulgarien): Ivanov 1996, 80, Abb. 8; 84, Nr. 26. - Ein fragmentiertes Exemplar (angeblich) aus Vetren (obšt. Silistra, obl. Ruse, Bulgarien): AtANASOV-JoRDANOV 1994, 55, Nr. 23, Taf. 3.23. - Vier fundortlose Exemplare: Pletn'ov-Pavlova 1994/1995, 190; 238, Taf. 47.836-837, 839; 239, Taf. 48.841. - Ein weiteres Exemplar mit zehn Kügelchen und Innenzier befindet sich in der Privatsammlung von B. T. Ivanov (Varna), die von B. Domanov (Sofia) bearbeitet wird (freundliche Mitteilung von St. Angelova). Außerdem ist kürzlich noch ein Stück aus Nadarevo (obšt. Tărgovište) vorgelegt worden, das in der obigen Summierung ebenfalls nicht berücksichtigt ist: KoNAKLIEV 2005, Nr. 10 - vgl. Nachtrag. 
Mit dem Aufkommen der Bijelo-Brdo-Kultur verschwindet der landnahmezeitliche Gürtelzierrat im Karpatenbecken. Dies ist nicht mit einer geänderten Beigabensitte, sondern mit einer neuen Kleidermode zu erklären. Im Bulgarenreich hatte der Metallbesatz am Gürtel aber anscheinend eine längere Laufzeit als im ungarischen Herrschaftsgebiet. So wurden bei den Ausgrabungen in der Festung Skala beim Dorf Kladenci solche Gürtelbesatzstücke noch in Kontexten des späten 10. und frühen 11. Jahrhunderts gefunden. ${ }^{143}$ Nach dem Münzspiegel gehören sie dort eindeutig in die Zeit nach $976 .{ }^{144}$

\section{Ungarisch-bulgarische Kontakte als Ursache für das Aufkommen des Gürtelbesatzes im postsasanidischen Stil an der unteren Donau}

Damit stellt sich die Frage nach dem historischen Hintergrund des Aufkommens dieser Gürtelbesatzstücke und der dahinter stehenden Gürtelmode an der unteren Donau. Die Anregungen zur Genese des postsasanidischen Stils werden gewöhnlich auf die mittelasiatischen kunsthandwerklichen Zentren zurückgeführt. Aber auch die mediterranen Kunsttraditionen sollten dabei nicht unberücksichtigt bleiben. Erst kürzlich ist von K. Mesterházy die ausschlaggebende Rolle dem abbasidischen Kunstgewerbe zugeschrieben worden. ${ }^{145}$ Ungewiss ist weiter, ob die Entstehung und Entwicklung des postsasanidischen Stils im Umfeld der Ungarn schon vor deren Wanderung nach Mitteleuropa erfolgt ist, also in der so genannten „levedischen“ Periode. Es waren dann aber wohl nur erste Ansätze - die eigentliche Blüte dieses Stils erfolgte erst im Karpatenbecken. ${ }^{146}$

Die bulgarisch-ungarischen Beziehungen im Mittelalter sind von der Geschichtsforschung detailliert untersucht worden. Die Kontaktaufnahme zwischen (Proto-)Bulgaren und Ungarn an der unteren Donau vollzog sich in Form eines Bündnisses. Auf bulgarische Bitte verfolgten die Ungarn im Jahre 837 die aus der Walachei fliehenden byzantinischen Kriegsgefangenen. In anderen Fällen entwickelten sich die Kontakte zu kriegerischen Konflikten, die auch nach der Niederlassung der Ungarn im Karpatenbecken andauerten. ${ }^{147}$

In der Bewertung dieser Kontakte sind die Autoren geteilter Meinung. Während sich der eine (U. F.) durchaus vorstellen kann, dass Gürtel als Handelsgüter, Geschenke oder Beutestücke über die Grenzen gelangt sein und zur Übernahme der Gürteltracht von den militärisch starken Nachbarn geführt haben könnten, glaubt der andere (St. St.) nicht, dass der Krieg der ungarischen Herrscher mit den Fürsten der nordwestbulgarischen Provinzen, wie ihn der ungarische Anonymus beschreibt, kulturelle Folgen wie die Übernahme und Herstellung des Gürtelbesatzes gehabt haben kann. Ihm zufolge geschah das schon vor dem historischen Datum der ungarischen Landnahme im Karpatenbecken. Dies begründet er wie folgt: Eine Erscheinung solchen Charakters kann nicht einfach von einem ethnokulturellen Raum zum anderen überwechseln. Die Herstellung von Metallbesatz in einem spezifischen Stil erfordert überdies Fachkenntnisse. Eine bloße Nachahmung durch fremde Handwerker erscheint daher unwahrscheinlich.

Deshalb wird vorgeschlagen, dass die Mode der ungarischen Gürtel zu den Bulgaren infolge des dritten ungarisch-bulgarischen Krieges im Jahre 895 oder 896 kam. Über diesen schrieb der Kaiser Konstantin VII. Porphyrogennetos: „Als die Türken [Ungarn] ins Feld zogen, zogen die Petschenegen mit Simeon gegen Türken, vernichteten ihre Familien völlig und vertrieben die zur Bewachung ihrer Felder hinterlassenen Türken. Als die Türken zurückkehrten, fanden sie so ihr Land verwüstet und gänzlich ruiniert. Sie besiedelten dann das Land, wo sie noch heute leben. “" 148

Wahrscheinlich nahmen auch die Bulgaren bei diesem Pogrom eine große Anzahl von Gefangenen, darunter auch Handwerker, die die Herstellung von Gürtelgarnituren im postsasanidischen Stil innerhalb des ersten bulgarischen Zarenreiches weiterführten. Die Mode der metallbesetzten Gürtel wurde von der Aristokratie übernommen. Wie aus der oben wiedergegebenen Schilderung Liudprands von Cremona über den bulgarischen Gesand-

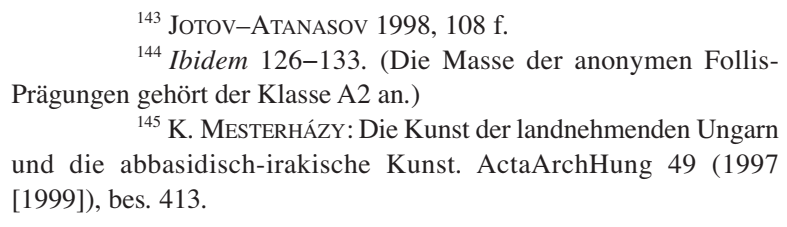

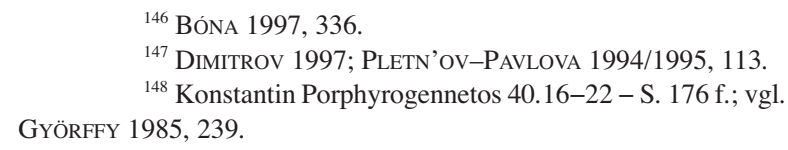




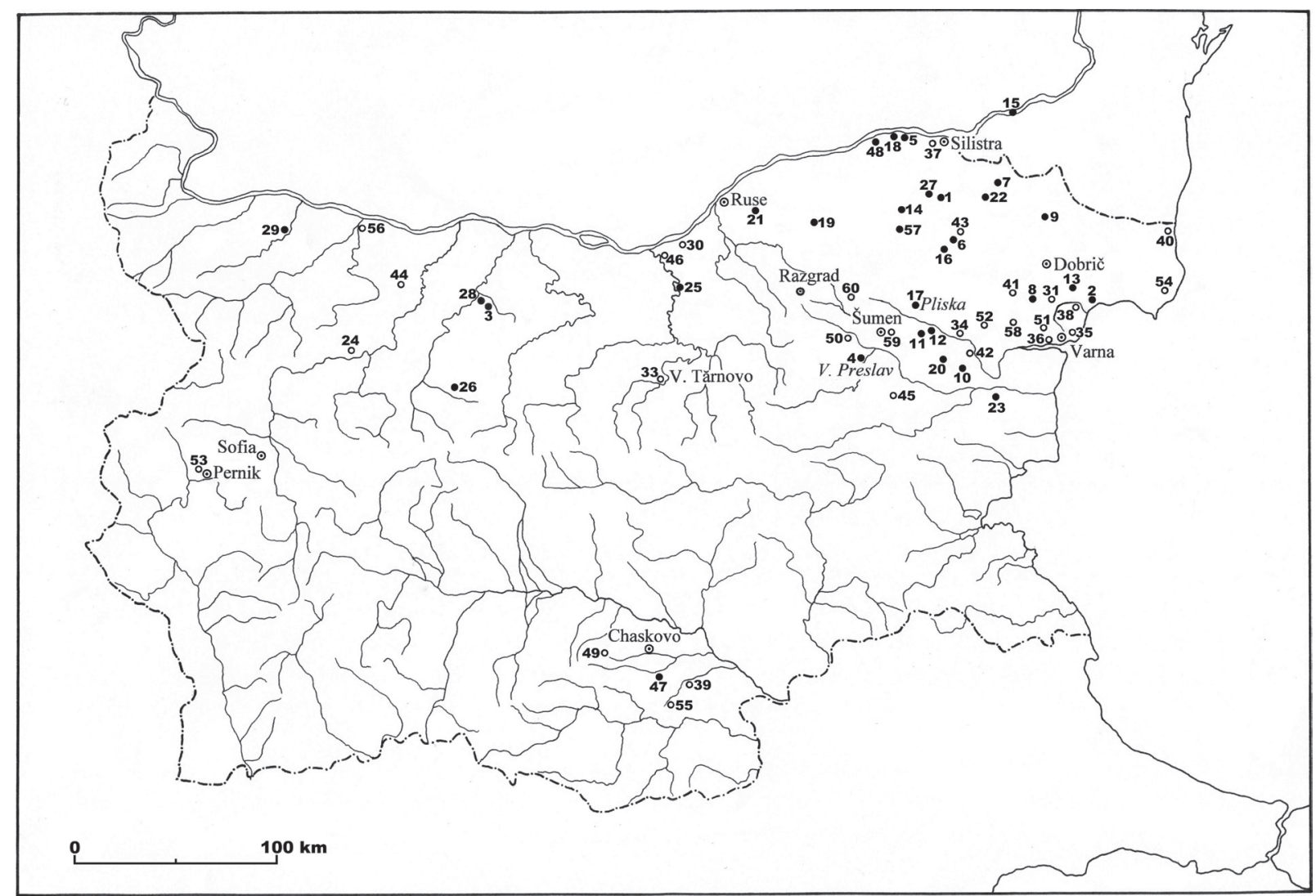

Abb. 9. Fundorte von Gürtelbesatzstücken des 9.-11. Jh. in Bulgarien. - - Im Katalog aufgeführt (Nr. 1-28); ○ nicht im Katalog aufgeführt (Nr. 29-58); v heutige größere Städte. - In der folgenden Liste ist hinter den Ortsnamen in Klammern die Zugehörigkeit zu den Regionen aufgeführt.

1. Alekovo (Silistra); 2. Balik (Dobrič); 3. Bežanovo (Loveč); 4. Veliki Preslav; 5. Vetren (Silistra); 6. Vojnikovo (Dobrič); 7. Goleš (Silistra); 8. Debrene (Dobrič); 9. Izvorovo (Dobrič); 10. Kiten (Provadija); 11. Madara; 12. Mogila (Šumen); 13. Odărci (Dobrič); 14. Okorš (Silistra); 15. Păcuiul lui Soare (jud. Călăraşi; Rumänien); 16. Pet mogili (Šumen); 17. Pliska; 18. Popina (Silistra); 19. Pujno (Silistra); 20. Slavejkovo (Provadija); 21. Smirnenski (Ruse); 22. Središte (Silistra); 23. Sredno selo (Varna); 24. Staro selo (Vraca); 25. Stărmen (Ruse); 26. Ugărčin (Loveč); 27. Car Asen (Silistra); 28. Ăglen (Loveč); 29. Jakimovo (Montana). - Nicht im Katalog aufgeführte Fundorte: 30. Batin; 31. Botevo (Varna); 32. Varna; 33. Veliko Tărnovo; 34. Venčan (Provadija); 35. Vinica (Varna); 36. Văglen (Varna); 37. Drăstăr (Silistra); 38. General Kantardžievo (Varna); 39. Goljam Izvor (Chaskovo); 40. Durankulak (Dobrič); 41. Izvornik (Varna); 42. Kiten (Provadija); 43. Kladenci (Dobrič); 44. Kneža; 45. Komunari (Dălgopol); 46. Krivina (Ruse); 47. Ljaskovec (Chaskovo); 48. Malăk Preslavec (Silistra); 49. Mineralni bani (Chaskovo); 50. Nadarevo (Tărgovište); 51. Novakovo (Varna); 52. Oveč (Provadija); 53. Pernik; 54. Sveti Nikola (Kavarna); 55. Rabovo (Chaskovo); 56. Selanovci (Vraca); 57. Skala bei Kladenci (Dobrič); 58. Suvorovo (Varna); 59. Šumen; 60. Chuma (Razgrad). Namentlich die zusätzlich bei Pletn'ov - Pavlova (1994/95) aufgeführten Orte in der Umgebung von Varna konnten nicht mehr eingearbeitet werden (Avren, Aksakovo, Dobroplodno [Dobroplodno], General Kantardžievo [Nr. 38], Grozd'ovo, Izvornik, Kičevo, Komunari [Nr. 45], Neševa [Provadija], Novakovo, Provadija [Provadija], Samotino, Snežina [Provadija], Suvorovo. - Nicht im Katalog angeführt: Asparuchovo [Provadija], Balčik [Balčik], Blăskovo, Borjana, Kalimanci, Karapelt [Dobrič], Klimentovo, Komarevo, Kus [Šumen], Lolište, Medovec [Provadija], Obročište [Dobrič], Orešak, Osenovo, Razdelna, Rogačevo [Dobrič], Samuil [Razgrad], Stan [Silistra]. - Regionszugehörigkeit in Klammern nur angegeben, wenn diese nicht Varna ist) (Graphik: Uwe Fiedler)

ten von 965 erkennen lässt, orientierte man sich in Bulgarien auch in der Haartracht an den Ungarn. Bei der Kleidung lässt sich dieses nur vermuten. (Oder waren dies nur Gemeinsamkeiten beider Völker?)

Die bulgarische Gesellschaft, die an der mittelmeerischen städtischen Kulturtradition anknüpfen konnte, besaß die Voraussetzungen, große Mengen von Produkten mit hohem ästhetischem Wert herzustellen. In Bulgarien wurden die Beschläge aus den verschiedensten Legierungen hergestellt, gemäß den unterschiedlichen Ressourcen des Landes. So gibt es eine große Menge von Beschlägen aus Blei, einem Metall mit nur geringem Wert, was zeigt, dass diese Mode auch die unteren Schichten der Gesellschaft erfasste. (Nachtrag: Die Stücke dienten wohl eher als Model.) Die beigefügte Karte der Fundorte von Besatzstücken im postsasanidischen Stil in Bulgarien (Abb. 9) gibt 
zu erkennen, dass sich deren Dichtezentrum mit dem Zentrum des bulgarischen Reiches im heutigen Nordostbulgarien deckte, wo auch die historischen Wohnsitze der (Proto-)Bulgaren zu suchen sind. ${ }^{149}$ Die Fundleere nördlich der Donau lässt sich dadurch erklären, dass sich diese Gebiete im 10. Jahrhundert nicht mehr unter bulgarischer Kontrolle befanden. Der Umstand, dass die meisten Besatzstücke von der Oberfläche altbulgarischer Festungen aufgelesen worden sind, weist darauf hin, dass die beschlagverzierten Gürtel auch zur Ausrüstung des bulgarischen Kriegers gezählt werden können. Die militärischen Erfolge der ungarischen Heere in der ersten Hälfte des 10. Jahrhunderts dürften zur Verfestigung dieser Trachteigenheit beigetragen haben.

Abschließend möchte der andere der beiden Autoren (U. F.) noch darauf hinweisen, dass das letzte Wort zu einer Entstehung des postsasanidischen Stils an der unteren Donau auf der Basis von byzantinischen Stilelementen und einer späteren Übernahme durch die Ungarn, wie sie V. Pletn'ov und V. Pavlova jüngst wieder vertreten haben, sicherlich noch nicht gesprochen ist.

Zweifellos nehmen diese Gürtelbeschläge eine Schlüsselstellung zum Verständnis der kulturellen Entwicklung Südosteuropas in der Zeit um 900 ein. Beide Autoren hoffen, mit dieser Vorlage einen Anreiz zur weiteren Beschäftigung mit dieser Problematik auf breiterer Basis geliefert zu haben.

\section{KATALOG}

Abkürzungen: obšt. - obština; obl. - oblast (hier die 1987-1999 gültigen neun größeren Bezirke, seit dem gibt es in Bulgarien 28 kleinere oblaste); unbek. FO - unbekannter Fundort; LF - Lesefund(e); altbulg. - altbulgarisch; Jh. - Jahrhundert(e); B. - Breite; Br. - Bronze; Cu - Kupfer; Nat. - national(es); Arch. - archäologisch(es); Hist. - historisch(es); Mus. - Museum; Inv.-Nr. - Inventarnummer; Lit. - Literatur.

\section{Schnallen (Abb. 2)}

1. Veliki Preslav. LF aus der inneren Stadt (Fundstelle unbekannt). Ovaler Bügel mit leichter Verdickung der Dornauflage; fünfeckiger Beschlag; rückseitig 2 Nieten auf gleicher Höhe, davon eine verloren. 2,9×2,0 cm; Br. (leicht abgerieben); Dornöffnung noch vom Guss verschlossen. Mus. „Veliki Preslav“, ohne Inv.-Nr.

Parallelen zu Nr. 1:

a. Isaccea (Novidunum, jud. Tulcea, R). In mittelalterlicher Siedlungsschicht der Festung. Abweichende Proportionen; Beschlag zur Spitze hin nur wenig verbreitert; Bügel verformt.

Lit.: BARNEA-MitREA 1959, 471, Abb. 10.9.

b. Jakimovo (obšt. Jakimovo, obl. Montana, BG). In der Kulturschicht des 9.-10. Jh. der Festung. Ovaler Bügel. Cu.

Lit.: MiLČEv 1966, 352 mit Abb. 13 (bulgarische Fassung: 34 f. mit Abb. 14).

c. Kladenci (obšt. Tervel, obl. Varna, BG). Ausgrabungsfund von der altbulg. Festung Skala.

Städt. Mus. Tervel, Inv.-Nr. 698.

Lit.: Jotov-Atanasov 1998, 161; 312, Taf. 113, Nr. 432.

d. Madara. Fundumstände unbekannt; spitz zulaufender Bügel; Beschlag kaum spitz zulaufend; eine Nietöffnung an einer Ecke des Beschlags. $\mathrm{Cu} ; 2,0 \times 1,8 \mathrm{~cm}$.

Lit.: FeHÉr 1939, 83, Abb. 49; FeHÉR 1940, 50, Abb. 18; 53, Abb. 22.

$e-f$. Păcuiul lui Soare (jud. Constanţa, R). In der altbulg. Festung Malăk Preslavec (?). 2 Exemplare. Das eine mit annähernd gleichen Proportionen, aber mit ovalem Bügel ohne Verbreiterung; das zweite, kleinere Exemplar mit nur kleinem Bügel(rest?) und drei Löchern für den Dorn und zwei Nieten auf dem Beschlag.

Lit.: Diaconu 1969, 503 f. mit Abb. 1.5, 9; Diaconu-Vîlceanu 1972, 155, Abb. 62.6, $12 ; 157$.

g-h. Veliki Preslav. Erzbischofspalast. 3 Exemplare. Davon 2 Exemplare mit kleinerem, breiter proportioniertem Beschlag. Cu.

Lit.: STANILOV 1995, 112 f. mit Abb. 3.19-22.

${ }^{149}$ FIEDLER 1992, 341, Abb. 117. 
2. Alekovo (obšt. Alfamar, obl. Ruse, BG). LF von der altbulg. Festung. Ovaler Bügel; fünfeckiger Beschlag mit rundlicher Mulde am Ende; rückseitig 2 Nieten auf gleicher Höhe, davon einer verloren. 2,0×17 cm; Cu; Rest eines eisernen Dorns in der Dornöffnung.

Hist. Mus. Silistra, Inv.-Nr. III 1137.

Parallelen zu Nr. 2:

a. Jakimovo (obšt. Jakimovo, obl. Montana, BG). In der Kulturschicht des 9.-10. Jh. der Festung. Cu.

Lit.: MiLČEV 1966, 352, mit Abb. 13 (bulgarische Fassung: 34 f. mit Abb. 14).

b. Veliki Preslav. Ostmauer der inneren Stadt. Ovaler Bügel; breiter proportionierter Beschlag.

Lit.: OvČAROv 1985, 154 f. mit Abb. 42 unten links.

3. Unbek. FO in Nordostbulgarien. Ovaler Bügel; fünfeckiger Beschlag, am Ende auf gleicher Höhe 2 Nietlöcher mit Nieten. 3,0×2,7 cm; Cu mit eisernem Dorn.

Hist. Mus. Šumen, Inv.-Nr. 10689.

4. Unbek. FO in Nordostbulgarien. Spitz zulaufender Bügel; Wulst am Übergang zum trapezförmigen Beschlag mit schwalbenschwanzförmigem Ende; rückseitig 3 symmetrisch angeordnete Dorne und 1 Niet. 2,8 $\times 2,3 \mathrm{~cm}$; Cu, in der Rille zwischen Bügel und Beschlag Spuren von Weißmetall (Silber oder Zinn); eiserner Dorn.

Lit.: Stanilov 1991a, 7; 10 f.; 27; 39, Abb. 18.46; 55, Taf. 1.1.

5. Unbek. FO in Nordostbulgarien. Ovaler Bügel mit leichter Verdickung der Dornauflage; trapezförmiger, fast rechteckiger Beschlag; rückseitig 4 symmetrisch angeordnete Dorne. $2,75 \times 2,2 \mathrm{~cm}$; Br.; Rest eines eisernen Dorns in der Dornöffnung.

Hist. Mus. Šumen, Inv.-Nr. 7421.

Parallelen zu Nr. 5:

a. Stărmen (obšt. Bjala, obl. Ruse, BG). Sektor IV, Quadrant 9 (südwestlicher Teil der altbulg. Festung; zur Ausgrabung vgl. VĂLov 1982, 70-113). Rundlicher Bügel; Rille am Übergang zum Beschlag. Cu.

Nat. Arch. Mus. Sofia, ohne Inv.-Nr.

b-c. Stărmen. Ostteil der altbulg. Festung. 2 Exemplare. Ovale Bügel; kurze Beschläge.

Lit.: HeNSEL 1980, 152, Abb. 53.129, 627.

d. Veliki Preslav. Südlich des Palastes, Aushub von Sektor 161. Ovaler Bügel; rechteckiger Beschlag. $2,1 \times 2,65 \mathrm{~cm} ; \mathrm{Cu}$.

Lit.: STANILOv 1995, 113, Abb. 3.25; 131, Nr. 25.

6. Pop Rusanovo (obšt. Kajnardža, obl. Ruse, BG). LF von der altbulg. Festung. Ovaler Bügel; fünfeckiger Beschlag mit Wulst beiderseits des Dornlochs; rückseitig 2 Nieten mit gemeinsamem Blech. 2,65×2,05 cm; Cu (Feilspuren; abgerieben).

Hist. Mus. Silistra, Inv.-Nr. III 2372.

Parallele zu Nr. 6:

a. Staro selo (obšt. Mezdra, obl. Montana, BG). Raubgrabungsfund in der Festung „Golemijat grad“. Bügel enger; zusätzliche Nietöffnung im Zentrum des Beschlags; die beiden anderen Nieten verloren. Br.

Lit.: IvANOv 1996, 79 f. mit Abb. 8 (oben links); 83, Nr. 16.

7. Unbek. FO in Nordostbulgarien. Ovaler Bügel mit Dornauflage; fünfeckiger Beschlag; 2 Nietlöcher. $2,75 \times 2,25 \mathrm{~cm}$; Cu; an der Dornöffnung Spuren eines eisernen Dorns.

Hist. Mus. Šumen, Inv.-Nr. 5503.

8. Veliki Preslav, Erzbischofspalast (?). Ovaler Bügel; Rille am Übergang zum trapezförmigen Beschlag mit Schwalbenschanzende; rückseitig 3 Nieten, davon 2 beiderseits der Dornöffnung und einer am Beschlagende. 2,75×2,1 cm; Br. (abgerieben).

Mus. ,Veliki Preslav“, Inv.-Nr. OF 22326.

Parallele zu Nr. 8:

a. Kladenci (obšt. Tervel, obl. Varna, BG). Ausgrabungsfund von der altbulg. Festung „Skala“.

Inv.-Nr. 239.

Lit.: Jotov-Atanasov 1998, 161; 312, Taf. 113, Nr. 431.

\section{Beschläge (Abb. 3-4)}

9A. Unbek. FO in Nordostbulgarien. Sehr breit-blattförmig mit 4 Kügelchen am Rand; leicht gewölbt mit Gravur von zwei gebogenen Zweigen mit Blattpaaren an den Enden. $2,0 \times 1,45 \mathrm{~cm} ; \mathrm{Cu}$.

Nat. Arch. Mus. Sofia, Inv.-Nr. 5100. 
Lit.: Stanilov 1991a, 16 f., Nr. 39-45; 29 f. mit Abb. 9.2; 39, Abb. 18.40; 49, Nr. 40; 61, Taf. 7.40.

Parallelen zu Nr. 9A:

a-c. Car Asen (obšt. Alfamar, obl. Ruse, BG). LF von der altbulg. Festung. 3 Exemplare. Abweichende Proportionen; merklich größer; bei III 1930 Zweige und Blätter länger. $\mathrm{Cu}$.

Hist. Mus. Silistra Inv.-Nr. III 945, III 1163 und III 1930.

d. Dobroplodno (obšt. Vetrino, obl. Varna, BG). Mit Durchbrechung im Unterteil.

Arch. Mus. Varna, Inv.-Nr. IV 4167.

Lit.: Pletn'ov-PaVlova 1994/1995, 160, Nr. 420; 215, Taf. 24.420.

e. Grozd'ovo (obšt. Georgi Trajkov, obl. Varna, BG). LF vom Hang der antiken Festung im Reservat Šerba. Mit keilförmiger Gravur zwischen den Ranken.

Arch. Mus. Varna, Inv.-Nr. IV 4139

Lit.: PletN'ov-PaVlova 1994/1995, 160, Nr. 414; 215, Taf. 24.414.

f. Kiten (obšt. Provadija, obl. Varna, BG). LF von antiker und spätmittelalterlicher Festung. Rückwärtige Befestigung durch Ösen.

Arch. Mus. Varna, Inv.-Nr. IV 3354.

Lit.: Pletn'ov-Pavlova 1994/1995, 160, Nr. 415; 215, Taf. 24.415.

g. Komarevo (obšt. Provadija, obl. Varna, BG).

Arch. Mus. Varna, Inv.-Nr. IV 3126.8.

Lit.: Pletn'ov-Pavlova 1994/1995, 160, Nr. 419; 215, Taf. 24.419.

h. Okorš (obšt. Dulovo, obl. Ruse, BG). LF von der altbulg. Festung. Abweichende Kontur. Cu.

Hist. Mus. Dobrič, ohne Inv.-Nr.

i. Pliska. Unbek. Fundstelle. Lange Blätter. $2,1 \times 2,1 \mathrm{~cm}$.

Lit.: FEHÉr 1940, 52, Abb. 21; Taf. 27; FEHÉR 1942, 25, Abb. 25

j. Središte (obšt. Kajnardža, obl. Ruse, BG). LF von der altbulg. Festung. Wenig größer; Blattspitzen berühren sich fast und ergeben dadurch eine herzförmige Kontur der Gravur. $\mathrm{Cu}$.

Hist. Mus. Silistra, Inv.-Nr. III 1818.

k. Sredno selo (obšt. Provadija, obl. Varna, BG), Flur „Babulka“.

Arch. Mus. Varna, Inv.-Nr. IV 2109.

Lit.: Pletn'ov-PaVlova 1994/1995, 159 f., Nr. 406; 214, Taf. 23.406.

l. Suvorovo (obšt. Suvorovo, obl. Varna, BG). LF von der antiken Festung.

Arch. Mus. Varna, Inv.-Nr. IV 1871. Mit Durchbrechung im Unterteil.

Lit.: PletN'ov-Pavlova 1994/1995, 160, Nr. 418; 215, Taf. 24.418.

$m-o$. Unbek. FO. 3 Exemplare. Gleiche Proportionen; merklich größer. $\mathrm{Cu}$.

Mus. des Zweiten Bulgarischen Reiches Veliko Tărnovo, Inv.-Nr. 6525.

$p-x$. Unbek. FO bzw. Umgebung von Varna. 9 Exemplare. $2 \times$ mit Durchbrechung im Unterteil.

Arch. Mus. Varna, Inv.-Nr. IV 2014-2016, 2645, 2735, 4001-4003 und 4006.

Lit.: Pletn'ov-PaVlova 1994/1995, 160, Nr. 407-413, 416-417; 214, Taf. 23.407-411; 215, Taf. 24.412-413, $416-417$.

9B. Unbek. FO in Nordostbulgarien. Blattförmig; sonst Form und Verzierung wie 9A; rückseitig längs der Längsachse 2 Nieten mit quadratischen Blechen. 1,5×1,85 cm; Cu.

Nat. Arch. Mus. Sofia, Inv.-Nr. 5099.

Lit.: Stanilov 1991a, 16 f., Nr. 39-45; 29 f. mit Abb. 9.2; 39, Abb. 18.41; 49, Nr. 41; 61, Taf. 7.41.

Parallelen zu Nr. 9B:

a. Balik (obšt. Tervel, obl. Varna, BG). Aus der altbulgarischen Siedlungsschicht der byzantinischen Festung „Hisar kale“. Abweichende Kontur; Durchbruch im Ornament. Cu.

Hist. Mus. Dobrič, Inv.-Nr. As 2498

b. Goleš (obšt. Kajnardža, obl. Ruse, BG). LF von der altbulg. Festung. Abweichende Proportionen; Basis spitz; lange gravierte Zweige. Br.

Hist. Mus. Silistra, ohne Inv.-Nr.

c. Car Asen (obšt. Alfamar, obl. Ruse, BG). LF von der altbulg. Festung. Abweichende Proportionen; lange, gravierte Zweige. Cu.

Hist. Mus. Silistra, Inv.-Nr. III 924.

$d-e$. Kiten (obšt. Provadija, obl. Varna, BG). LF von der antiken und spätmittelalterlichen Festung. 2 Exemplare. $1 \times$ rückwärtige Befestigung durch Ösen.

Arch. Mus. Varna, Inv.-Nr. IV 3066 und 3199. 
Lit.: Pletn'ov-Pavlova 1994/1995, 159, Nr. 401 und 403; 214, Taf. 23.401, 403.

f. Kladenci (obšt. Tervel, obl. Varna, BG). Ausgrabungsfund von der Festung „Skala“.

Hist. Mus. Silistra, Inv.-Nr. III 848.

Lit.: Jotov-Atanasov 1998, 162; 313, Taf. 114, Nr. 447.

g-h. Novakovo (obšt. Aksakovo, obl. Varna, BG). LF von der antiken und mittelalterlichen Festung. 2 Exemplare.

Arch. Mus. Varna, Inv.-Nr. IV 3245-3246.

Lit.: Pletn'ov-Pavlova 1994/1995, 159, Nr. 397 und 400; 214, Taf. 23.397, 400.

i. Središte (obšt. Kajnardža, obl. Ruse, BG). LF von der altbulg. Festung. 3 Nieten. Cu.

Hist. Mus. Silistra, Inv.-Nr. III 1421.

j. Suvorovo (obšt. Suvorovo, obl. Varna, BG). LF von der antiken Festung.

Arch. Mus. Varna, Inv.-Nr. IV 2405.

Lit.: Pletn'ov-Pavlova 1994/1995, 159, Nr. 404; 214, Taf. 23.404.

k. Vojnikovo (obšt. Tervel, obl. Varna, BG). LF von der altbulg. Festung. Cu (Vorderseite mit Weißmetallüberzug).

Hist. Mus. Dobrič, Inv.-Nr. As 2465.

l. Unbek. FO in Nordostbulgarien. Abweichende Proportionen; größer; lange, gravierte Zweige. $2,0 \times 2,35 \mathrm{~cm} ; \mathrm{Cu}$.

Nat. Arch. Mus. Sofia, Inv.-Nr. 5098.

Lit.: Stanilov 1991a, 16 f., Nr. 39-45; 39, Abb. 18.42; 49, Nr. 42 f.; 61, Taf. 7.42.

$m-p$. Unbek. FO bzw. Umgebung von Varna. 4 Exemplare.

Arch. Mus. Varna, Inv.-Nr. IV 2686-2687, 2720, 4004.

Lit.: Pletn'ov-Pavlova 1994/1995, 159, Nr. 398-399, 402 und 405; 214, Taf. 23.398-399, 402, 405.

10A. Unbek. FO in Nordostbulgarien. Vierpassförmig bzw. vier Blätter (ein Blatt spitz zulaufend) in kreuzförmiger Anordnung; Kügelchen in den Zwickeln; Negativmuster: breite Randleiste und tropfenförmiges, erhabenes Medaillon; rückseitig 2 in Richtung Basis gebogene Dorne. $1,9 \times 1,8 \mathrm{~cm} ; \mathrm{Cu}$.

Hist. Mus. Šumen, Inv.-Nr. 2908.

Parallelen zu Nr. 10A:

a. Balik (obšt. Tervel, obl. Varna, BG). Aus der altbulg. Siedlungsschicht der byzantinischen Festung „Hisar kale“. Praktisch identisch. $1,9 \times 1,8 \mathrm{~cm} ; \mathrm{Br}$.

Nat. Arch. Mus. Sofia, Inv.-Nr. 10040/2.

Lit.: Melamed 1993, 164 f., Nr. 4, Abb. 5; Taf. 2 oben.

b-c. Garvăn (Dinogetia, jud. Tulcea, R). 2 Exemplare aus der Kulturschicht des 10.-11. Jh. der altbulg. Festung. Bei einem Exemplar unklares Ornament (wahrscheinlich ähnlich wie Parallele aus Păcuiul lui Soare [e]); das andere mit Ringanhänger am Scharnier, Beschlag eher blattförmig. B. $1,75 \mathrm{~cm} ; \mathrm{Br}$.

Lit.: Dinogetia 1, 295, Abb. 173.11, 15; 297; 299.

d. Klimentovo (obšt. Aksakovo, obl. Varna, BG). Seitlich des Medaillons 2 Bögen.

Arch. Mus. Varna, Inv.-Nr. IV 3048.

Lit.: PletN'ov-Pavlova 1994/1995, 156, Nr. 352; 211, Taf. 20.352.

e-g. Novakovo (obšt. Aksakovo, obl. Varna, BG). LF von der antiken und mittelalterlichen Festung. 3 Exemplare. $1 \times$ seitlich des Medaillons

2 Bögen; 2-mal Voluten der Randleiste viergeteilt.

Arch. Mus. Varna, Inv.-Nr. IV 2905, 2954, 2956.

Lit.: Pletn'ov-PaVlova 1994/1995, 156, Nr. 350; 359-360; 211, Taf. 20.350, 359-360.

h. Odărci (obšt. Dobrič, obl. Varna, BG). Aus der altbulg. Schicht der frühbyzantinischen Festung. Abweichende Proportionen; größeres Medaillon. Br.

Lit.: DonČEva-PetKova 1986, 167, Abb. 4; DonČEva-PetKova 1999, 163, Nr. 677; Taf. 51-52.

i. Păcuiul lui Soare (jud. Constanţa, R). Aus der Kulturschicht der altbulg. Festung „Malăk Preslavec“ (?). Blattförmig (Kontur ähnlich Nr. 9A); seitlich Rankenbordüre; großes Medaillon. B. 1,8 cm; Br.

Lit.: Diaconu 1969, 501; 503, Abb. 1.2; DiaconU-VÎLCEANu 1972, 154, Nr. 8; 155, Abb. 62.

j-k. Pet mogili (obšt. Novi Pazar, obl. Varna, BG). Aus einem Grubenhaus in der altbulg. Festung, das auch Bleiplättchen des 10. Jh. mit griechisch-altkirchenslawischer Inschrift enthielt. 2 Exemplare. Blattförmig; seitlich des Medaillons 2 Bögen. Ca. 1,8 $\times 1,9 \mathrm{~cm}$ und 1,5 × 1,5 cm; Cu. Lit.: PopkonstantinOv-ATANASOv 1993, 153, Abb. 2.13-14.

l. Pliska. LF aus der inneren Stadt. Größer; seitlich des Medaillons 2 Bögen. Cu (massiv).

Filiale Šumen des Arch. Inst. Mus., Fund-Nr. 90/1985. 
m-n. Popina (obšt. Silistra, obl. Ruse, BG). LF von der altbulg. Festung „Kaleto“. 2 Exemplare. Seitlich des Medaillons 2 Bögen. Cu. Hist. Mus. Silistra, Inv.-Nr. III 882-883.

o. Pop Rusanovo (obšt. Kajnardža, obl. Ruse, BG). LF von der altbulg. Festung. Größer; seitlich des Medaillons 2 Bögen. Cu. Hist. Mus. Dobrič, Inv.-Nr. As 2443.

p. Razdelna (obšt. Beloslav, obl. Varna, BG). LF von der antiken und spätmittelalterlichen Festung „Petrič kale“. Perlrand bei Mittelmedaillon; Voluten der Randleiste viergeteilt.

Arch. Mus. Varna, Inv.-Nr. IV 3996.

Lit.: Pletn'ov-Pavlova 1994/1995, 156, Nr. 361; 212, Taf. 21.361.

q. Suvorovo (obšt. Suvorovo, obl. Varna, BG). LF von der antiken Festung. Seitlich des Medaillons 2 Bögen.

Arch. Mus. Varna, Inv.-Nr. IV 2406.

Lit.: Pletn'ov-PaVlova 1994/1995, 156, Nr. 351; 210, Taf. 19.351.

r. Ugărčin (obšt. Ugărčin, obl. Loveč, BG). Unbek. Fundstelle in der Dorfflur. Größer; seitlich des Medaillons 2 Bögen. Cu (dicker Weißmetallüberzug).

Nat. Arch. Mus. Sofia, ohne Inv.-Nr.

s. Vetren (obšt. Silistra, obl. Ruse, BG) (?). ${ }^{150}$ LF von der altbulg. Festung „Kale“. Bordüre aus 4 Voluten, die von den kugelförmigen Fortsätzen getrennt sind. $1,8 \times 1,9 \mathrm{~cm}$; Br.

Hist. Mus. Silistra, Inv.-Nr. III 972.

Lit.: AtANASOV-JoRDANOV 1994, 20 f.; 54, Nr. 15; Taf. 3.15.

$t-u$. Unbek. FO. 2 Exemplare. Seitlich des Medaillons 2 Bögen. $1,7 \times 1,5 \mathrm{~cm}$ und 1,8 $\times 1,7 \mathrm{~cm} ; \mathrm{Cu}$.

Nat. Arch. Mus. Sofia, Inv.-Nr. 5104-5105.

Lit.: STANILOv 1991b, 17, Nr. 48-52; 39, Abb. 18.48-49; 50, Nr. 48-49; 62, Taf. 8.48-49.

v. Unbek. FO in Nordostbulgarien. Großes Medaillon; äußere Enden von Randleiste verdeckt. Cu (massiv).

Hist. Mus. Šumen, Inv.-Nr. 2906.

w. Unbek. FO in der südlichen Dobrudscha. Seitlich des Medaillons 2 Bögen. Cu.

Hist. Mus. Dobrič, Inv.-Nr. As 1989.

$x-a k$. Unbek. FO bzw. Umgebung von Varna. 14 Exemplare.

Arch. Mus. Varna, Inv.-Nr. IV 2050 (2 Exemplare), 2268-2269, 2661, 2672, 2708-2709, 2711-2714, 3975, 4082.

Lit.: Pletn'ov-Pavlova 1994/1995, 155, Nr. 335-347; 210, Taf. 19.335-340; 211, Taf. 20.341-347 (2 Exemplare bei Nr. 338).

al-ao. Unbek. FO bzw. Umgebung von Varna. 4 Exemplare. Voluten der Randleiste viergeteilt; 2-mal Perlrand bei Mittelmedaillon.

Arch. Mus. Varna, Inv.-Nr. IV 2069, 2264-2665, 3996.

Lit.: Pletn'ov-Pavlova 1994/1995, 156, Nr. 357-358, 362-363; 211, Taf. 20.357-358; 212, Taf. 21.362-363.

10B. Unbek. FO in Nordostbulgarien. Blatt- bis vierpassförmig mit 4 Kügelchen in den Zwickeln; innerer Aufbau wie Nr. 10A; rückseitig 2 zum Zentrum gebogene Dorne. $1,75 \times 1,35 \mathrm{~cm} ; \mathrm{Cu}$.

Hist. Mus. Šumen, Inv.-Nr. 2910.

Parallelen zu Nr. 10B:

a. Car Asen (obšt. Alfamar, obl. Ruse, BG). LF von der altbulg. Festung. Größer; seitlich des Medaillons 2 Bögen. Cu.

Hist. Mus. Silistra, Inv.-Nr. III 928.

b. Izvornik (obšt. Vălčidol, obl. Varna, BG). LF von der altbulg. Festung. Voluten der Randleiste viergeteilt.

Arch. Mus. Varna, Inv.-Nr. IV 3202.

Lit.: Pletn'ov-Pavlova 1994/1995, 156, Nr. 354; 211, Taf. 20.354.

c. Kičevo (obšt. Aksakovo, obl. Varna, BG).

Arch. Mus. Varna, Inv.-Nr. IV 3516.

Lit.: Pletn'ov-PaVlova 1994/1995, 155, Nr. 333; 210, Taf. 19.333.

d. Komunari (obšt. Provadija, obl. Varna, BG), Flur Darboaz. Voluten der Randleiste viergeteilt.

Arch. Mus. Varna, Inv.-Nr. IV 2367.

Lit.: Pletn'ov-Pavlova 1994/1995, 156, Nr. 356; 211, Taf. 20.356.

e. Popina (obšt. Silistra, obl. Ruse, BG). LF von der altbulg. Festung „Kaleto“. Randleiste an der Spitze nicht einbiegend. Cu.

Hist. Mus. Silistra, ohne Inv.-Nr.

${ }^{150}$ Bei der Fundortangabe Vetren ist Vorsicht angebracht, denn nach freundlicher Mitteilung von Frau St. Angelova stammt nur ein geringer Teil der bei ATANASOV-JoRDANOV 1994 abgebildeten
Funde wirklich aus diesem Ort. (Eine Rezension von Frau Angelova ist im Druck.)

Acta Archaeologica Academiae Scientiarum Hungaricae 67, 2016 
f. Ruse, unbekannte Fundstelle. Voluten der Randleiste viergeteilt. Ca. 2,6×3,8 cm; Cu (?).

Lit.: FeHÉr 1939, 92, Abb. 62; FeHÉr 1940, 55, Abb. 26; FEHÉR-GöLlnER 1942, 3, Abb. mit Beschlägen unten (Ruszcsuk).

g. Središte (obšt. Kajnardža, obl. Ruse, BG). LF von der altbulg. Festung. Seitlich des Medaillons 2 Bögen. Cu.

Hist. Mus. Silistra, Inv.-Nr. III 1710.

h. Suvorovo (obšt. Suvorovo, obl. Varna, BG). LF von der antiken Festung.

Arch. Mus. Varna, Inv.-Nr. IV 1880.

Lit.: Pletn'ov-PaVlova 1994/1995, 155, Nr. 334; 210, Taf. 19.334.

i. Sv. Nikola (obšt. Kavarna, obl. Varna, BG). Voluten der Randleiste viergeteilt.

Arch. Mus. Varna, Inv.-Nr. IV 4143.

Lit.: Pletn'ov-PaVlova 1994/1995, 156, Nr. 355; 211, Taf. 20.355.

j. Unbek. FO in Nordbulgarien. Cu.

Mus. des Zweiten Bulgarischen Reiches Veliko Tărnovo, ohne Inv.-Nr.

$k$. Unbek. FO in Nordostbulgarien. Voluten der Randleiste viergeteilt. $\mathrm{Cu}$.

Hist. Mus. Šumen, Inv.-Nr. 2915.

l. Unbek. FO in der südlichen Dobrudscha. Fortsätze vertieft; 2. Randleiste; seitlich des Medaillons 2 Bögen. Cu.

Hist. Mus. Dobrič, Inv.-Nr. As 1989.

$m-p$. Unbek. FO bzw. Umgebung von Varna. 4 Exemplare.

Arch. Mus. Varna, Inv.-Nr. IV 2715-2718.

Lit.: PletN'ov-Pavlova 1994/1995, 154 f., Nr. 329-332; 210, Taf. 19.329-332.

$q$. Unbek. FO bzw. Umgebung von Varna. Voluten der Randleiste viergeteilt.

Arch. Mus. Varna, Inv.-Nr. IV 2719.

Lit.: PletN'ov-PaVlova 1994/1995, 156, Nr. 353; 211, Taf. 20.353.

11A. Smirnenski (obšt. Vjatovo, obl. Ruse, BG). LF von der altbulg. Festung. Herz- bis blattförmig mit Kügelchen an Basis und Spitze (bei letzterer auch Manschette); Randleiste; fünfblättrige Palmette, deren unteres Blattpaar eingerollt ist; Mittelblatt mit der Randleiste verschmolzen. $1,55 \times 1,5 \mathrm{~cm} ; \mathrm{Cu}$; Durchbrechungen beiderseits des Mittelblattes.

Hist. Mus. Razgrad, Inv.-Nr. 4300.

Parallelen zu Nr. 11A:

a. Avren (obšt. Avren, obl. Varna, BG). LF von der Festung „Kišišlika“.

Arch. Mus. Varna, Inv.-Nr. IV 2873.

Lit.: Pletn'ov-PaVlova 1994/1995, 176, Nr. 662; 228, Taf. 37.662.

b. Izvornik (obšt. Vălčidol, obl. Varna, BG). LF von der altbulg. Festung.

Arch. Mus. Varna, Inv.-Nr. IV 3208.

Lit.: Pletn'ov-PaVlova 1994/1995, 176, Nr. 665; 228, Taf. 37.665.

c-d. Novakovo (obšt. Aksakovo, obl. Varna, BG). LF von der antiken und mittelalterlichen Festung. 2 Exemplare.

Arch. Mus. Varna, Inv.-Nr. IV 3244 und 3265.

Lit.: Pletn'ov-Pavlova 1994/1995, 176, Nr. 660 und 663; 228, Taf. 37.660, 663.

e. Okorš (obšt. Dulovo, obl. Ruse, BG). LF von der altbulg. Festung. Gelappte Randleiste; Kügelchen an der Spitze ohne Manschette; isoliertes, schwalbenschwanzförmiges Mittelblatt. $\mathrm{Cu}$.

Hist. Mus. Silistra, Inv.-Nr. III 1036.

f. Pop Rusanovo (obšt. Kajnardža, obl. Ruse, BG). LF von der altbulg. Festung. Kügelchen an der Spitze ohne Manschette. Cu. Hist. Mus. Silistra, Inv.-Nr. III 2389.

g. Provadija (obšt. Provadija, obl. Varna, BG). LF von der Hochebene nördlich der antiken und spätmittelalterlichen Festung Oveč

Arch. Mus. Varna, Inv.-Nr. IV 3090.

Lit.: PletN'ov-PaVlova 1994/1995, 176, Nr. 657; 228, Taf. 37.657.

h. Samotino (obšt. Bjala, obl. Varna, BG). LF von der antiken und spätmittelalterlichen Festung.

Arch. Mus. Varna, Inv.-Nr. IV 2969.

Lit.: Pletn'ov-Pavlova 1994/1995, 176, Nr. 659; 228, Taf. 37.659.

i. Suvorovo (obšt. Suvorovo, obl. Varna, BG). LF von der antiken Festung.

Arch. Mus. Varna, Inv.-Nr. IV 1885.

Lit.: Pletn'ov-PaVlova 1994/1995, 176, Nr. 661; 228, Taf. 37.661.

$j-s$. Unbek. FO bzw. Umgebung von Varna. 10 Exemplare. 
Arch. Mus. Varna, Inv.-Nr. IV 2035-2036, 2583-2588, 3992, 4087.

Lit.: Pletn'ov-Pavlova 1994/1995, 176, Nr. 653-656, 658, 664, 666-669; 228, Taf. 37.653-656, 658, 664, 666-669.

$t$. Unbek. FO in der Ludogorie. Kügelchen an der Spitze ohne Manschette; unteres Blattpaar verschmolzen; Mittelblatt von Randleiste getrennt. Hist. Mus. Kubrat, Inv.-Nr. 271 RA.

11B. Smirnenski (obšt. Vjatovo, obl. Ruse, BG). LF von der altbulg. Festung. Aufbau wie 11A; rückseitig auf der Längsachse 2 nach innen gebogene Dorne. $1,6 \times 1,3 \mathrm{~cm}$; $\mathrm{Cu}$ (Oberfläche stark abgerieben).

Hist. Mus. Razgrad, Inv.-Nr. 4301.

Parallelen zu Nr. 11B:

a. Novakovo (obšt. Aksakovo, obl. Varna, BG). LF von der antiken und mittelalterlichen Festung.

Arch. Mus. Varna, Inv.-Nr. IV 3243.

Lit.: Pletn'ov-Pavlova 1994/1995, 176, Nr. 670; 228, Taf. 37.670

$b-c$. Pet mogili (obšt. Novi Pazar, obl. Varna, BG). 2 Exemplare. Aus einem Grubenhaus in der altbulg. Festung, das auch Bleiplättchen des 10. Jh. mit griechisch-altkirchenslawischer Inschrift enthielt. Kügelchen mit Manschette an der Spitze verschwommen; unteres Blattpaar offen. Ca. $1,4 \times 1,6 \mathrm{~cm} ; \mathrm{Cu}$.

Lit.: Popkonstantinov-Atanasov 1993, 153, Abb. 2.9.

d. Rujno (obšt. Dulovo, obl. Ruse, BG). LF von der altbulg. Festung.

Hist. Mus. Silistra, Inv.-Nr. 2270.

e. Veliki Preslav. Innere Stadt, westlich des Verwaltungsgebäudes. Kügelchen an der Spitze ohne Manschette; breites Mittelblatt. Cu. Mus. „Veliki Preslav“, Inv.-Nr. 22755/1984.

$f$. Unbek. FO in Nordostbulgarien. Doppelte Randleiste; Kügelchen an der Spitze ohne Manschette; isoliertes, schwalbenschwanzförmiges Mittelblatt.

Hist. Mus. Šumen, Inv.-Nr. 4628 (Magazin auf der Šumener Festung Nr. 2/19402).

g. Unbek. FO in der Umgebung von Varna.

Arch. Mus. Varna, Inv.-Nr. IV 3983.

Lit.: Pletn'ov-Pavlova 1994/1995, 176, Nr. 671; 228, Taf. 37.671.

12A. Veliki Preslav. Innere Stadt, südlich des Palastes (?). Breit-blattförmig mit Kügelchen an Spitze und Basis; doppelter breiter Randwulst; im herzförmigen Mittelfeld dreiblättrige Palmette mit zweigeteiltem Mittelblatt (spitzovaler Unterteil und großer Winkel als Oberteil); rückseitig Dorn und Niet. 1,85×1,65 cm; Cu-Blech; gepresst und nachträglich graviert.

Mus. „Veliki Preslav“, Inv.-Nr. OF 2233.

Lit.: StANilov 1995, 116 f. mit Abb. 5.49; 132, Nr. 48 (mit Nr. 49 verwechselt).

Parallelen zu Nr. 12A:

a. Bežanovo (obšt. Lukovit, obl. Loveč, BG). Unbek. Fundstelle in der Dorfflur. Abweichende Kontur; 3 Nieten. Br.

Nat. Arch. Mus. Sofia, ohne Inv.-Nr.

b. General Kantardžievo (obšt. Aksakovo, obl. Varna, BG), Flur „Sarălăka“.

Arch. Mus. Varna, Inv.-Nr. IV 2346.

Lit.: Pletn'ov-Pavlova 1994/1995, 172, Nr. 603; 225, Taf. 34.603.

c. Novakovo (obšt. Aksakovo, obl. Varna, BG). LF von der antiken und mittelalterlichen Festung.

Arch. Mus. Varna, Inv.-Nr. IV 2952.

Lit.: Pletn'ov-Pavlova 1994/1995, 172, Nr. 606; 225, Taf. 34.606.

d. Središte (obšt. Kajnardža, obl. Ruse, BG). LF von der altbulg. Festung. Nur sehr kleines Kügelchen an der Basis; grobe Machart. Cu. Hist. Mus. Silistra, Inv.-Nr. III 1466.

e. Središte (obšt. Kajnardža, obl. Ruse, BG). LF von der altbulg. Festung. Gerade, nicht voneinander abgegrenzte Palmettenblätter. Cu. Hist. Mus. Silistra, Inv.-Nr. III 1485.

f. Unbek. FO in Nordostbulgarien. Abweichende Kontur. $\mathrm{Cu}$.

Hist. Mus. Šumen, Inv.-Nr. 2927.

g. Unbek. FO in Nordostbulgarien. Abweichende Kontur. Cu (Vorderseite mit Weißmetallüberzug).

Hist. Mus. Šumen, Inv.-Nr. 11264.

$h-j$. Unbek. FO in der Umgebung von Varna. 3 Exemplare.

Arch. Mus. Varna, Inv.-Nr. IV 2037-2038, 3982.

Lit.: Pletn'ov-PavLova 1994/1995, 172, Nr. 604-605, 607; 225, Taf. 34.604-605, 607. 
12B. Veliki Preslav. Innere Stadt, Erzbischofspalast (?). Aufbau wie 12A; rückseitig 2 Nieten. Cu.

Mus. ,Veliki Preslav“, Inv.-Nr. 27957.

Lit.: StANILOv 1995, 116 f. mit Abb. 5.48; 132, Nr. 49 (mit Nr. 48 verwechselt).

Parallelen zu Nr. 12B:

$a-b$. Bežanovo (obšt. Lukovit, obl. Loveč, BG). Unbek. Fundstelle in der Dorfflur. 2 Exemplare. Abweichende Kontur. Cu.

Nat. Arch. Mus. Sofia, ohne Inv.-Nr.

$c-d$. General Kantardžievo (obšt. Aksakovo, obl. Varna, BG), Flur „Sarălăka“. 2 Exemplare.

Arch. Mus. Varna, Inv.-Nr. IV 2117-2118.

Lit.: Pletn'ov-PaVlova 1994/1995, 171 f., Nr. 601-602; 225, Taf. 34.601-602.

e. Središte (obšt. Kajnardža, obl. Ruse, BG). LF von der altbulg. Festung. Mittelblatt der Palmette mit abweichender Kontur; grob bearbeitet. Cu. Hist. Mus. Silistra, Inv.-Nr. III 1823.

13A. Veliki Preslav. Westlich des Verwaltungsgebäudes. Breit-herzförmig mit Kügelchen an Basis und beiderseits der Spitze; Rahmen aus zwei stilisierten Halbpalmetten und schmale fünfblättrige Palmette im Zentrum (Blatteinschnitte auf gleicher Höhe wie die der seitlichen Halbpalmetten); Mittelrippe; rückseitig 2 nach innen gebogene Dorne wenig unterhalb der Querachse. 1,8 $\times 1,6 \mathrm{~cm} ; \mathrm{Cu}$.

Mus. „Veliki Preslav“, Fund-Nr. 22756.

Parallelen zu Nr. 13A:

a. Balik (obšt. Tervel, obl. Varna, BG). Aus der altbulg. Siedlungsschicht der byzantinischen Festung „Hisar kale“. Abweichende Kontur. Br. Hist. Mus. Dorbrič, Inv.-Nr. A 2497.

b. Nevša (obšt. Provadija, obl. Varna, BG), „Malkoto Eleme“.

Arch. Mus. Varna, Inv.-Nr. IV 4204.

Lit.: Pletn'ov-PaVlova 1994/1995, 174, Nr. 634; 227, Taf. 36.634.

c. Suvorovo (obšt. Suvorovo, obl. Varna, BG). LF von der antiken Festung.

Arch. Mus. Varna, Inv.-Nr. IV 2402.

Lit.: Pletn'ov-PaVlova 1994/1995, 174, Nr. 635; 227, Taf. 36.635.

$d-f$. Unbek. FO in der Umgebung von Varna. 3 Exemplare.

Arch. Mus. Varna, Inv.-Nr. IV 1995.

Lit.: Pletn'ov-PaVlova 1994/1995, 174, Nr. 633; 227, Taf. 37.633a-c.

g. Unbek. FO in Nordbulgarien. Größer. Cu.

Mus. des Zweiten Bulgarischen Reiches Veliko Tărnovo, ohne Inv.-Nr.

$h$. Unbek. FO in Nordostbulgarien. Abweichende Kontur. Br.

Hist. Mus. Šumen, ohne Inv.-Nr.

13B. Veliki Preslav, östlich des Verwaltungsgebäudes in 0,4 m Tiefe. Aufbau wie Nr. 13A; rückseitig 2 lange Nieten auf der Längsachse. 1,9×1,4 $\mathrm{cm}$; Br. (schwache Vergoldungsspuren).

Mus. ,Veliki Preslav“, Inv.-Nr. 19242.

Parallelen zu Nr. 13B:

a. Botevo (obšt. Vetrino, obl. Varna, BG). LF von der antiken Festung „Chač burun kale“. Klein und gedrungen.

Arch. Mus. Varna, Inv.-Nr. IV 2960.

Lit.: Pletn'ov-Pavlova 1994/1995, 174, Nr. 629; 227, Taf. 36.629.

b. Dobroplodno (obšt. Vetrino, obl. Varna, BG).

Arch. Mus. Varna, Inv.-Nr. IV 4169.

Lit.: Pletn’ov-PaVlova 1994/1995, 174, Nr. 631; 227, Taf. 36.631.

c. Nevša (obšt. Provadija, obl. Varna, BG), „Malkoto Eleme“. LF von der antiken und spätmittelalterlichen Festung. Klein und gedrungen.

Arch. Mus. Varna, Inv.-Nr. IV 4202.

Lit.: Pletn’ov-PaVlova 1994/1995, 174, Nr. 630; 227, Taf. 36.630.

d. Okorš (obšt. Dulovo, obl. Ruse, BG). LF von der altbulg. Festung. Kleiner und mit abweichender Kontur; schmale Palmette, deren Spitze mit der Bordüre verschmolzen ist. $\mathrm{Cu}$; gegossen und nachträglich graviert.

Hist. Mus. Silistra, Inv.-Nr. III 1064.

e. Provadija (obšt. Provadija, obl. Varna, BG). LF von der Hochebene nördlich der antiken und spätmittelalterlichen Festung Oveč. Klein und gedrungen.

Arch. Mus. Varna, Inv.-Nr. IV 2258.

Lit.: Pletn’ov-Pavlova 1994/1995, 173 f., Nr. 628; 227, Taf. 36.628. 
f. Veliki Preslav, Nordmauer der inneren Stadt. Basis der Palmette mit Rahmen verschmolzen; Blätter isoliert; untere Blätter der randlichen Halbpalmetten ebenfalls abgetrennt; gegossen; nachträglich graviert.

Mus. „Veliki Preslav“, Inv.-Nr. 22755/1984.

g. Unbek. FO in Nordostbulgarien. Gedrungener; nur 1 Kügelchen an der Basis, nicht aber beiderseits der Spitze; breite, außen glatte Bordüre und sehr kleine Palmette. $1,3 \times 1,7 \mathrm{~cm}$; $\mathrm{Cu}$.

Nat. Arch. Mus., Inv.-Nr. 5118.

Lit.: Stanilov 1991a, 9; 17 f., Nr. 53-63; 39, Abb. 18.55; 51, Nr. 55; 63, Taf. 9.55.

h. Unbek. FO in der Umgebung von Varna.

Arch. Mus. Varna, Inv.-Nr. IV 2018.

Lit.: Pletn'ov-Pavlova 1994/1995, 174, Nr. 632; 227, Taf. 37.632.

14A. Središte (obšt. Kajnardža, obl. Ruse, BG). LF von der altbulg. Festung. Breit-winkelförmig; an den Längsseiten Furchen; eingravierte stilisierte fünfblättrige Palmette; rückseitig längs der Querachse 2 nach innen gebogene Dorne. Cu.

Hist. Mus. Silistra, Inv.-Nr. III 1486.

Parallele zu Nr. 14A:

a. Središte. LF von der altbulg. Festung. Abweichendes Ornament. $\mathrm{Cu}$.

Hist. Mus. Silistra, Inv.-Nr. III 1479.

14B. Središte (obšt. Kajnardža, obl. Ruse, BG). LF von der altbulg. Festung. Schmal-winkelförmig; an der Basis eingravierte Furchen, davon ausgehend stilisierte fünfblättrige Palmette; rückseitig auf der Längsachse 2 nach innen gebogene Dorne. Cu.

Hist. Mus. Silistra, Inv.-Nr. III 1829.

15A. Unbek. FO in Nordostbulgarien. Sehr breit blatt- bis herzförmig; Kügelchen an der Basis und zwei Paare von Spiralrundeln an den Seiten; an der Basis kleine, eingravierte Volute; Gravur auch auf der Rückseite noch schwach sichtbar; dort 3 Nieten, 1 an der Spitze, 2 auf der Querachse. $3,25 \times 2,4 \mathrm{~cm} ; \mathrm{Cu}$ (stark abgerieben).

Hist. Mus. Šumen, Inv.-Nr. 4674.

Verwandte Stücke mit einfachen Kügelchen und ohne Spiralen - auch mit rechteckigen Durchbrüchen - stammen aus Debrene, Kiten, Kus und Provadija sowie anderen unbekannten Fundorten aus der Umgebung von Varna (PLETN'ov-PAVLOVA 1994/1995, 143, Nr. 174-178, 180-182; 201, Taf. 10.174-178, 180-182).

Verwandte Stücke mit einfachen Kügelchen und ohne Spiralen stammen aus der Kladenci (Jotov-Atanasov 1998, 313, Taf. 114, Nr. 445), aus Debrene, General Kantardžievo und Samotino sowie anderen unbekannten Fundorten aus der Umgebung von Varna (PLeTn'ov-Pavlova 1994/1995, 142 f., Nr. 162-173; 200, Taf. 10.162-173).

15 B. Unbek. FO in Nordostbulgarien. Sehr breit blatt- bis herzförmig; Kügelchen an der Basis und 2 Paare von Spiralrundeln an den Seiten; an der Basis kleine, eingravierte Volute; Gravur auch auf der Rückseite noch schwach sichtbar; dort 3 Nieten, 1 an der Spitze, 2 auf der Querachse. $3,25 \times 2,4 \mathrm{~cm} ; \mathrm{Cu}$ (stark abgerieben).

Hist. Mus. Šumen, Inv.-Nr. 4674.

16A. Mogila (obšt. Kaspičan, obl. Varna, BG). LF von der Flur „Dălbokoto“. Breit-blattförmig; kleines Kügelchen an der Basis und 2 Paare rundlicher Fortsätze an den Seiten; im Ober- und Unterteil zwei gegenständige Bündel von 4 bzw. 3 gravierten Winkellinien; rückseitig 2 Nieten auf der Längsachse. $2,65 \times 1,55 \mathrm{~cm}$; $\mathrm{Cu}$.

Hist. Mus. Šumen, ohne Inv.-Nr.

Vgl. hier auch den Hinweis zu 15A.

16B. Unbek. FO in Nordostbulgarien. Schlank-blattförmig; kleines Kügelchen an der Basis und zwei Paare rundlicher Fortsätze an den Seiten; im Ober- und Unterteil zwei gegenständige Bündel von je 4 gravierten Winkellinien; rückseitig 2 Nieten auf der Längsachse, einer dornartig nach außen gebogen. $2,85 \times 1,5 \mathrm{~cm}$; $\mathrm{Cu}$.

Nat. Arch. Mus., ohne Inv.-Nr.

Vgl. hier auch den Hinweis zu 15B.

17A. Debrene (obšt. Dobrič, obl. Varna, BG). LF von der altbulg. Festung. 4 Exemplare aus der gleichen Form. Breit-herzförmig; 2 Randwulste, der äußere breit; an der Basis an Stelle des äußeren Wulstes eine abgesetzte Manschette; je ein länglich-ovaler Fortsatz an Basis und Spitze; ein weiteres Paar an den Seiten (diese an der Spitze und den Seiten am äußeren Randwulst beginnend); glattes herzförmiges Mittelfeld; rückseitig Negativ der Verzierung; wenig unterhalb der Querachse 2 Nieten. 2,35 $\times 2,0 \mathrm{~cm}$; $\mathrm{Cu}$ (oder Br).

Hist. Mus. Dobrič, Inv.-Nr. As 1488 (4 Exemplare).

Parallele zu Nr. 17A: 
a. Unbek. FO in Nordostbulgarien. Die Basis der zusätzlichen Fortsätze schwalbenschwanzförmig ausgestaltet; auch im Negativ klar umrissenes Ornament. $\mathrm{Cu}$ (gegossen).

Hist. Mus. Šumen, Inv.-Nr. 4683

17B. Debrene (obšt. Dobrič, obl. Varna, BG). LF von der altbulg. Festung. 5 Exemplare aus der gleichen Form. Schlank-herzförmig; Aufbau ähnlich Nr. 17A, die Manschette hat aber an der Basis die Form eines Blattpaares; auch im Negativ klar umrissenes Ornament. 2,4× 1,85 cm; Br (oder Cu). Hist. Mus. Dobrič, Inv.-Nr. As 1489 (5 Exemplare).

Parallelen zu Nr. 17B:

$a-b$. Unbek. FO in Nordostbulgarien. 2 Exemplare. Auch im Negativ klar umrissenes Ornament. Cu.

Hist. Mus. Šumen, Inv.-Nr. 2861 und 11258.

18A. Unbek. FO in Nordostbulgarien. Breit-herzförmig; 2 Randwulste; je ein länglich-ovaler Fortsatz an Basis und Spitze (Letzterer „leer“); zwei weitere Paare an den Seiten (die Fortsätze unterbrechen den äußeren Randwulst); glattes herzförmiges Mittelfeld; rückseitig wenig unterhalb der Querachse 2 Nieten. 2,2×2,1 cm; Cu.

Hist. Mus. Šumen, Inv.-Nr. 2858.

Parallelen zu Nr. 18A:

a. Izvornik (obšt. Vălčidol, obl. Varna, BG). LF von der altbulg. Festung.

Arch. Mus. Varna, Inv.-Nr. IV 3193.

Lit.: Pletn'ov-PaVlova 1994/1995, 149, Nr. 263; 206, Taf. 15.263.

b. Snežina (obšt. Provadija, obl. Varna, BG), LF von der antiken und mittelalterlichen Festung „Chambarlăka“.

Arch. Mus. Varna, Inv.-Nr. IV 2258.

Lit.: Pletn'ov-PaVlova 1994/1995, 149, Nr. 262; 205, Taf. 14.262.

c. Veliki Preslav. Runde Kirche, in der altbulg. Schicht. Fortsatz an der Spitze nicht abweichend; innere Leiste doppelt. $2,5 \times 2,0 \mathrm{~cm}$; Cu (stark beschädigt).

Mus. „Veliki Preslav“, ohne Inv.-Nr.

Lit.: Mijatev 1932, 180, Nr. 346; 181, Abb. 283.4.

d. Veliko Tărnovo (?). Blattförmig, ohne Einschnitt an der Basis; Fortsätze an Basis und Spitze fehlen; Randleisten an der Spitze unterbrochen (vgl. Nr. 19A). $3,2 \times 2,2 / 2,5 \mathrm{~cm}$.

Lit.: FEHÉR 1940, 52, Abb. 21; Taf. 26 unten.

Verwiesen werden kann auch auf ein Exemplar aus der Festung „Skala“ bei Kladenci, das Spiralknöpfe aufweist (JoTOV-ATANASOV 1998, 313, Taf. 114, Nr. 450).

$e-g$. Unbek. FO in der Umgebung von Varna. 3 Exemplare. $1 \times$ mit rechteckiger Durchbrechung an der Basis.

Arch. Mus. Varna, Inv.-Nr. IV 1992, 2615, 2734.

Lit.: Pletn'ov-Pavlova 1994/1995, 149, Nr. 261, 263, 265; 205 f., Taf. 14.261, 27.263, 265.

18B. Unbek. FO in Nordostbulgarien. Schlank herz- bis blattförmig; Aufbau wie Nr. 18A; rückseitig 3 Nieten, 2 direkt an der Basis und 1 an der Spitze; 4. Niet in einer Öffnung seitlich an der Basis. 2,6×1,8 cm; Cu (Gussfehler).

Hist. Mus. Šumen, Inv.-Nr. 2858.

Parallelen zu Nr. 18B:

a. Komunari (obšt. Provadija, obl. Varna, BG), Flur „Darboaz“.

Arch. Mus. Varna, Inv.-Nr. IV 2913.

Lit.: Pletn'ov-Pavlova 1994/1995, 149, Nr. 258; 205, Taf. 14.258.

b. Odărci (obšt. Dobrič, obl. Varna, BG). In der altbulg. Schicht der frühbyzantinischen Festung. Fortsatz an der Spitze verkümmert; der Einschnitt an der Basis stärker akzentuiert. $\mathrm{Cu}(?)$.

Lit.: DonČEva-Petkova 1986, 166 f. mit Abb. 4, unten links; DončEva-PetKova 1999, 162, Nr. 667, Taf. 50, 667, Taf. 52, 667.

c. Pliska. LF westlich von der Zisterne in der inneren Stadt. Fortsatz an der Spitze massiv; der Einschnitt an der Basis stärker ausgeprägt. Cu. Filiale Šumen des Arch. Inst. Mus., Fund-Nr. 18/1985.

d. Rujno (obšt. Dulovo, obl. Ruse, BG). LF von der altbulg. Festung. Cu (grobe Machart).

Hist. Mus. Silistra, ohne Inv.-Nr.

$e-f$. Stărmen. Ostteil der altbulg. Festung. 2 Exemplare. Basis rund; Fortsatz an der Spitze massiv. Ca. 1,9×2,9 cm; Br.

Lit.: HeNSEL 1980, 124; 195, Taf. 16.209.

g. Suvorovo (obšt. Suvorovo, obl. Varna, BG). LF von der antiken Festung.

Arch. Mus. Varna, Inv.-Nr. IV 1869.

Lit.: Pletn'ov-PaVlova 1994/1995, 149, Nr. 257; 205, Taf. 14.257. 
h. Unbek. FO in Nordbulgarien. Abweichende Kontur; Fortsatz an der Spitze massiv. Cu (grobe Machart).

Mus. des Zweiten Bulgarischen Reiches Veliko Tărnovo, ohne Inv.-Nr.

i. Unbek. FO in Nordostbulgarien. Abweichende Kontur; Fortsatz an der Spitze massiv; Ornament auch im Negativ. Cu.

Hist. Mus. Šumen, Inv.-Nr. 2859.

j. Unbek. FO in Nordostbulgarien. Abweichende Kontur. Cu (grobe Machart).

Hist. Mus. Šumen, Inv.-Nr. 5351.

$k-l$. Unbek. FO in der Umgebung von Varna. 2 Exemplare.

Arch. Mus. Varna, Inv.-Nr. IV 2003, 2499.

Lit.: Pletn'ov-Pavlova 1994/1995, 149, Nr. 259-260; 205, Taf. 14.259-260.

19A. Unbek. FO in Nordostbulgarien. Fast quadratisch mit konvexen Seiten; Rundel an den Ecken; an 3 Seiten leichte, längliche Vertiefungen, an der 4. Seite ist diese durch einen Steg unterbrochen; Mittelfeld plan; rückseitig 2 Nieten längs der Querachse, davon einer fehlend. 2,3 $\times 2,0$ $\mathrm{cm} ; \mathrm{Cu}$ (2 Durchbrechungen am Rand).

Hist. Mus. Šumen, Inv.-Nr. 2921.

Parallele zu Nr. 19A:

a. Unbek. FO in der Umgebung von Varna.

Arch. Mus. Varna, Inv.-Nr. IV 2518.

Lit.: PletN'ov-Pavlova 1994/1995, 152, Nr. 302; 208, Taf. 17.302.

19B. Unbek. FO in Nordostbulgarien. Aufbau wie Nr. 19A; rückseitig 2 Nieten auf der Längsachse, davon einer fehlend. 2,2 $\times 2,1 \mathrm{~cm}$; Cu (Dellen auf der Rückseite der Rundeln).

Hist. Mus. Šumen, Inv.-Nr. 2923.

Zur Parallele vgl. 19A.

20A. Središte (obšt. Kajnardža, obl. Ruse, BG). LF von der altbulg. Festung. Breit-blattförmig; Kügelchen an Basis und 2 Einschnitte an den Seiten; breiter glatter Randbereich; vom Kügelchen ausgehende Vertiefungen: geschweift-tropfenförmiges Blattpaar, dazwischen lanzettförmiges Mittelblatt, dessen Innenzier nur noch in Spuren erhalten ist; rückseitig 3 Nieten, 2 auf der Querachse und 1 an der Spitze. 2,7×2,2 cm; Cu; sehr dünnes Blech (Ornament auch im Negativ sichtbar).

Hist. Mus. Silistra, Inv.-Nr. III 1829.

Parallelen zu Nr. 20A:

a. Avren (obšt. Avren, obl. Varna, BG). LF von der Festung „Kišišlika“.

Arch. Mus. Varna, Inv.-Nr. IV 2874.

Lit.: Pletn'ov-Pavlova 1994/1995, 163, Nr. 460; 217, Taf. 26.460.

b. Odărci (obšt. Dobrič, obl. Varna, BG). Br. (Mittelblatt oval).

Lit.: DonČEva-PetKova 1999, 163, Nr. 676, Taf. 50, 676, Taf. 52, 676.

c. Središte. LF von der altbulg. Festung. Abweichende Kontur. Cu (Blech).

Hist. Mus. Silistra, Inv.-Nr. III 1814.

$d-e$. Unbek. FO in Nordostbulgarien. 2 Exemplare. Nur Mittelblatt abweichend. $\mathrm{Cu}$ (Blech).

Hist. Mus. Šumen, Inv.-Nr. 8928 und 10551.

$f-g$. Unbek. FO in der Umgebung von Varna. 2 Exemplare.

Arch. Mus. Varna, Inv.-Nr. IV 2523 und 4011.

Lit.: Pletn'ov-Pavlova 1994/1995, 163, Nr. 461-462; 217, Taf. 26.461-462.

20B. Goleš (obšt. Kajnardža, obl. Ruse, BG). LF von der altbulg. Festung. Schlank-blattförmig; Aufbau wie Nr. 20A; im Mittelblatt graviertes Tannenzweigmuster; rückseitig 2 nach innen gebogene Dorne auf der Längsachse. 2,5 ×1,75 cm; Cu (Ornament auch schwach im Negativ sichtbar). Hist. Mus. Silistra, ohne Inv.-Nr.

Parallelen zu Nr. 20B:

a. Goleš. LF von der altbulg. Festung. Cu.

Hist. Mus. Silistra, Inv.-Nr. III 843.

b. Grozd'ovo (obšt. Georgi Trajkov, obl. Varna, BG). Reservat Šerba.

Arch. Mus. Varna, Inv.-Nr. IV 4260.

Lit.: Pletn'ov-PaVlova 1994/1995, 162, Nr. 459; 217, Taf. 26.459.

c. Kladenci (obšt. Tervel, obl. Varna, BG). Ausgrabungsfund von der altbulg. Festung „Skala“.

Hist. Mus. Silistra, Inv.-Nr. 843.

Lit.: Jotov-ATANASOv 1998, 161, Nr. 440, 313, Taf. 114, 440. 
d. Novakovo (obšt. Aksakovo, obl. Varna, BG). LF von der antiken und mittelalterlichen Festung.

Arch. Mus. Varna, Inv.-Nr. IV 3320.

Lit.: Pletn'ov-PaVlova 1994/1995, 162, Nr. 458; 217, Taf. 26.458.

e. Odărci (obšt. Dobrič, obl. Varna, BG). Br.

Lit.: DončEva-Petkova 1986, 166 f. mit Abb. 4, unten rechts; DončEva-PetKova 1999, 163, Nr. 689, Taf. 51, Taf. 52 (dort mit der falschen Nr. 686).

f-g. Središte (obšt. Kajnardža, obl. Ruse, BG). LF von der altbulg. Festung. 2 Exemplare. Unterschiedliche Größen. Cu (Blech).

Hist. Mus. Silistra, Inv.-Nr. III 1481 und 1821

h. Pliska. LF von der inneren Stadt (nordwestlich des „Bojarenhauses“). Abweichendes Ornament im Mittelblatt. Cu.

Filiale Šumen des Arch. Inst. u. Mus., ohne Inv.-Nr.

$i$. Unbek. FO in der südlichen Dobrudscha. Leicht asymmetrisch. Br.

Hist. Mus. Dobrič, Inv.-Nr. As 2204.

$j$. Unbek. FO in der Umgebung von Varna.

Arch. Mus. Varna, Inv.-Nr. IV 2533.

Lit.: Pletn'ov-PaVlova 1994/1995, 162, Nr. 457; 217, Taf. 26.457.

8 verwandte, gegossene Beschläge aus Dobroplodno, Izvornik, Varna-Vinica, Venčan und von unbekannten Fundplätzen in der Umgebung von Varna sind aufgeführt bei PletN'ov-PAVlova 1994/1995, 164, Nr. 486-493; 219, Taf. 28.486-493.

21A. Unbek. FO in Nordbulgarien. 2 Exemplare. Breit-herzförmig; Kügelchen an der Basis, dort geht die breite Randleiste in ein volutenförmiges Blattpaar über; dazwischen ein rhombisches Mittelblatt, dessen Spitze mit der Randleiste verschmilzt; rückseitig 2 nach unten gebogene Dorne auf der Querachse, 1 Dorn an der Spitze. 2,2×1,8 cm; Cu (Ornament auch im Negativ sichtbar).

Mus. des Zweiten Bulgarischen Reiches Veliko Tărnovo, Inv.-Nr. 6490 (2 Exemplare).

Parallelen zu Nr. 21A:

a-c. Cărkva (obšt. Dobrič, obl. Varna, BG). 3 Exemplare.

Arch. Mus. Varna, Inv.-Nr. IV 3476-3478.

Lit.: Pletn'ov-Pavlova 1994/1995, 169, Nr. 573-575; 223, Taf. 32.573-574; 224, Taf. 33.575.

d-e. General Kantardžievo (obšt. Aksakovo, obl. Varna, BG), Flur Sarălăka. 3 Exemplare.

Arch. Mus. Varna, Inv.-Nr. IV 2347-2349.

Lit.: PletN'ov-PaVlova 1994/1995, 170, Nr. 577; 581-582; 224, Taf. 33.577, 581-582.

f. Izvornik (obšt. Vălčidol, obl. Varna, BG). LF von der altbulg. Festung. Breit.

Arch. Mus. Varna, Inv.-Nr. IV 3212.

Lit.: Pletn'ov-PaVlova 1994/1995, 169, Nr. 568; 223, Taf. 32.568.

g. Kladenci (obšt. Tervel, obl. Varna, BG). Ausgrabungsfund von der altbulg. Festung „Skala“.

Hist. Mus. Silistra, Inv.-Nr. 846 (Hist. Mus. Silistra).

Lit.: Jotov-Atanasov 1998, 161, Nr. 439; 313, Taf. 114, 439.

h. Nevša (obšt. Provadija, obl. Varna, BG). LF von der antiken und spätmittelalterlichen Festung „Malkoto Eleme“.

Arch. Mus. Varna, Inv.-Nr. IV 4201.

Lit.: Pletn'ov-PaVlova 1994/1995, 170, Nr. 580; 224, Taf. 33.580.

i-k. Novakovo (obšt. Aksakovo, obl. Varna, BG). LF vom Hang der antiken und mittelalterlichen Festung. 3 Exemplare.

Arch. Mus. Varna, Inv.-Nr. IV 2953, 3266-3267.

Lit.: Pletn’ov-PaVlova 1994/1995, 170, Nr. 578-579, 585; 224, Taf. 33.578-579, 585.

l. Okorš (obšt. Dulovo, obl. Ruse, BG). LF von der altbulg. Festung. Abweichende Kontur. Cu.

Hist. Mus. Silistra, Inv.-Nr. III 1056.

$m-n$. Odărci (obšt. Dobrič, obl. Varna, BG). Ausgrabungsfunde von der spätantiken Festung. 2 Exemplare. Br; 1-mal mit größerem Mittelblatt. Lit.: DončEvA-PETKova 1999, 163, Nr. 684-685, Taf. 51, 684-685, Taf. 52, 684-685.

o. Pliska. Unbekannte Fundstelle. Unteres Blattpaar zu Rundeln verkümmert. 1,9×1,7 cm; Cu.

Lit.: FEHÉr 1940, 52, Abb. 21, oben links; Taf. 27, oben links.

p. Provadija (obšt. Provadija, obl. Varna, BG). LF von der Hochebene nördlich der antiken und spätmittelalterlichen Festung Oveč. Klein.

Arch. Mus. Varna, Inv.-Nr. IV 2877.

Lit.: Pletn'ov-PaVlova 1994/1995, 169, Nr. 557; 223, Taf. 32.557.

$q-$ u. Suvorovo (obšt. Suvorovo, obl. Varna, BG). LF von der antiken Festung. 5 Exemplare.

Arch. Mus. Varna, Inv.-Nr. IV 1883, 1886, 1873, 2395, 4206. 
Lit.: Pletn'ov-Pavlova 1994/1995, 169 f., Nr. 569-570, 572, 576, 586; 223, Taf. 32.569-570; 224, Taf. 33.572 , $576,586$.

$v$-aa. Unbek. FO in der Umgebung von Varna. 7 Exemplare; 2-mal klein; 1-mal mit rechteckiger Durchbrechung an der Basis.

Arch. Mus. Varna, Inv.-Nr. IV 2006, 2034, 2049, 2574, 2603, 2725.

Lit.: Pletn'ov-PaVlova 1994/1995, 169 f., Nr. 555-556, 571, 583-584, 587; 223, Taf. 32.555-556, 571; 224 , Taf. 33.583 , 587.

$\mathrm{Zu}$ diesem Typ könnte man auch die Beschläge hinzuzählen, bei denen das volutenförmige Blattpaar an der Basis verkümmert ist. Im Museum Varna lagern allein 15 Exemplare dieser Variante aus Izvornik und anderen unbekannten Fundorten (PLETN'OV-PAVLOVA 1994/1995, 168, Nr. 534-548; 222, Taf. 31.534-548).

21B. Unbek. FO in Nordbulgarien. 2 Exemplare. Schlank-herzförmig; Aufbau wie Nr. 21A; rückseitig 2 nach außen gebogene Dorne auf der Längsachse. $2,3 \times 1,55 \mathrm{~cm}$; $\mathrm{Cu}$ (Ornament schwach auch im Negativ sichtbar).

Mus. des Zweiten Bulgarischen Reiches Veliko Tărnovo, Inv.-Nr. 6462 (2 Exemplare).

Parallelen zu Nr. 21B:

$a-b . \breve{g}$ glen (obšt. Lukovit, obl. Loveč, BG). 2 Exemplare. Rückseitig bei einem 2, beim anderen 3 Dorne. Cu (gegossen).

Nat. Arch. Mus. Sofia, ohne Inv.-Nr.

c. Aksakovo (obšt. Aksakovo, obl. Varna, BG). LF unterhalb der antiken und spätmittelalterlichen Festung „Michljuza“ („Mjuchljuz kale“).

Arch. Mus. Varna, Inv.-Nr. IV 3385.

Lit.: Pletn'ov-PaVlova 1994/1995, 169, Nr. 566; 223, Taf. 32.566.

d-e. Balik (obšt. Tervel, obl. Varna, BG). Aus der altbulg. Siedlungsschicht der byzantinischen Festung „Hisar kale“. 2 Exemplare. 1,6×2,5 cm; Br. Nat. Arch. Mus. Sofia, Inv.-Nr. 10040/5-6.

Lit.: Melamed 1993, 165, Nr. 7, Abb. 7; Taf. 2, zweite Reihe rechts.

f. Balik. Fundumstände wie bei c-d. Abweichend gestaltetes Ornament. Cu.

Hist. Mus. Dobrič, Inv.-Nr. As 2862.

g-i. Kladenci (obšt. Tervel, obl. Varna, BG). Ausgrabungsfunde von der altbulg. Festung „Skala“. 3 Exemplare.

Städt. Mus. Tervel, Inv.-Nr. 391-392, 448.

Lit.: Jotov-ATANASOv 1998, 161; 313, Taf. 114, Nr. 436-438.

j. Odărci (obšt. Dobrič, obl. Varna, BG). Ausgrabungsfund von der antiken Festung. Br.

Lit.: DonČEVA-PetKova 1999, 163, Nr. 686, Taf. 51.

$k-n$. Suvorovo (obšt. Suvorovo, obl. Varna, BG). LF von der antiken Festung. 4 Exemplare.

Arch. Mus. Varna, Inv.-Nr. IV 1875, 1889, 1902, 2972.

Lit.: Pletn'ov-Pavlova 1994/1995, 168 f., Nr. 553, 562-564; 222, Taf. 31.553; 223, Taf. 32.562-564.

o. Sv. Nikola (obšt. Kavarna, obl. Varna, BG).

Arch. Mus. Varna, Inv.-Nr. IV 4271.

Lit.: PletN'ov-PaVlova 1994/1995, 168, Nr. 550; 222, Taf. 31.550.

p. Unbek. FO in Nordostbulgarien. 2 Nieten unterhalb der Längsachse. $\mathrm{Cu}$.

Hist. Mus. Šumen, Inv.-Nr. 5180.

$q-v$. Unbek. FO in der südlichen Dobrudscha. 6 Exemplare. $\mathrm{Cu}$.

Hist. Mus. Dobrič, Inv.-Nr. As 1782 (2 Exemplare), 1882 (2 Exemplare) und 2234 (2 Exemplare).

$\mathrm{Zu}$ diesem Typ könnte man auch die Beschläge hinzuzählen, bei denen das volutenförmige Blattpaar an der Basis verkümmert ist. Im Museum Varna lagern allein 5 Exemplare dieser Variante aus Kiten und anderen unbekannten Fundorten (PLETN'Ov-PAVLOVA 1994/1995, 167 f., Nr. 527-533; 221, Taf. 30.527-533).

$w-a d$. Unbek. FO in der Umgebung von Varna. 9 Exemplare.

Arch. Mus. Varna, Inv.-Nr. IV 2048, 2078, 2543-2544, 2560, 2565, 2567-2568.

Lit.: Pletn'ov-PaVlova 1994/1995, 168 f., Nr. 551-552, 554, 558-561, 565, 567; 222, Taf. 31.551-552; 223, Taf. 32.554, 558-561, 567.

22A. Car Asen (obšt. Alfamar, obl. Ruse, BG). LF von der altbulg. Festung. Breit-blattförmig; Kügelchen an der Basis; breiter Rand; stilisierte fünfblättrige Palmette, deren oberes Blattpaar und Stil mit dem Rand verschmelzen; unteres Blattpaar eingerollt-kreisförmig; rhombisches, freistehendes Mittelblatt; rückseitig 2 Nieten auf der Querachse und 1 Niet an der Spitze. 2,6×2,25 cm; Cu (dünnes Blech; Ränder stark zurückgebogen).

Hist. Mus. Silistra, Inv.-Nr. III 931.

22B. Bežanovo (obšt. Lukovit, obl. Loveč, BG). Unbek. Fundstelle in der Dorfflur. Schlank-herzförmig; Aufbau wie Nr. 22A; Spitze des Mittelblattes geht in den Randbereich über; rückseitig 2 Nieten an der Basis und 1 Niet an der Spitze. 2,4×2,15 cm; Cu.

Nat. Arch. Mus. Sofia, ohne Inv.-Nr.

Parallelen zu Nr. 22A: 
a. Vojnikovo (obšt. Tervel, obl. Varna, BG). LF von der altbulg. Festung. Cu.

Hist. Mus. Dobrič, Inv.-Nr. As 2464.

b. Unbek. FO in der südlichen Dobrudscha. $\mathrm{Cu}$.

Hist. Mus. Dobrič, Inv.-Nr. As 2869.

c. Unbek. FO in der Ludogorie. Cu.

Hist. Mus. Kubrat, ohne Inv.-Nr.

23A. Unbek. FO in Nordostbulgarien. Breit-blattförmig mit Öse an der Basis; seitlich davon 2 Fortsätze; ziemlich breite Randleiste, davon ausgehend 3 dreiblättrige Palmetten in kreuzförmiger Anordnung; Spitzen der Mittelblätter verschmilzen mit der Randleiste; rückseitig 2 Nieten mit quadratischen Blechscheiben auf der Querachse. 2,5 × 1,95 cm; Cu.

Hist. Mus. Šumen, Inv.-Nr. 4596.

Lit.: Stanilov 1992, 51 f. mit Abb. 5.

Parallelen zu Nr. 23A:

a. General Kantardžievo (obšt. Aksakovo, obl. Varna, BG), Flur Sarălăka.

Arch. Mus. Varna, Inv.-Nr. IV 2350.

Lit.: Pletn'ov-Pavlova 1994/1995, 182, Nr. 749; 234, Taf. 43.749.

$b-d$. Novakovo (obšt. Aksakovo, obl. Varna, BG). 3 Exemplare.

Arch. Mus. Varna, Inv.-Nr. IV 2861-2862; 2930.

Lit.: Pletn'ov-Pavlova 1994/1995, 182 f., Nr. 747, 751, 753; 233, Taf. 42.747; 234, Taf. 43.751, 753.

e. Rujno (obšt. Dulovo, obl. Ruse, BG). LF von der altbulg. Festung. Gekreuzte Palmettenstämme besonders deutlich. Ca. 2,3×2,1 cm; Cu.

Hist. Mus. Silistra, ohne Inv.-Nr.

Lit.: STANiLov 1992, 51 f. mit Abb. 2.

$f$. Unbek. FO in Nordbulgarien. Abweichende Kontur mit seitlichen Einschnitten und großer, rechteckiger Öse; Palmetten zu einer neunblättrigen Palmette verschmolzen. Ca. $3,2 \times 2,4 \mathrm{~cm}$; Cu.

Mus. des Zweiten Bulgarischen Reiches Veliko Tărnovo, ohne Inv.-Nr.

Lit.: STANILOv 1992, 51 f. mit Abb. 10.

$g-k$. Unbek. FO in der südlichen Dobrudscha. 5 Exemplare. Abweichende, unterschiedliche Konturen. Cu.

Hist. Mus. Dobrič, Inv.-Nr. As 2225, 2503 (3 Exemplare) und 2998 (2 unterschiedliche Exemplare).

$l-n$. Unbek. FO in der Umgebung von Varna. 3 Exemplare. 1-mal Öse verschlossen.

Arch. Mus. Varna, Inv.-Nr. IV 2531, 2730, 4223.

Lit.: Pletn'ov-Pavlova 1994/1995, 182 f., Nr. 748, 750, 752; 233, Taf. 42.748; 234, Taf. 43.750, 752.

23B. Unbek. FO in Nordbulgarien. Breit-blattförmig; Kügelchen an der Basis; davon ausgehend 3 dreiblättrige Palmetten in kreuzförmiger Anordnung. Nur das Mittelblatt der oberen Palmette berührt die Randleiste; rückseitig zwei Nieten unterhalb der Querachse. 2,5×1,9 cm; Br. Mus. des Zweiten Bulgarischen Reiches Veliko Tărnovo, Inv.-Nr. 6552.

Lit.: STANilov 1992, 51 f. mit Abb. 4.

Parallelen zu Nr. 23B:

a. Jakimovo (obšt. Jakimovo, obl. Montana, BG). In der Kulturschicht des 9.-10. Jh. der Festung. Kontur seitlich stärker gerundet; Ornament identisch. $\operatorname{Br}(?)$.

Lit.: MiLČEV 1966, 348 f. mit Abb. 11 (bulgarische Fassung: 34 f. mit Abb. 12).

b. Provadija (obšt. Provadija, obl. Varna, BG). LF von der Hochebene nördlich der antiken und spätmittelalterlichen Festung Oveč. Mittelblätter verwaschen.

Arch. Mus. Varna, Inv.-Nr. IV 2876.

Lit.: Pletn'ov-Pavlova 1994/1995, 182, Nr. 742; 233, Taf. 42.742.

c. Ruse. Unbekannte Fundstelle. Kontur seitlich stärker gerundet; Mittelblätter der Palmetten nicht von unterem Blattpaar abgegrenzt. Cu (?); ca. $2,6 \times 2,0 \mathrm{~cm}$.

Lit.: FeHÉr 1939, 85, Abb. 52; FeHÉr 1940, 51, Abb. 20; Taf. 26; FeHÉR-Göllner 1942, Abb. 2 mit Beschlägen unten links (Ruszcsuk).

d. Središte (obšt. Kajnardža, obl. Ruse, BG). LF von der altbulg. Festung. Palmetten ohne Stile; Seiten verschmolzen. Cu.

Hist. Mus. Silistra, Inv.-Nr. III 1788.

e. Unbek. FO in der Ludogorie. Kontur oben geschweift wie bei Nr. 23A. Ca. 2,4×1,9 cm; Cu.

Hist. Mus. Kubrat, ohne Inv.-Nr.

Lit.: STANiLov 1992, 51 f. mit Abb. 3.

$f-i$. Unbek. FO in der Umgebung von Varna. 4 Exemplare. 
Arch. Mus. Varna, Inv.-Nr. IV 2472-2473, 2591, 3045.

Lit.: Pletn'ov-Pavlova 1994/1995, 182, Nr. 743-746; 233, Taf. 42.743-746.

23C. Unbek. FO in Nordostbulgarien. Schlank-herzförmig; Kügelchen an der Basis; Aufbau der Verzierung wie Nr. 23A; rückseitig 2 Nieten auf der Längsachse, weitere 2 Nieten auf gleicher Höhe an der Basis sind verloren gegangen. $2,2 \times 1,9 \mathrm{~cm} ; \mathrm{Cu}$.

Hist. Mus. Šumen, Inv.-Nr. 4659.

Lit.: StANILOv 1992, 51 f. mit Abb. 7.

Parallelen zu Nr. 23C:

a. Dobroplodno (obšt. Vetrino, obl. Varna, BG). Klein und stilisiert.

Arch. Mus. Varna, Inv.-Nr. IV 4172.

Lit.: Pletn'ov-PaVlova 1994/1995, 182, Nr. 775; 233, Taf. 42.775.

b. Izvorovo (obšt. General Toševo, obl. Varna, BG). LF von der altbulg. Festung. Nur halb so groß; Ornament feingliedriger. Cu.

Hist. Mus. Dobrič, Inv.-Nr. As 3073.

c. Pliska. LF von der inneren Stadt. Schlanker; feingliedriges Ornament. Ca. 1,8×2,8 cm; Cu.

Filiale Šumen des Arch. Inst. Mus., ohne Inv.-Nr.

Lit.: STANILOv 1992, 51 f. mit Abb. 6.

d. Popina (obšt. Silistra, obl. Ruse, BG). LF von der altbulg. Festung „Kaleto“. Spitze fehlt; an der Basis zusätzliche Randleiste; Palmetten nicht unterteilt; breiter Stil. Ca. $2,1 \times 2,9 \mathrm{~cm}$.

Hist. Mus. Silistra, ohne Inv.-Nr.

Lit.: STANILOv 1992, 51 f. mit Abb. 8.

e. Rujno (obšt. Dulovo, obl. Ruse, BG). LF von der altbulg. Festung. 4 Nieten. Cu.

Hist. Mus. Silistra, Inv.-Nr. III 2256.

f. Rujno. LF von der altbulg. Festung. 4 Nieten, davon 2 verloren. $\mathrm{Cu}$.

Hist. Mus. Dulovo, ohne Inv.-Nr.

g. Smirnenski (obšt. Vjatovo, obl. Ruse, BG). LF von der altbulg. Festung. Cu.

Hist. Mus. Razgrad, Inv.-Nr. 4333.

h. Veliki Preslav. Innere Stadt, nordwestlich des Palastes. 3 Nieten. Cu.

Mus. „Veliki Preslav“, Fund-Nr. 26229.

$i$. Unbek. FO. Kleine dreieckige Öse anstelle des Kügelchens an der Basis; im Zwickel oberhalb des Mittelblattes der mittleren Palmette Blattfortsatz mit schwalbenschwanzförmigem Ende. $2,0 \times 2,8 \mathrm{~cm} ; \mathrm{Cu}$.

Nat. Arch. Mus., ohne Inv.-Nr.

Lit.: STANILOV 1992, 51 f. mit Abb. 9.

j. Unbek. FO in der Ludogorie. Sehr breite Randleiste; Palmettenblätter untereinander und vom Stamm deutlich abgegrenzt. Ca. $2,3 \times 2,8 \mathrm{~cm} ; \mathrm{Cu}$.

Hist. Mus. Kubrat, ohne Inv.-Nr.

Lit.: STANILOV 1992, 51 f. mit Abb. 1.

$k$. Unbek. FO in der südlichen Dobrudscha. Schmalere Randleiste. $\mathrm{Cu}$.

Hist. Mus. Dobrič, Inv.-Nr. As 1493.

l. Unbek. FO in der südlichen Dobrudscha. Feingliedriges Ornament; Mittelblatt der mittleren Palmette isoliert. Cu.

Hist. Mus. Dobrič, Inv.-Nr. As 2195.

$m-q$. Unbek. FO in der Umgebung von Varna. 5 Exemplare.

Arch. Mus. Varna, Inv.-Nr. IV 2475-2477, 2479, 3046.

Lit.: PletN'ov-PAVlova 1994/1995, 182, Nr. 736-740; 233, Taf. 42.736-740.

24A. Veliki Preslav. Innere Stadt, westlich des Verwaltungsgebäudes (Quadrant 12; Tiefe 1,2 m). Breit-winkelförmig; Perlbandimitation parallel zum Rand; im Mittelfeld rhomischer Einschnitt, von dem zwei gravierte Ranken ausgehen, die in jeweils zwei Blättern (Halbpalmetten) enden; rückseitig ehemals 2 Nieten an den Ecken und 1 Niet an der Spitze. 2,2×1,75 cm; Blei.

Mus. ,Veliki Preslav“, ohne Inv.-Nr.

Lit.: StANILOV 1993b, 152, Abb. 1.6; 155, Abb. 6.1.

Parallelen zu Nr. 24A:

$a-b$. Veliki Preslav. Palast, Schicht des 9./10. Jh. 2 Exemplare. Etwas breiter proportioniert.

Lit.: MaVrodinov 1959, 227-229 mit Abb. 268-269.

Nachtrag: Ein bei PLETN'ov 1997, 88, Taf. 5.8 abgebildetes Stück ist wohl nur eine schlechte Umzeichnung von Nr. 24A. 
24B. Unbek. FO in Nordostbulgarien. Schlank-winkelförmig. Aufbau wie Nr. 24A; zusätzlicher kleiner Rhombus zwischen Ranken und Einschnitt; rückseitig 2 nach außen gebogene Dorne in den Ecken und 1 verlorener Dorn an der Spitze. 1,9×1,65 cm; Cu.

Hist. Mus. Šumen, Inv.-Nr. 2986

Lit.: Stanilov 1993b, 152, Abb. 1.5; 154 f., Abb. 3.5; Abb. 6.1

Parallele zu Nr. 24B:

a. Unbek. FO in Nordostbulgarien. Abweichendes Ornament; Bekrönung anstelle des kleinen Rhombus. Br.

Hist. Mus. Šumen, Inv.-Nr. 2286.

Nachtrag: Ein bei PletN'ov 1997, 88, Taf. 5.14 abgebildetes Stück ist wohl nur eine schlechte Umzeichnung von Nr. 24B.

\section{Riemenzungen (Abb. 5)}

25. Unbek. FO in Nordbulgarien. Einschnitt mit Kügelchen am oberen Ende; Mittelgrat; sonst unverziert; rückseitig 4 Nieten mit runden Blechen, davon 2 an den oberen Ecken und 2 auf der unteren Hälfte der Längsachse. 5,9×1,5 cm; Cu (Spuren von Silberüberzug).

Mus. des Zweiten Bulgarischen Reiches Veliko Tărnovo, Inv.-Nr. 6753.

Parallelen zu Nr. 25:

a. Goleš (obšt. Kajnardža, obl. Ruse, BG). LF von der altbulg. Festung. Kleiner und mit abweichenden Proportionen; Kanten gewölbt. Cu.

Hist. Mus. Silistra, Inv.-Nr. III 929.

b. Kiten (obšt. Provadija, obl. Varna, BG). LF von der altbulg. Festung. Asymmetrisch; Einschnitt wenig tief und Kügelchen flach. $3,9 \times 1,5 \mathrm{~cm}$; $\mathrm{Cu}$ (Spuren von Weißmetall auf der Vorderseite).

Arch. Mus. Varna, Inv.-Nr. IV 3142.

Lit.: Pletn'ov-Pavlova 1992, 169 f.; 197, Taf. 3.20; 208, Nr. 20.

c. Popina (obšt. Silistra, obl. Ruse, BG). LF von der altbulg. Festung „Kaleto“. Sehr viel kleiner; Fortsatz länglich. Cu.

Hist. Mus. Silistra, ohne Inv.-Nr.

d. Slavejkovo (obšt. Provadija, obl. Varna, BG). LF von der altbulg. Festung „Kjučuk hisar“. Gerader Abschluss mit rundlichem Fortsatz (darunter kein Einschnitt). 3,45×1,15 cm; Cu (?).

Arch. Mus. Varna, Inv.-Nr. IV 3540.

Lit.: Pletn'ov-PaVlova 1992, 169 f.; 197, Taf. 3.19; 208, Nr. 19.

e. Unbek. FO in der südlichen Dobrudscha. Kleiner; flach; nur kurze Rille unterhalb des Kügelchens. Cu.

Hist. Mus. Dobrič, Inv.-Nr. As 1767.

26. Unbek. FO in der südlichen Dobrudscha. Oberer Abschluss gerade mit mittigem Einschnitt und kugelförmigem Fortsatz; auf der Längsachse 3 eingravierte vegetabile Ornamente ( 2 zweiblättrige Ranken/Halbpalmetten von einem Stamm ausgehend); rückseitig je ein Dornpaar in der Mitte und am oberen Abschluss; weiterer Dorn an der Spitze. 5,2×1,45 cm; Cu.

Hist. Mus. Dobrič, Inv.-Nr. As 1755.

Parallelen zu Nr. 26:

a. Odărci (obšt. Dobrič, obl. Varna, BG). Altbulg. Schicht der frühbyzantinischen Festung. Schwalbenschwanzförmiger oberer Abschluss; 4 Ranken (untere Blattpaare größer und tiefer). Br.

Hist. Mus. Dobrič, ohne Inv.-Nr.

Lit.: DončEva-PetKova 1987, 76 f. mit Abb. 8d; DonČEva-PetKova 1999, 164, Nr. 696, Taf. 51, 696; $52,696$.

b. Sredno selo (obšt. Vertino, obl. Varna, BG). LF von der Flur „Babuka“. Kürzer und oben breiter; oberer Abschluss schwalbenschwanzförmig; ohne Fortsatz; 2 Ranken, an der Spitze nur Volute. $3,55 \times 1,6 \mathrm{~cm}$; Cu (?).

Arch. Mus. Varna, Inv.-Nr. IV 2115.

Lit.: Pletn'ov-PaVlova 1992, 174; 199, Taf. 5.39; 211, Nr. 39; PletN'ov 1997, 88, Taf. 5.4.

c. Unbek. FO in der südlichen Dobrudscha. Kürzer; gerundete Spitze; 4 unterschiedliche Ranken (bis auf zweitunterste beschädigt). Cu.

Hist. Mus. Dobrič, Inv.-Nr. As 1758.

27. Unbek. FO in der südlichen Dobrudscha. Auf der Längsachse 4 gravierte hängende Voluten, abwechselnd mit kurzem und langem Stamm; oberer Abschluss jeweils ein Rhombus; oben einfache Volute und statt des Stammes eine Verzweigung längs des schwalbenschwanzförmigen Einschnittes; an der Spitze isolierter Rhombus; rückseitig Nietenpaar am oberen Abschluss und je ein Niet mit runder Scheibe in der Mitte und an der Spitze. $6,9 \times 1,65 \mathrm{~cm} ; \mathrm{Cu}$.

Hist. Mus. Dobrič, Inv.-Nr. As 1753. 
28. Veliki Preslav. Lesefund von der äußeren Stadt. Leicht zackige Kontur; am oberen Abschluss gerade Einsattelung mit Kügelchen in der Mitte; Mittelgrat; in der oberen Hälfte eingravierte Palmette. 3,8×2,0 cm; Cu.

Privatsammlung Borislav Brajkov, Preslav.

29. Veliki Preslav. Südtor (Quadrant 142). Breit proportioniert mit wenig akzentuierter Spitze und seitlicher Verstärkung; unterhalb des geraden oberen Abschlusses ein von einer schwachen Ritzlinie markiertes unregelmäßiges rechteckiges Feld, das auch die drei Nietlöcher umschließt; die übrige Fläche der Vorderseiten ist von einem gravierten, asymmetrischen Rankenmuster bedeckt. $3,6 \times 2,2 \mathrm{~cm} ; \mathrm{Cu}$.

Mus. „Veliki Preslav“, Fund-Nr. 18216.

30. Alekovo (obšt. Alfamar, obl. Ruse, BG). LF von der altbulg. Festung. Fragmentiert (oberer Abschluss fehlt); Reliefverzierung mit 3 gerahmten, tropfenförmigen Medaillons, von deren oberem Ende zwei Fortsätze (Stabranken) abgehen; rückseitig oben und unten Nieten mit runden Blechscheiben. $4,6 \times 1,3 \mathrm{~cm}$; Br. (massiv).

Hist. Mus. Silistra, Inv.-Nr. III 1130.

31. Veliki Preslav. Ostmauer. Fragmentiert (nur ein gutes unteres Drittel); spitz zulaufend; schmale Randleiste; im Zentrum des sich wiederholenden Verzierungsmotivs eine dreiblättrige Palmette, die von zwei Ranken mit eingeschobener S-förmiger Partie seitlich umrahmt wird; rückseitig an der Spitze Nietrest. $3,2 \times 1,75 \mathrm{~cm} ; \mathrm{Cu}$.

Mus. „Veliki Preslav“, Fund-Nr. 831.

32. Rujno (obšt. Dulovo, obl. Ruse, BG). LF von der altbulg. Festung. Fragmentiert (nur Oberteil). Am oberen Abschluss schwacher Einschnitt und sehr kleines Kügelchen; oben zwei Halbpalmetten, deren gemeinsamer Stamm sich zu einer rhombischen Rankenschlaufe verzweigt; in deren äußeren Zwickeln nochmals Halbpalmetten (?); rückseitig am oberen Abschluss 2 Nieten (eine verloren). 3,25× 1,8 cm; Cu.

Hist. Mus. Silistra, Inv.-Nr. III 2294.

\section{ABKÜRZUNGEN}

ActaHistHung

AOR

BiArh

Byzantion

FolArch

GMSB

GNAM

IAI

INIM

INMVarna

IMJIB

IMSB

MCA

$\mathrm{RPr}$

SA

SlAnt

\author{
Acta Historica Academiae Scientiarum Hungaricae (Budapest) \\ Archeologičeski otkritija i razkopki (Sofija) \\ Biblioteca de arheologie (Bucureşti) \\ Byzantion. Revue Internationale des Études Byzantines (Bruxelles) \\ Folia Archaeologica (Budapest) \\ Godišnik na muzeite ot Severna Bălgarija (Varna) \\ Godišnik na Nacionalnija archeologičeski muzej (Sofija) \\ Izvestija na Arheologičeski Institut pri BAN (Sofija) \\ Izvestija na Nacionalen istoričeski muzej (Sofija) \\ Izvestija na Nardonija muzej - Varna (Varna) \\ Izvestija na muzeite ot jugoiztočna Bălgarija (Sofija) \\ Izvestija na muzeite v severozapadna Bălgarija (Pleven) \\ Materiale şi Cercetări Arheologice (Bucureşti) \\ Razkopki i Proučvanija (Sofija) \\ Sovetskaja archeologija (Moskva) \\ Slavia Antiqua (Poznań)
}

\section{ANGELOV-STANČEV 1955}

ANTONOVA 1986

ANTONOVA-VItLJANOV 1985

ARNE 1914

AtANASOv 1985

ATANASOV-JORDANOV 1994

BAJALOVIĆ-HADŽI-PEŠIĆ 1984

\section{LITERATUR}

= N. ANGelov-St. StančEv: Graždanska postrojka v dolinata Bjal brjag pri Preslav. IAI 20 (1955) 429-444.

= V. ANTONOVA: Starobălgarski kolanni ukrasi ot Okrăžnija istoričeski muzej v Šumen. GMSB 12 (1986 [1989]) 49-54; Taf. 1-2.

= V. Antonova-St. VitLJAnov: Pliska. Zapadna krepostna stena - sektor Sever (Archeologičeski razkopki 1973-1975 g.). Pliska-Preslav 4 (1985) 44-78.

$=$ T. A. J. Arne: La Suede et l'Orient. Upsala 1914.

= G. AtAnASOv: Srednovekovna kolanna garnitura ot s. Središte, Silistrenski okrăg. Dobrudža 2 (1985) 129-135; Taf. 13.1-2.

= G. AtANASOV-I. JoRDANov: Srednovekovnijat Vetren na Dunav. Silistra-Šumen 1994.

= M. BAJALOVIĆ-HADŽI-PEŠıć: Nakit VIII-XVIII veka u Muzeju grada Beograda. Muzej Grada Beograda, serija - zbirke i legati. Katalog 15. Beograd 1984. 
BÁLINT 1991

BÁLINT 1992

BARNEA-MITREA 1959

BARTHA 1972

BÓNA 1997

BONEV 1993

BUDINSKÝ-KRIČKA-FETTICH 1973

ČAnGOVA 1957

ČAngOVA 1983

ČAngOva 1992

Capidava 1

CHALIKOVA-KaZAKOV 1977

DAIM 2000

DeČEV 1922

DiACONU 1969

DiACONU-VÎLCEANU 1972

DiENES 1959

DiEnes 1960

DIENES 1964

DIENES 1972

DiENES 1973

DIETHART-KISLINGER 2000

Dimitrov 1997

Dimitrov 1995

Dinogetia 1

DonČEVA-PETKOVA 1986

DonČEVA-PETKOVA 1987

DoNČEVA-PETKOVA 1992

DonČEVA-PETKOVA 1993

DonČEVA-PETKOVA 1999

DŽINGOV 1982

ÉRY 1968

FEHÉR 1939

FEHÉR 1940
= Cs. BÁlint: Südungarn im 10. Jahrhundert. Studia Archaeologica 11. Budapest 1991.

= Cs. BÁLINT: Kontakte zwischen Iran, Byzanz und der Steppe. In: F. Daim (Hrsg.): Awarenforschungen Bd. 1. Archaeologia Austriaca, Monographien 1 = Studien zur Archäologie der Awaren 4. Wien 1992, 309-496.

= I. BARnEA-B. MitreA: Săpăturile de salvare de la Novidunum (Isaccea). MCA 5 (1959) 461-473.

= A. BARTHA: Istoki vengerskoj kul'tury X v. In: A. K. Ambroz-I. Ėrdeli [Erdélyi] (Hrsg.): Problemy archeologii i drevnej istorii Ugrov. Moskva 1972, 118-127, $301 \mathrm{f}$.

= I. BóNA: István Dienes (1929-1995). ActaArchHung 49 (1999) 327-343.

= ST. BonEv: Architekturen kompleks v Preslav. Preslav 4 (1993) 56-78.

$=$ V. BUDINSKÝ-KRIČKA-N. FETTICH: Das altungarische Fürstengrab von Zemplín. Archaeologica Slovaca - Monographiae 2. Nitra 1973

= J. ČANGOvA: Tărgovski pomeštenija kraj južnata krepostna stena v Preslav. IAI 21 (1957) 233-290.

= J. ČANGOvA: Kăm proučvaneto na starobălgarskata metaloplastika ot IX-X v. Preslav 3 (1983) 198-202.

= J. ČAngova: Pernik 3: Krepostta Pernik VIII-XIV v. Sofija 1992.

= G. Florescu-R. Florescu-P. Diaconu: Capidava 1. BiArh 2. Bucureşti 1958.

= E. A. Chalikova-E. P. Kazakov: Le cimetiere de Tankeevka. In: I. Erdélyi (red.): Les anciens Hongrois et les ethnies voisines a l'est. Studia Archaeologica 6. Budapest 1977, 21-221.

= F. DAIM: „Byzantinische“ Gürtelgarnituren des 8. Jahrhunderts. In: F. Daim (Hrsg.): Die Awaren am Rand der byzantinischen Welt. Monographien zur Frühgeschichte und Mittelalterarchäologie 7. Innsbruck 2000, 77-204.

= D. DEČEv: Responsa Nicolai Papae I. ad consulta Bulgarorum anno 866 / Otgovoritě na Papa Nikolaj I. po dopitvanijata na Bălgaritě. Sofija 1922.

= P. DiAconu: Einige Zierrate und Zaumzeugstücke von Păcuiul lui Soare. Dacia N.S. 13 (1969) 501-506.

= P. DiACONU-D. VîlcEAnU: Păcuiul lui Soare 1: Cetatea bizantină. BiArh 18. Bucureşti 1972.

= I. DiEnES: A perbetei lelet. Milyen volt a honfoglaló magyarok öve? [Der Fund von Perbete. Wie war der Gürtel der landnehmenden Ungarn?]. ArchÉrt 86 (1959) 145-158; Taf. 27-30.

= I. DiENES: Honfoglaló magyarok sírjai Nagykőrösön [Die Gräber der landnehmenden Ungarn in Nagykőrös]. ArchÉrt 87 (1960) 177-187.

= I. DIENES: A karancslapujtői honfoglalás kori öv és mordvinföldi hasonmása [Der landnahmezeitliche Gürtel von Karancslapujtő und sein Pendant vom Land der Mordwinen]. ArchÉrt 91 (1964) 18-40.

= I. DiENES: Die Ungarn um die Zeit der Landnahme. Budapest 1972.

= I. DiEnES: Honfoglalás kori veretes tarsoly Budapest-Farkasrétről [Beschlagverzierte landnahmezeitliche Tasche von Budapest-Farkasrét]. FolArch 24 (1973) 177-217.

= J. DieTharT-E. KislingeR: „Bulgaren“ und „Hunnen“ in Ägypten. In: F. Daim (Hrsg.): Die Awaren am Rand der byzantinischen Welt. Monographien zur Frühgeschichte und Mittelalterarchäologie 7. Innsbruck 2000, 9-14

= CH. Dimitrov: Bălgaro-ungarski otnošenija prez srednovekovieto. Manuskript. Sofija 1997. (Mit freundlicher Genehmigung des Autors; dort sämtliche Literatur zur Problematik.)

= JA. Dimitrov: Cărkva i nekropol văv Vănšnija grad na Pliska (kraja na X-XI v.). Pliska-Preslav 7 (1995) 42-70

= G. Stefan-I. BARnEA-M. ComŞA-E. ComşA: Dinogetia. Aşezarea feudală timpurie de la BisericuţaGarvăn. Bd. 1. BiArh 13. Bucureşti 1967.

= L. DonČEva-PetKova: Selište ot vremeto na Părvoto bălgarsko carstvo pri s. Odărci, tolbuchinsk okrăg. In: M. Apostolski (Hrsg.): Zbornik posveten na Boško Babić / Mélange Boško Babić. Prilep 1986, 165-168.

= L. DonČEVA-PetKova: Sur la chronologie du site bulgare médiéval pres du village Durankulak, département de Tolbuhin. In: Dobrudža. Études ethno-culturelles. Sofia 1987, 69-82.

= L. DonČEvA-PetKova: Dva modela za kolanni aplikacii. In: Prinosi kăm Bălgarskata archeologija 1. Sofija 1992, 210-213.

= L. DončEva-Petkova: Srednovekoven nekropol pri selo Odărci, Dobričko (Predvaritelno săobštenie). Dobrudža 10 (1993) 134-144.

= L. DončEva-PetKova: Odărci 1. Selište ot Părvoto bălgarsko carstvo. Sofija 1999.

= G. DžINGOv: Archeologičeski izsledvanija v zapadnata čast na ukrepenoto selište pri Stărmen (sektor I, III, V i VI). In: MichaJLOV et al. 1982, 9-69.

$=\mathrm{K}$. K. ÉRY: Reconstruction on the tenth century population of Sárbogárd on the basis of archaeological and anthropological data. Alba Regia 8/9 (1968) 93-147.

= G. FEHÉR: Roljata i kulturata na Prabălgarite. Sofija 1939.

= G. FEHÉR: A bolgár-törökök szerepe és műveltsége [Die Rolle und Kultur der Bulgar-Türken]. Budapest 1940 
FEHÉR 1942

FEHÉR-GÖLLNER 1942

Fеттісн 1931

FetTICH 1937

FIEDLER 1992

FIEDLER 1995

FIEDLER 1996

FIEDLER 1997

FoDOR 1996

FoDOR et al. 1998

GEORGIEV 1993

GEORGIEVA 1963

Goossens 1935

Gospodinov 1948

GoŠEV 1932

GYÖRFFY 1985

HAMPEL 1905

HANULIAK 1994

HEISER 1979

HENSEL 1980

INKOVA 2004

INKOVA 2005

Istorija na Bălgarija 2

IvANOV 1996

ЈАСОВ 1927

JANSSON 1986

JóSA 1914

Joтоv 1993

JoTOV-ATANASOV 1998

JUHÁSZ 1996

JURUKOVA 1992

Konstantin Porphyrogennetos

KovÁcs 1989
= G. FeHÉR: Oblekloto i orăžieto na starata bălgarska vojska. Sofija 1942.

= G. FEHÉR-A. GöLLNER: Magyarok és bolgárok [Ungarn und Bulgaren]. Budapest 1942.

= N. FEтTich: Adatok a honfoglaláskor archaeológiájához [Angaben zur Archäologie der Landnahmezeit]. ArchÉrt 45 [59] (1931) 48-112/119.

= N. Fetтich: Die Metallkunst der landnehmenden Ungarn. Archaeologia Hungarica 21. Budapest 1937.

= U. FIEDLER: Studien zu Gräberfeldern des 6. bis 9. Jahrhunderts an der unteren Donau. Universitätsforschungen zur Prähistorischen Archäologie 11. Bonn 1992.

= U. FIEDLER: Die Gürtelbesatzstücke von Akalan. Ihre Funktion und kulturelle Stellung. IAI 38 (1995) 31-47.

= U. FIEDLER: Die spätawarenzeitlichen Gürtelbestandteile vom Typ Vrap-Ersëke aus Velino (obl. Varna). Germania 74 (1996) 248-264.

= U. FIEDLER: Nochmals zur Datierung von Grab 5 in Hügel III von Madara. In: R. Rašev (Hrsg.): Problemi na Prabălgarskata istorija i kultura 3. Četvirta srešta po prabălgarska archeologija i istorija, Šumen 1996. Šumen 1997, 125-140.

= I. FODOR (ed.): The ancient Hungarians. Exhibition catalogue. Budapest 1996.

= I. FodOR-L. RÉVÉSZ-M. Wolf-I. M. NEPPER-J.-Y. MARIN (éd.): La Hongrie de l'an Mil. Naissance d'une nation européenne. Ausstellungskatalog Caen. Milano 1998.

= P. GEORGIEv: Martiriumăt v Pliska i načaloto na christijanstvoto v Bălgarija. Sofija 1993.

= S. GEORGIEVA: K voprosu ot t.n. ,prabolgarskoj“ chudožestvennoj promyšlennosti. SlAnt 10 (1963) 331-365.

= R. Goossens: Les Bulgares et le commerce du cuir. - Rezension von Gy. Moravcsik. Byzantion 10 (1935) $754 \mathrm{f}$.

= J. GosPodinov: Razkopki iz dolinata na Bjal brjag v Preslav. RPr 3 (1948) 73-77.

= I. GošEv: Oblěkloto na starobălgarskitě monasi. Izvestija na Narodnija etnografski muzej v Sofija 10-11 (1932) 39-72.

= Gy. GYÖRFFY: Landnahme, Ansiedlung und Streifzüge der Ungarn. ActaHistHung 31 (1985) 231-270.

= J. HAMPEL: Alterthümer des frühen Mittelalters in Ungarn. Braunschweig 1905.

= M. HANUliaK: Malé Kosihy I. Pohrebisko z 10.-11. storočia. Materialia Archaeologica Slovaca 12 Nitra 1994.

= L. HeISER: Die Responsa ad consulta Bulgarorum des Papstes Nikolaus I. (858-867). Ein Zeugnis päpstlicher Hirtensorge und ein Dokument unterschiedlicher Entwicklungen in den Kirchen von Rom und Konstantinopel. Trierer Theologische Studien 35. Trier 1979.

= W. HeNSEL (Hrsg.): Starmen nad Jantrą (Bułgaria). Badania archeologiczne w latach 1961-1964 i 1967-1968. Wrocław-Warszawa-Kraków-Gdańsk 1980.

= M. INKOVA: Kolanite na grupata „Vrap“ v Bălgarija (Funkcionalna charakteristika na okovite za kolani i opit za socializacija). INIM 14 (2004) 150-182.

= M. INKovA: Avarski inovacii v starobălgarskata kultura? In: K. Popkonstaninov-B. Borisov-R. Kostova (Hrsg.): Prof. d.i.n. Stančo Vaklinov i srednovekovnata bălgarska kultura. Konferenz Veliko Tărnovo 2001. Veliko Tărnovo 2005, 99-112.

= D. ANGelov et al. (Hrsg.): Istorija na Bălgarija. Tom. 2: Părva bălgarska dăržava. Sofija 1981.

= P. IvANOv: Krepostta golemijat grad pri Staro selo, obština Mezdra (Terenno proučvane prez 1994 g.). IMSB 24 (1996) 73-86.

= G. JACOB: Arabische Berichte von Gesandten an germanische Fürstenhöfe aus dem 9. und 10. Jahrhundert. Berlin-Leipzig 1927.

= I. JANSSON: Gürtel und Gürtelzubehör vom orientalischen Typ. In: G. Arwidsson (Hrsg.): Birka II:2. Systematische Analysen der Gräberfunde. Stockholm 1986, 77-108.

= A. JósA: Honfoglaláskori emlékek Szabolcsban [Landnahmezeitliche Denkmäler in Szabolcs]. ArchÉrt 34 (48) (1914) 311-316.

= V. Jotov: Nachodka ot remăčni ukrasi ot rannosrednovekovnoto selište do selo Debrene, Dobričko. Dobrudža 10 (1993) 123-130.

= V. Jotov-G. Atanasov: Skala. Krespost ot X-XI vek do s. Kladenci, Tervelsko. Sofija 1998.

= I. JuHÁsz: X-XI. századi temetkezések Békés megye északi területén [Bestattungen aus den 10.-11. Jahrhunderten auf dem nördlichen Gebieten des Komitates Békés]. A Békés Megyei Múzeumok Közleményei 16 (1996) 157-173.

= J. JURUKOVA: Săkrovišteto ot Akalan. Numizmatika i Sfragistika 1 (1992) 10-16.

= Konstantin Porphyrogennetos: De Administrando imperio. Hrsg. von Gy. Moravcsik und R. J. H. Jenkins. Magyar-görög tanulmányok 29. Budapest 1949.

= L. KovÁcs: Münzen aus der ungarischen Landnahmezeit. Fontes Archaeologici Hungariae 19. Budapest 1989. 
KUNIK-RoZEN 1878

KUZEV 1980

LÁSZLÓ 1988

Liutprand von Cremona

MĂRGHITAN 1965

MARTIN 1990

MaVRodinov 1936

MaVRodinOv 1959

Melamed 1993

MesterháZy 1994

MichaJlov 1970

MichaJlov 1979

MiCHAJLOV et al. 1982

Mujatev 1926/1927

Mujatev 1932

MILČEV 1966

MILČEV 1979

MORAVCSIK 1935

OGNENOVA-GeORGIEVA 1955

OvČAROV 1985

OvČAROV-ToTEV-PoPOV 1980

Pletneva 1992

PletN’ov 1997

PletN'ov-PaVlova 1992

Pletn'ov-PaVlova 1994/1995

Popkonstantinov-AtanAsov 1993

PosTICĂ 1994

Pseudo-Mauricius

RAŠEV 1984

RAŠEV 1990

RAŠEV 1992

RAŠEV 1996
= A. KunIK-B. Rozen: Izvestija al-Bekri i drugich avtorov o Rusi i Slavjanach. Sankt Petersburg 1878.

= A. KUZEV: Rannesrednevekovoyj nekropol pod Varnoj. In: Rapports du IIIe Congres International d'Archéologie Slave, Bratislava 1975. Bd. 2. Bratislava 1980, 259-263.

= GY. LÁsZló: Árpád népe [Das Volk von Árpád]. Budapest 1988.

= Liutprand von Cremona: Werke. In: Quellen zur Geschichte der sächsischen Kaiserzeit. Hrsg. von A. Bauer und R. Rau. Ausgewählte Quellen zur deutschen Geschichte des Mittelalters 8. Darmstadt 1972, 233-589. - Vgl. Liudprandi relatio de legatione Constantinopolitana a. 968-969. Hrsg. von R. Pertz. Monumenta Germaniae Historica A 1.3 (Scriptores 3). Hannoverae 1839, 347-363.

= L. MăRghitan: Mormînte din epoca feudală timpurie descoperite la Seitin. SCIVA 16 (1965) 581-586.

= M. MARTIN: Awarische und germanische Funde in Männergräbern von Linz-Zizlau und Környe. Ein Beitrag zur Chronologie der Awarenzeit. In: Internationale Konferenz über das Frühmittelalter, Szekszárd 1989= A Wosinsky Mór Múzeum Évkönyve 15 (1990) 65-90.

= N. MAVRodinov: Prabălgarskata chudožestvena industrija. In: Madara 2. Sofija 1936, 154-273.

= N. MaVRodinOv: Starobălgarskoto izkustvo. Sofija 1959.

= K. MelamED: Kolekcija srednovekovni predmeti (Chisar Kale, s. Balik, Dobričko). GNAM 9 (1993) 163-167; Taf. 1-4.

= K. Mesterházy: Die Landnahme der Ungarn aus archäologischer Sicht. In: M. Müller-WilleR. Schneider (Hrsg.): Ausgewählte Probleme europäischer Landnahmen des Früh- und Hochmittelalters. Vorträge und Forschungen 41. Sigmaringen 1994, 23-65.

$=$ St. MichaJlov: Une nouvelle inscription protobulgare dans l'ancienne capitale Pliska. Byzantion 40 (1970) 421-434.

= ST. MichaJlov: Kamennite sarkofazi do Goljamata bazilika v Pliska. Pliska-Preslav 1 (1979) 44-59.

$=$ ST. MichaJlov et al $:$ Rannosrednovekovnoto selište pri selo Stărmen. RPr 7. Sofija 1982.

= K. MuJATEV: Starobălgarski zlaten nakit ot Madara. IAI 4 (1926/1927) 14-25.

= K. MusATEv: Krảglata cărkva v Preslav. Izdanija na Narodnija archeologičeski muzej 25. Sofija 1932.

= A. MiLČEv: Die frühmittelalterlichen bulgarischen Schmucksachen und Kreuze-Enklopien aus Nordwestbulgarien. S1Ant 13 (1966) 325-357. Bulgarische Fassung: Archeologija 5 (1963) H. 3, 22-37.

= A. MILČEv: Materiali, otkriti v zanajatčijskite i tărgovskite pomeštenija severno ot južnata porta na Vătrešnija grad na Pliska. Pliska-Preslav 1 (1979) 139-176.

= Gy. MoravcsiK: Der Name der Bulgaren in einem griechischen Papyrus. Körösi Csoma-Archivum. Ergänzungsband 1 (1935) H. 2, 119-128.

= L. OgnenOvA-S. GeORgIEva: Razkopkite na manastira pod Vălkašina v Preslav prez 1948-1949 g. IAI 20 (1955) 373-417.

= D. OvČARov: Razkopki i proučvanija na iztočnata stena na Vătrešnija grad v Preslav (1970-1976). Pliska-Preslav 4 (1985) 132-160.

= D. OvČArov-T. Totev-A. Popov: Stari bălgarski stolici. Pliska - Veliki Preslav - Tărnovgrad. Sofija 1980.

= S. Pletneva: Stratigrafičeskie issledovanija Pliski (raboty sovetskogo otrjada 1977-1980 gg.). Pliska-Preslav 5 (1992) 35-63.

= V. PletN'ov: Remăčni nakiti ot tipa Martinovka văv Varnenskija archeologičeski muzej. Bălgarite v Severnoto Pričernomorie 6 (1997) 75-88.

= V. PletN'ov-V. PAVlova: Rannosrednovekovni remăčni nakrajnici văv Varnenskija archeologičeski muzej. INMVarna 28 (43) (1992 [1995]) 158-223.

= V. PletN'ov-V. PAVlova: Rannosrednovekovni remăčni aplikacii văv Varnenskija archeologičeski muzej. INMVarna 30/31 (45/46) (1994/1995 [2000]) 24-239.

= K. Popkonstantinov-G. Atanasov: Olovna plastinka s nadpis ot X vek. Pliska-Preslav 6 (1993) 149-151.

= GH. PosticĂ: Românii din codrii Moldovei în evul mediu timpuriu. Chişinău 1994.

= Pseudo-Mauricius: Das Strategikon des Maurikios [griechisch-deutsch]. Hrsg. von G. T. Dennis und E. Gamillscheg. Corpus Fontium Historiae Byzantinae, Series Vindobonensis 17. Wien 1981.

$=$ R. RAŠEV: Za ezičeskija licev obraz (po povod njakoi kolanni ukrasi). In: Sbornik v pamet na prof. Stančo Vaklinov. Sofija 1984, 129-135.

= R. RAŠEV: Rannosrednovekovna bronzova toka ot Karamanite. Archeologija 32 (1990) H. 4, 46-50.

= R. RAŠEV: Bălgarskijat kolan prez VIII-IX v. GNAM 8 (1992) 242-248.

= R. RAŠEV: Madarskijat grob III/5 i analogite mu v Severnoto Černomorie. In: Stranici ot istorijat na Bălgarite v Severnoto Pričernomorie. Veliko Tărnovo 1996, 49-57. Erstmals abgedruckt in: Bălgarite v Severnoto Pričernomorie 2 (1993) 52-60. 
RAŠEV 1997

RAŠEV 2000

RAŠEV-STANILOV 1987

RÉVÉSZ 1996

RYBAKOV 1953

SCHULZE-DÖRRLAMM 1988

SLAVČEV 1991

SOMOGYI 1997

STANČEV 1984

STANČEV 1955

STANČEV 1960

STANČEV-IVANOV 1958

STANILOV 1990

STANILOV 1991a

STANILOV 1991b

STANILOV 1992

StANILOV $1993 a$

STANILOV 1993b

STANILOV 1994

STANILOV 1995

STANILOV 1999

STANILOV 2006

SZEGEDY 1960

TočíK 1968

Tос̌ík 1992

ToDOROVA 1989

TOTEV 1969

ToTEV 1976

ToTEV 1983

ToTEV 1986

ToTEV 1993

TOTEV 1998

Totev-STANILOV 1993

VAKLINOV 1977

VAKLINOV 1984

VAKLINOV-STANILOV 1981

VĂLOV 1982

VINOGRADOV 1983
= R. RAŠEv: Prăstenăt ot Vărbjane. In: R. Rašev (Hrsg.): Problemi na Prabălgarskata istorija i kultura 3. Četvirta srešta po prabălgarska archeologija i istorija, Šumen 1996. Šumen 1997, 180-185.

= R. RAŠEV: Bălgarite prez V-VII vek. Veliko Tărnovo 2000.

= R. RAŠEV-ST. STANILOV: Starobălgarskoto ukrepeno selište pri s. Chuma, Razgradski okrăg. RPr 18 (1987).

= L. RÉVÉSZ: A karosi honfoglalás kori temetők. Magyarország honfoglalás kori és kora Árpád-kori sírleletei 1. [Die landnahmezeitlichen Gräberfelder von Karos. Grabfunde der Landnahmezeit und der frühen Arpadenzeit in Ungarn 1]. Miskolc 1996.

= B. A. Rybakov: Drevnie Rusy. SA 17 (1953) 23-104.

= M. Schulze-DöRrLAMM: Untersuchungen zur Herkunft der Ungarn und zum Beginn ihrer Landnahme im Karpatenbecken. JRGZM 35 (1988) 373-478.

= P. SLAVČEv: Srednovekovni žilišta severozapadno ot patriaršijata na Carevec. GMSB 17 (1991) 61-65, Abb. 1-9.

= P. Somogyı: Byzantinische Fundmünzen der Awarenzeit. Monographien zur Frühgeschichte und Mittelalterarchäologie 5. Innsbruck 1997.

= D. STANČEv: Rannosrednovekoven nekropol do gara Tabačka. GMSB 10 (1984) 33-42, Abb. 1-5

= ST. STANČEV: Razkopki i novootkriti materiali v Pliska prez 1948 g. IAI 20 (1955) 183-227.

= ST. STANČEv: Materiali ot dvorcovija centăr v Pliska. IAI 23 (1960) 23-65.

= ST. StanČEv-St. Ivanov: Nekropolăt do Novi Pazar. Sofija 1958.

= ST. STANILOV: Kăm văprosa za tipologijata i chronologijata na njakoi starobălgarski remăžni ukrasi. Vekove (1990) 3, 89-94.

= ST. StAnILOv: Starobălgarski remăčni ukrasi ot Nacionalnija archeologičeski muzej. RPr 22 (1991) 5-70.

= ST. StanILOv: Pametnici na metaloplastika ot VIII-IX v. v Bălgarija. In: Problemi na prabălgarskata istorija i kultura 2 (Tagung Šumen 1990). Sofija 1991, 181-197.

$=$ ST. STANILOV: Proizchod i značenie na edin ornamentalen motiv ot rannosrednovekovnata metaloplastika. Problemi na izkustvoto 26, H. 2 (1992) 48-53.

= ST. STANILOv: Preslavskoto săkrovište i proizchodăt na starobălgarskata metaloplastika. Preslav 5 (1993) 138-164.

= ST. STANILOv: Dve grupi starobălgarski remăčni ukrasi ot severoiztočna Bălgarija. Pliska-Preslav 6 (1993) 152-163.

= ST. STANILOv: Starobălgarski remăčni ukrasi c pravoăgălna forma. In: Sbornik v čest na akad. Dimităr Angelov. Sofija 1994, 177-189.

= ST. Stanilov: Metalni garnituri za remăci i obleklo ot dvoreca văv Veliki Preslav. Pliska-Preslav 7 (1995) 110-135.

= ST. STANILOV: Starobălgarski garnituri za orăžie ot severoiztočna Bălgarija / Old-bulgarian armament fittings from north-eastern Bulgaria. Archeologičeski Vesti 2, H. 1 (1999) 33-40.

= ST. Stanilov: Chudožestvennijat metal na Bălgarskoto Chanstvo na Dunav 7-9 vek / Die Metallkunst des Bulgarenkhanats an der Donau (7.-9. vek.). Sofija 2006.

= E. SzEGEDY: Beiträge zur Metalltechnik der IX.-XI. Jahrhunderte in Ungarn. ActaArchHung 12 (1960) 299-330.

= A. ToČík: Altmagyarische Gräberfelder in der Südwestslowakei. Archaeologica Slovaca - Catalogi 3. Bratislava 1968.

= A. Tос̌ík: Materiály k dejinám južného Slovenska v 7.-14. storiočí. Študijné Zvesti 28 (1992) $5-250$.

= CH. Todorova (Hrsg.): Durankulak 1. Sofija 1989.

= T. Totev: Archeologičeski muzej Preslav. Sofija 1969.

= T. Totev: Bazilika pri Sakalova mogila v Preslav. Preslav 2 (1976) 38-61.

= T. Totev: Preslavsko zlatno săkrovište. Sofija 1983.

= T. ToTEv: Preslavskoto săkrovište. INMVarna 22 (37) (1986) 81-107, Taf. 1-25.

= T. Totev: The Preslav Treasure. Shoumen 1993.

= T. Totev: Dvorcovijat manastir v Preslav. Sofija 1998.

= T. Totev-ST. Stanilov: Maramoren kapitel ot Bazilikata v Stambol Joly kraj Preslav. Pliska-Preslav 6 (1993) 116-119.

= ST. VAKLINOV: Formirane na starobălgarskata kultura VI-XI vek. Sofija 1977.

= ST. VAKLINOV (WAKLINOW): Kultura starobułgarska (VI-XI w.). Warszawa 1984.

= ST. VAKLINOV-ST. StANILOV: Kladenci. Rannosrednovekovno bălgarsko selište. Varna 1981.

= V. VĂLOV: Archeologičeski proučvanija v jugozapadnata čast na rannosrednovekovnoto ukrepeno selište pri Stărmen. In: MichaJLOV et al. 1982, 70-113.

= V. B. VinogRadov: Altungarische Parallelen zu einigen Gräbern des alanischen Gräberfeldes bei Martan-Cu. ActaArchHung 35 (1983) 211-220. 
VITLJANOV 1990

VITLJANOV 1994

WENDEL 1986

WERNER 1974
$=$ St. Vitluanov (Witluanow): Ein vergoldetes Silbermedaillon aus Preslaw. ActaArchHung 42 (1990) 195-204.

= ST. VITLJANOv: Interesna tvorba na starobălgarskata torevtika. In: Sbornik v čest na akad. Dimităr Angelov. Sofija 1994, 209-214.

= M. WendEL: Iatrus-Krivina 3: Die mittelalterlichen Siedlungen. Schriften zur Geschichte und Kultur der Antike 17. Berlin 1986.

= J. WERnER: Nomadische Gürtel bei Persern, Byzantinern und Langobarden. In: La civiltà dei Longobardi in Europa. Konferenz Roma/Cividale del Friuli 1971. Accademia Nazionale dei Lincei 371. Roma 1974, 109-139.

\section{NACHTRAG (NOVEMBER 2015)}

Die bulgarische Urfassung bzw. der Kern dieses Beitrags wurde bereits im Juni 1997 von Stanislav Stanilov fertiggestellt. Der Beitrag wurde dann im Mai 1998 unter dem Titel Trugen die Donau-Bulgaren im 10. Jahrhundert Gürtel vom „ungarischen Typ“? zum Druck eingereicht. Nach Erscheinen der wichtigen Materialvorlage von PletN’ov-Pavlova 1994/1995 (2000) folgte im Februar 2001 eine überarbeitete Fassung. Im Januar 2006, als der Druck endlich erfolgen sollte, wurden einige wenige Neuerscheinungen in die Fußnoten und in das Literaturverzeichnis eingearbeitet. Eine Berücksichtigung sämtlicher Neuerscheinungen hätte jedoch Veränderungen bei den Abbildungen zur Folge gehabt. Deshalb wurden schon damals die neuen Publikationen von Gürtelbesatzstücken „vom ungarischen Typ“ in Bulgarien zumeist nur in einem Nachtrag aufgelistet. Diese Liste ist nunmehr nochmals ergänzt worden. Auf die Auflistung neuer Vergleichstücke aus dem Karpatenbecken wurde verzichtet.

Selbst die Produktion der besagten Gürtelbesatzstücke ist mittlerweile an drei Orten in der Umgebung von Preslav (Nadarevo, Novosel und Zlatar) nachgewiesen. Nur für Novosel liegt eine Monographie vor.

St. Bonev-St. DonČEva: Starobălgarski proizvodstven centăr za chudožestven metal pri s. Novosel, Šumensko. Veliko Tărnovo 2011, bes. 104-127; 202-226 und 273-291; Taf. 31-49. - U. a. Schnallen der Typen 3 und 7, Riemenzungen und Beschläge der Typen 10B (3×), 11A (1×), 11B (3×), 12A (4×), 12B (7×), 13A (1×), 13B $(1 \times), 21 \mathrm{~A}(7 \times)$ und 21B $(25 \times)$.

Aus Zlatar und Nadarevo hat vornehmlich Stela Dončeva in Vorberichten einen Querschnitt des Fundguts vorgelegt, aber auch Gürtelrekonstruktionen erstellt:

ST. DONČEvA: Metal Art Production in Medieval Bulgaria. Jewelry craftsmanship in Bulgaria at the Middle Ages. Saarbrücken 2012, bes. 2-20 und 43-56. - S. 19 f., Abb. I.13-14 mit den Beschlagtypen 11A, 21A und 21B.

ST. DonČEvA: Nov centăr za proizvodstvo na chudožestven metal v okolnostite na Preslav (Predvaritelno săobštenie). Izvestija na Istoričeskija muzej Šumen 15 (2014) 54-64, bes. 59, Abb. 7. - Zlatar.

ST. DONČEVA: Rekonstrukcija na kolani garnituri po materiali ot rannosrednovekovnija centăr za metaloplastika pri s. Zlatar, Preslavsko. Preslav 7 (2013) 152-170. - Dabei die Beschläge der Typen 9A-B und 10A-B, Schnallen und Riemenzungen der Typen 13 und 27.

ST. DonČEvA: Metalni ukrasi ot proizvodstvenija centăr pri s. Nadarevo, Tărgovištko. Pametnici, Restavracija, Muzei 2010, H. 3-6 (Juni-Dezember), 16-36. - U. a. Beschläge der Typen 11B, 13A, 18A und 18B.

A. KonAKLIEv: Model za aplikacii ot c. Nadarevo, Tărgovištko. Pliska-Preslav 8 (2000) 235-238. - 6 Bleimodel aus zwei, im Jahre 1992 vom Museum Tărgovište angekauften Gruppen von insgesamt 250 Objekten, die angeblich aus der Flur ,Jukja“ bei Nadarevo (obšt. Tărgovište) stammen sollen. Darunter je $1 \times$ Schnalle, ähnlich dem Typ 1 (Nr. 1), und Beschlag Typ 20B (Nr. 3).

A. KonaKliev: Kolani aplikacii ot selo Nadarevo, Tărgovištko. In: K. Popkonstantinov-B. BorisovR. Kostova (Hrsg.): Prof. d.i.n. Stančo Vaklinov i srednovekovnata bălgarska kultura. Konferenz Veliko Tărnovo 2001. Veliko Tărnovo 2005, 230-242. - Unter den 79 hier publizierten Gürtelbeschlägen und verwandten Stücken befinden sich: $1 \times$ Typ 10A/B (Nr. 28), 3× Typ 13B (Nr. 5), 1× Typ 20A (Nr. 25), 2× Typ 20B (Nr. 6), 1× Typ 21B (Nr. 16). 13 (Nr. 3 und 4) entsprechen anscheinend denen des Gürtels von Krivina, wenngleich die Gravur nicht erkennbar ist. 
Metallanalysen sind durchgeführt worden, jedoch für Zlatar nur summarisch nach Gruppen (Beschlägen) aufgelistet.

St. Dončeva-I. Penev-G. Tserova-E. Furu-Z. Szikszai-I. Uzonyi: Elemental Composition of Metal Artefacts from the 10th c. Metal Art Centre near the Village of Zlatar, Preslav Region, NE Bulgaria. Archaeologia Bulgarica 17/1 (2013) 71-85.

An anderer Stelle hat St. Dončeva fünf andere Stücke aus Zlatar (u. a. einen Beschlag vom Typ 20A), einen Beschlag vom Typ 13A (?) und eine Schnalle aus Nadarevo sowie einen Beschlag aus Novosel publiziert. Eine Metallanalyse wurde bei drei Gürtelbeschlägen durchgeführt.

ST. DonČEva: Proizvodstvoto na srebărni ukrasi v centrovete za chudožestven metal v okolnostite na Preslav. In: P. Georgiev et al. (Hrsg.): Gradăt v bălgarskite zemi (po archeologičeski danni). Tagung zum Gedenken an V. Antonova, Šumen 2013. Šumen 2014, 279-290.

Verwiesen sei auch auf die Analysen von Fundstücken anderer Herkunft, die M. Inkova vorgelegt hat.

M. INKOVA: A contribution to the problem of producing the Old Bulgarian belt fittings from the 10th century. In: B. Tobias (Hrsg.): Die Archäologie der frühen Ungarn. Workshop Budapest 2009. RGZM - Tagungen 17. Mainz 2012, 277-293.

Ihre 86 Metallanalysen belegen wie die oben angeführten Untersuchungen, dass die bulgarischen Produkte vorwiegend aus unedlen Metallen gefertigt wurden, allenfalls gab man ihnen ein äußeres Aussehen von Edelmetall.

Von der 2004 abgeschlossenen Sofijoter Dissertation der Autorin über die altbulgarischen Gürtel des ausgehenden 7. bis beginnenden 11. Jahrhunderts (Starobălgarskite kolani [kraja na VII-načaloto na XI]), die von einem der Autoren (St. St.) betreut wurde, ist bislang nur ein 36-seitiges „Avtoreferat“ ohne Abbildungen erschienen. (Die Gürtel vom ,ungarischen“ Typ dort S. 17 ff.)

Die Anzahl der mehr oder weniger vollständigen Gürtelgarnituren hat sich auf mutmaßlich acht erhöht. Zu Jakimovo und Debrene sind neben der schon oben erwähnten Garnitur aus Krivina ein Neufund aus Slavnata kanara und vier weitere Garnituren von unbekannten Fundorten hinzugekommen.

G. GoMOLKA-FuCHS: Eine Gürtelgarnitur vom ungarischen Typ aus der frühmittelalterlichen Siedlung von Krivina, Bezirk Ruse, Bulgarien. Eurasia Antiqua 8 (2002) 493-514. - Publikation der oben genannten Garnitur (vgl. Anm. 72), von denen Teile auch schon in BerRGK 82 (2001) 621, Abb. 5 farbig abgebildet worden sind. Der Autorin wurde das Manuskript des vorliegenden Aufsatzes zur Verfügung gestellt. Mit unserem Einverständnis hat sie auch den Vorläufer unserer Karte als Abb. 4 übernommen, jedoch wurden dort leider sämtliche Fundpunkte eliminiert und nur noch die zur Orientierung eingetragenen größeren Orte belassen.

B. Totev-D. Dobrev: Archeologiceski kompleks v m. Slavata kanara, obština Dobrič. In: Bălgarska Archeologija 2014. Sofija 2015, 35 f. - Aus Grubenhaus 6 Beschläge vom Typ 23A; 8 Beschläge vom Typ 23C; Schnalle und Riemenzunge.

V. Pletn'ov: Časti ot dva rannosrednovekovni kolana ot Severiztočna Bălgarija. In: Ch. Charitonov (Hrsg.): Jubileen sobornik v čest na prof. Dimităr Ovčarov. Veliko Tărnovo 2002, 83-85. - Garnituren aus 13 und 42 Teilen, die ein Sondengänger in der Umgebung von Šumen gefunden hat. Die zweite Garnitur gehört zum Typ 10A (24x) und 10B (18x). In schlechter Abbildungsqualität; vgl. besser PletN'ov 2005, Abb. 1-2.

V. PLETN'ov: Novi rannosrednovekovni kolani ot Severoiztočna Bălgarija. In: V. Gjuzelev (Hrsg.): Kulturnite tekstove na minaloto. Nositeli, simboli i idei. Konferenz Veliko Tărnovo 2003 zu Ehren von K. Popkonstantinov. Bd. 3: Znaci, tekstove, nositeli. Sofija 2005, 58-64, bes. Abb. 3-5. - Weitere Garnituren mit 34, 7 und 14 Teilen, die von Sondengängern in Nordostbulgarien gefunden worden sind. Die letztgenannte Garnitur war wahrscheinlich Riemenbesatz von Pferdegeschirr. 
Nachfolgend sind weitere 29, nach Abschluss des Manuskripts erschienene Arbeiten zum Thema aufgelistet, vornehmlich Publikationen von Neufunden (ohne Garantie der Vollständigkeit).

A. ALADŽOV-V. GRIGOROv: Kolanni aplikacii i nakrajnici ot obekt v reperen kvadrat V-11 văv vătrešnija grad na Pliska. In: B. Petrunova-A. Aladžov-E. Vasileva (Hrsg.): Laurea. In honorem Margaritae Vaklinova. Sofija 2009, Bd. 1, 185-190. - U. a. Beschlag vom Typ 9A; vgl. Grigorov 2013.

G. AtAnASOv-V. Jotov-G. V. ZasypKinA-N. D. Russev: Issledovanija gorodišča Rujno - Kartal-kale (Predvaritel'noe soobščenie). Stratum plus (2000) 5, 97-107. - 3 Beschläge aus Grubenhaus 4.

Ja. Dimitrov-M. Inkova: Kăm archeologičeskata karta na Vănšnija grad na Pliska. Pliska-Preslav 11 (2015) 91-114, bes. 107, Abb. 29. - 1 Beschlag.

St. DonČEva: Za edin vid ornamentalna ukrasa v rannosrednovekovnata Bălgarska metaloplastika. Preslav 6 (2004) 212-227. - 1 Schnalle, 11 Beschläge und 10 Riemenzungen aus den Museen in Šumen und Preslav, darunter 2-mal Typ 9A (Nr. 3-4), 1-mal Typ 9B (Nr. 5), 1-mal Variante Typ 15A (Nr. 8) sowie mehrere verwandte Riemenzungen der Typen 26-27 (Nr. 13-15 und 18). Nr. 12 gehört wohl ins 6. Jahrhundert.

St. DonČEvA-N. NiKolov: An Early Medieval Lead Mould for the Production of Wax Models from the Region of Preslav, NE Bulgaria. Archaeologia Bulgarica 14 (2010) 1, 81-92. - Wiederabgedruckt in: DonchEvA 2012, 43-56.

L. DonČEvA-PetKova: Odărci 2. Nekropol ot XI vek. Sofia 2005, bes. 144, Abb. 22. - Mehrere Beschläge aus verschiedenen Gräbern.

P. GEORGIEV-R. VASILEv: Dărvena krepost văv Vătrešnija grad na Pliska. In: Bălgarska Archeologija 2008. Sofija 2009, 68 f. - 1 Beschlag.

P. Georgiev-St. Vitluanov: Archiepiskopijata - Manastir v Pliska. Sofija 2001, 137, Abb. 70.13; 140, Abb. 72. - Riemenzunge.

V. GRIGOROv: Pliska „Dvorcov centăr-iztok“. AOR (2011 [2012]) 385-388, bes. 387, Abb. 3 oben (2 Beschläge); Bălgarska Archeologija 2013, Sofija 2014, 26 (1 Beschlag) und ebd. 2014, Sofija 2015, 39 f. (1 Beschlag).

V. GRIGOROv: Archeologičesko proučvane južno ot groba na Karel Škorpil v Pliska. In: Prinosi kăm bălgarskata archeologija 7. Sofija 2013, 57-77, bes. 60, Abb. 3; 62, Abb. 5.1; 64, Abb. 7. - Vgl. AlaDžov-GRIGOROV 2009.

J. Henning: Katalog archäologischer Funde aus Pliska. In: J. Henning (ed.): Post-Roman Towns, Trade and Settlement in Europe and Byzantium. Bd. 2: Byzantium, Pliska, and the Balkans. Millennium-Studien 5/2. Berlin-New York 2007, 663-704, Taf. 19; bes. 693, Nr. 178-186, Taf. 15.178-186. - U. a. Beschläge ähnlich den Typen 18A-B und 20A.

M. INKovA: Problemăt za kolanite s vertikalni remăci prez christijanskija period na Părvoto bălgarsko carstvo. Preslav 6 (2004) 196-211.

A. KonaKLIEv-St. DončEva: Patriaršeska čast na carskija dvorec - Veliki Preslav. AOR (2013 [2014]) 462-464, bes. 463 f. mit Abb. 3. - 5 Beschläge ähnlich Typ 9A.

K. KonSTANTINOv: Metalni nakiti i kolanni garnituri ot razkopkite na kompleksa pri južnija sektor na zapadnata krepostna stena v Pliska. Pliska-Preslav 11 (2015) 199-216, 206, Abb. 4 (Riemenzungen); 209, Abb. 5 (u. a. Beschläge der Typen 9B, 13A, 18B, 21A und B).

D. MomČILov: Starobălgarski aplikacii ot fonda na istoričeski muzej - Karnobat. In: B. PetrunovaA. Aladžov-E. Vasileva (Hrsg.): Laurea. In honorem Margaritae Vaklinova. Sofija 2009, Bd. 2, 167-178. - U. a. Beschläge ähnlich Typ 12A, 13B, 20A und 21A (2x).

D. MoмČILOv: Pametnici na metaloplastikata ot Markeli. IAI 40 (2012) 141-149.

D. MомČILOv: Starobălgarski aplikacii ot Markeli. Pliska-Preslav 11 (2015) 401-418. - U. a. Beschläge der Typen 9B, 13A, 18A und B, 20A und 23B.

M. NiKOLOv: Proizvodstvoto na kolanni garnituri v rannosrednovekovna Bălgarija. Preslav 6 (2004) 228 240. - 40 Beschläge und 5 Riemenzungen, die 2002 vom Museum in Varna von einem Sondengänger angekauft worden sind, darunter je 1-mal Typ 9B (Nr. 6), 18B (Nr. 4), 20B (Nr. 16), 21A (Nr. 14), 23A (Nr. 27) und 31 (Nr. 45).

M. NIKOLOv: Rannosrednovekovni remăčni kolani i kolani aplikacii ot fonda na IM Kortel. IMJIB 22 (2006) 155-162. - In groben Skizzen u. a. Beschläge der Typen 15A und 21A. 
M. NIKOLOv: Rannosrednovekovni remăčni i kolanni aplikacii ot krepostta Rusokastro i priležanštija i rajon. INIM 25 (2013) 59-64. - U. a. Tpyen 9A und 21A.

V. PLETN'ov: Bronzov model za kolanni aplikacii ot Severoiztočna Bălgarija. Šumenski Universitet Episkop Konstantin Preslavski. Trudove na katedrata po istorija i bogoslovie 4 (2001) 49-51.

Regionalen istoričeski muzej Varna: Bălgarite i technite săsedi prez V-X vek. Katalog na izložba. Varna 2004, 73, 94, Nr. 54. - Einige Stücke aus der 2002 erworbenen Sammlung; vgl. PLETN’ov 2004.

R. RAšEv: Bălgarskata ezičeska kultura VII-IX vek. Sofija 2008, 163, Taf. 75. - Gesichtsdarstellungen wie schon 1984 vom Autor vertreten; vgl. auch STANILOv 2005.

S. VeliKova: Srednovekovni nachodki ot proučvanijata na Trimamium prez 2006-2009 g. Izvestija na Regionalen Istoričeski Muzej Ruse 15 (2012) (Sexaginta Prista et Vicinia) 404-419, bes. 419, Abb. 4. - U. a. Beschlag vom Typ 20A.

St. Vitluanov: Proučvanija na iztočnata kreposna stena na Vătrešnija grad na Veliki Preslav. Preslav 6 (2004) 24-39, bes. 36, Taf. 1.13-14. - 1-mal Typ 20B.

St. Vitluanov: Nepublikani kolanni garnituri ot Veliki Preslav. In: P. Georgiev (Hrsg.): Izsledvanija po bălgarska srednovekovna archeologija. Sbornik v čest na prof. Rašo Rašev. Veliko Tărnovo 2007, 245-258, bes. 249 ff., Taf. 1.1-6, Taf. 2.2-19. - U. a. Schnallen und Beschläge der Typen 9A, 10B, 13B und ähnlich 20A.

N. SIRAKOv: Novopostăpili rannobălgarski aplikacii văv fonda na Regionalen istoričeski muzej - Sliven ot mestnostta Chisarlăka kraj grad Sliven. IMJIB 24 (2009) 167-171. - Typen 18B und 23C (mit Knopf an der Spitze).

St. STANILov: Tezata za „licevija obraz“ i pametnicite nach chudožestvenija metal na dolnija Dunav. In: K. Popkonstantinov-B. Borisov-R. Kostova (Hrsg.): Prof. d.i.n. Stančo Vaklinov i srednovekovnata bălgarska kultura. Konferenz Veliko Tărnovo 2001. Veliko Tărnovo 2005, 113-123. - These einer der Ornamentik zugrunde liegenden Gesichtsdarstellung auch in der Gruppe der hier behandelten Gürtelbeschlägen; bes. Abb. 3.

T. Tотеv: Sondažni proučvanija v mestnostta Stambol joly kraj Veliki Preslav. Pliska-Preslav 10 (2004) 229-243, bes. 237, Abb. 6.6; 238, Abb. 7.1-7, 9-10, 14, 16, 19. - 1× Typ 11B, $2 \times$ Typ 20A.

Auch von Fundstücken aus Moldawien gibt es neue Publikationen.

E. N. ABYZOVA-S. S. RJABCEVA: O nekotorych specifičeskich čertach nabora juvelirnych izdelij iz zolotoordynskich pamjatnikov Pruto-Dnestrovskogo Meždureč'ja. In: D. V. Vasil'ev-Ju. A. Zeleneev-A. G. Simdikov (Hrsg.): Dialog gorodskoj i stepnoj kul'tur na evrazijskom prostranstve. Materialy V Meždunarodnoj konferencii „Dialog gorodskoj i stepnoj kul'tur na evrazijskom prostranstve“" posvjaščennoj pamjati G. A. Fedorova-Davydova, g. Astrachan, 2-6 oktjabja 2011 g. Kazan'-Astrachan' 2011, 63-70, bes. 312, Abb. 1.

S. RJABCEvA: O balkanskich svjazach naselenija Pruto-Dnestrovskogo regiona. Po materialam nachodok predmetov cvetnoj metalloobrabotki. Preslav 7 (2013) 171-183, bes. 181, Abb. 1.8-28; 183, Abb. 3.

Bei den Häufigkeiten der ausgewählten Beschlagtypen gab es keine grundsätzlichen Verschiebungen. Die Spitzenstellung des Typs 21 wird vor allem durch den Produktionsort Novosel bestätigt. Zu den häufigsten Beschlagtypen der alten Statistik (Abb. 5) sind jeweils Neufunde hinzugekommen. An Gewicht gewonnen haben besonders die Typen 20 und 13 (sowie durch Novosel der Typ 12). Die Ausnahmestellung der Typen 14, 16, 19, 22 und 24 hat ihre Bestätigung gefunden: Es gibt hier keine Neufunde zu verzeichnen. Zugleich ist aber auch deutlich geworden, dass eine Reihe von gängigen Beschlagtypen bei der hier getroffenen Auswahl keine Berücksichtigung fand.

Gegenüber der Entstehungszeit dieses Beitrags haben sich die Gewichtungen bei der überregionalen Verbreitung durch die vielen Neufunde erheblich verschoben, wenngleich im Karpatenbecken - bedingt durch die Beigabensitte und den größeren Reichtum der militärisch erfolgreichen Ungarn - weitaus mehr vollständige Garnituren und viel mehr Beschläge aus Edelmetall gefunden worden sind. Die Entstehung des Gürteltyps ist aber kaum mehr auf die Ungarn zurückzuführen. Auf den Punkt gebracht hat dies Péter Langó (Bulgarian Connections of the Find-horizon of the 10th Century in the Carpathian Basin. Some Remarks and Observations. In: L. DonchevaPetkova-Cs. Balogh-A. Türk (Hrsg.): Avars, Bulgars and Magyars on the Middle and Lower Danube. Tagung Sofia 2009. Sofija-Piliscsaba 2014, 157-164, bes. 157): „The number of known pieces from the Carpathian Basin is relatively small, if compared to their conterparts from Bulgaria. It is therefore high time to ask, if the type has anything 
to do with the Hungarians at all.“ Langó lehnt einen östlichen, postsasanidischen Hintergrund ab. Er sucht die Leitbilder vielmehr in der Kunstindustrie des Mittelmeerraumes, der die Bulgaren ungleich näher standen als die Ungarn (ebd. S. 160 f.). Nach wie vor bedarf es einer überregionalen Erfassung aller Gürtelbeschlagtypen, um chronologische und regionale Unterschiede herauszuarbeiten. 